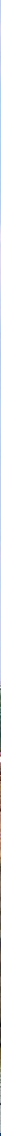

www.eraz-conference.com

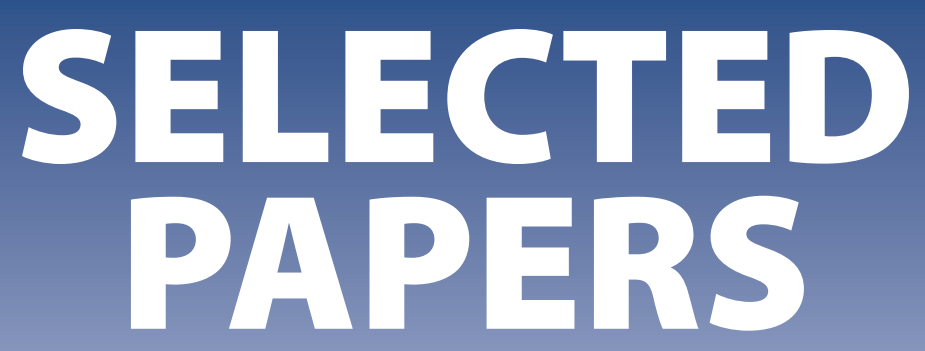



THE $6^{\text {TH }}$ INTERNATIONAL SCIENTIFIC CONFERENCE

ERAZ 2020

\section{KNOWLEDGE BASED SUSTAINABLE DEVELOPMENT \\ Selected Papers}


International Scientific Conference ERAZ - Knowledge Based Sustainable Development

ISSN 2683-5568

Selected Papers (part of ERAZ conference collection)

Editor:

Vuk Bevanda, PhD, Associate Professor, Faculty of Social Sciences, Belgrade, Serbia

Scientific Committee:

1. Christian Tanushev, PhD, Associate Professor, Vice Dean for International Cooperation, Faculty of Management and Administration, University of National and World Economy, Sofia, Bulgaria

2. Dragoljub Janković, PhD, Associate Professor, Government of Montenegro, Adviser to the Deputy Prime Minister for Economic Policy and Financial System, Faculty of Business Studies, Mediterranean University, Podgorica, Montenegro

3. Evgenia Yazovskikh, PhD, Associate Professor, Marketing Department, Ural federal University named after the first President of Russia B.N. Yeltsin, Yekaterinburg, Russia

4. Tatjana Kovač, PhD, Assistant Professor, Vice Dean, Faculty of Business and Commercial Sciences, Celje, Slovenia

5. Vesna Milanović, PhD, Full Time Professor, Faculty of International Economics, Megatrend University, Belgrade, Serbia

6. Jelena Žugić, PhD, Associate Professor, Vice Dean for Academic Affairs, Finance and International Cooperation, Faculty of Business Studies, Mediterranean University, Podgorica, Montenegro

7. Ivana Simić, PhD, Full Time Professor, Faculty of Economics, University of Niš, Niš, Serbia

8. Galina Mladenova, PhD, Associate Professor, Vice Dean, Faculty of Management and Administration, University of National and World Economy, Sofia, Bulgaria

9. Marija Janković, PhD, Associate Professor, Dean, Faculty of Economics and Business, Mediterranean University, Montenegro

10. Dragana Bašić, PhD, Associate Professor, Head of the Department of Accounting and Business Finance, Faculty of Economics, University of Banja Luka, Bosnia and Herzegovina

11. Elvis Mujačević, PhD, Full Time Professor, Faculty of Tourism and Hospitality Management Opatija, University of Rijeka, Republic of Croatia

12. Tatjana Dolinšek, PhD, Assistant Professor, Faculty of Commercial and Business Sciences, Celje, Slovenia

13. Gabriela Lobonțiu, PhD, Associate Professor, Faculty of Engineering, Department of Engineering and Technology Management, Technical University of Cluj-Napoca, North University of Baia Mare Centre, Maramures, Romania

14. Edmond Hoxha, PhD, Full Time Professor, Department of Mineral Resources, Faculty of Geology and Mine, Polytechnic University of Tirana, Tirana, Albania

15. Slobodanka Krivokapić, PhD, Associate Professor, Faculty of Business Studies, Mediterranean University, Podgorica, Montenegro

16. Nadežda Fuksová, PhD, Assistant Professor, Slovak University of Technology, Institute of Management, Bratislava, Slovak Republic

17. Yovka Bankova, PhD, Assistant Professor, Department of Marketing and Strategic Planning, University of National and World Economy, Sofia, Bulgaria

18. Stefan O. Grbenic, PhD, Assistant Professor, Institute of Business Economics and Industrial Sociology, University of Technology, Graz, Austria

19. Denis Tomše, PhD, Assistant Professor, Faculty of Commercial and Business Sciences, Celje, Slovenia

20. Tomislav Brzaković, PhD, Associate Professor, Dean, Faculty of Applied Management, Economy and Finance, Belgrade, Serbia

21. Miodrag Brzaković, PhD, Associate Professor, Faculty of Applied Management, Economy and Finance, Belgrade, Serbia

22. Saša Virijević Jovanović, PhD, Associate Professor, Faculty of Applied Management, Economy and Finance, Belgrade, Serbia

23. Fadil Zendeli, PhD, Associate Professor, South East European University, Faculty of Public Administration and Political Sciences, Tetovo, Republic of Macedonia

24. Milica Nestorović, PhD, Assistant Professor, Faculty of Business Studies, Megatrend University, Belgrade, Republic of Serbia

25. Darjan Karabašević, PhD, Assistant Professor, Faculty of Applied Management, Economy and Finance, Belgrade, Serbia

Organizational Committee:

Anton Vorina, $\mathrm{PhD}$, Associate Professor;

Nikolina Vrcelj, PhD candidate;

Nevena Bevanda, PhD student;

Pavle Brzaković, PhD student,

Ivana Mirčević, BSc;

Uroš Mirčević, Ing.;

Goran Stevanović, BSc

Published by:

Association of Economists and Managers of the Balkans,

Ustanicka 179/2 St. 11000 Belgrade, Serbia

office@udekom.org.rs

+381628125779

Conference partners:

Faculty of Economics and Business, Mediterranean University, Montenegro;

University of National and World Economy - Sofia, Bulgaria;

Faculty of Commercial and Business Studies - Celje, Slovenia;

College of Regional Development and Banking Institute - Ambis, Czech Republic

Faculty of Applied Management, Economics and Finance - Bel-

grade, Serbia

Printed by: SKRIPTA International, Belgrade, Serbia

Cover image by: Markéta Machová from Pixabay.

Belgrade, 2020

ISBN 978-86-80194-34-9

ISSN 2683-5568

DOI: https://doi.org/10.31410/ERAZ.S.P.2020

Disclaimer: The author(s) of each paper appearing in this publication is/are solely responsible for the content thereof; the findings, interpretations and conclusions expressed in the papers are those of the authors and do not reflect the view of the editor, reviewers, scientific committee members, the publisher, conference partners or anyone else involved in creating, producing or delivering this publication.

(c) (1) (8) This work is licensed under a Creative Commons Attribution-NonCommercial 4.0 International License.

CIP - Katalogizacija u publikaciji

Narodna biblioteka Srbije, Beograd

$338.1(082)$

$330.3(082)$

$336(082)$

$502.131 .1(082)$

007:004(082)

346(082)

INTERNATIONAL Scientific Conference Knowledge Based Sustainable Development ERAZ (6; 2020)

Selected Papers / Sixth International Scientific Conference ERAZ 2020, Knowledge Based Sustainable Development, Online-virtual Ma 21, 2020 ; [organizer Association of Economists and Managers of the Balkans ... [et al.]; editor Vuk Bevanda]. - Belgrade : Association of Economists and Managers of the Balkans, 2020 (Belgrade : Skripta International). - XIV, 117 str. : graf. prikazi, tabele; $30 \mathrm{~cm}$. - (ERAZ Conference Collection, ISSN 2683-5568

Tiraž 100. - Napomene i bibliografske reference uz tekst. Bibliografija uz svaki rad.

ISBN 978-86-80194-34-9

a) Ekonomija -- Zbornici b) Privredno pravo -- Zbornici v) Finansije -- Zbornici g) Održivi razvoj -- Zbornici d) Informaciona tehnologija -- Zbornici

COBISS.SR-ID 30750217 


\section{CONTENTS}

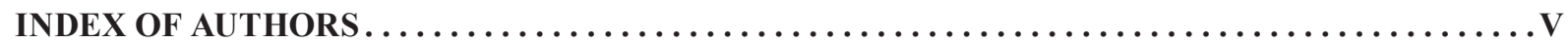

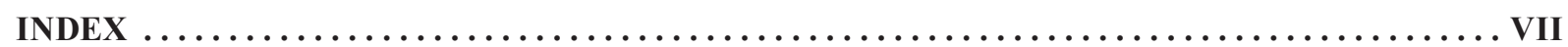

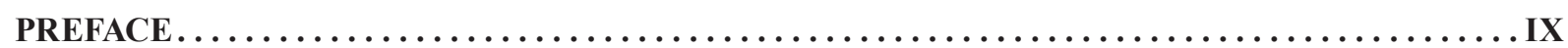

AUTHORS' AFFILIATION. .............................................. XIII

STRINGENCY OF COVID-19 RESTRICTIONS AMONG ITALIAN REGIONS

AND THE ROLE OF REGIONAL ECONOMIC SYSTEMS $\ldots \ldots \ldots \ldots \ldots \ldots \ldots \ldots \ldots \ldots \ldots$

Giorgio Tassinari

Fabrizio Alboni

Arianna Tassinari

Ignazio Drudi

MODELING OF COVID-19 PANDEMIC INDICES

AND THEIR RELATIONSHIPS WITH SOCIO-ECONOMIC INDICATORS. . . . . . . . . . 11

Mikhail Pomazanov

ANALYSIS OF POTENTIAL EMPLOYMENT CONSEQUENCES

ASSOCIATED WITH THE NOVEL CORONAVIRUS: CASE OF KUWAIT $\ldots \ldots \ldots \ldots \ldots \ldots \ldots 25$

Dušana Alshatti Schmidt

THE EFFECT OF INCOME STABILISATION TOOL ON SLOVAK AGRICULTURE . . . . . . . 33

Andrea Boháčiková

Tatiana Bencová

Zuzana Kapustová

THE ECONOMIC VIABILITY OF THE ENERGY PRODUCTION

FROM BIOMASS VIA ANAEROBIC DIGESTION $\ldots \ldots \ldots \ldots \ldots \ldots \ldots \ldots \ldots \ldots \ldots \ldots \ldots \ldots, 41$

Zuzana Kapustová

Andrea Boháčiková

Ján Lajda

THE EFFICIENCY OF PUBLIC HIGHER EDUCATION INVESTMENT

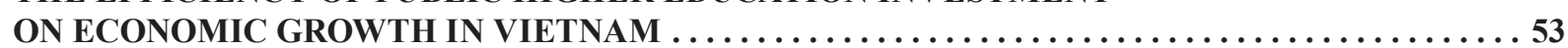

Thi Hoai Trinh Nguyen

Viet An Kieu

Thi Cam Nhung Dao

FINANCIAL LITERACY OF UNIVERSITY STUDENTS MEASURED BY P-FIN INDEX . . . . . 61

Josef Polák

Zuzana Kozubíková

Aleš Kozubík

SUSTAINABILITY COMPETENCIES FROM THE UNIVERSITY DISCOURSE $\ldots \ldots \ldots \ldots \ldots \ldots 7$

Vesna Nikolić

Tamara Vukić

AN EXPLORATORY ANALYSIS OF BRAND EQUITY BASED

ON TANGIBLE AND INTANGIBLE ATTRIBUTES ON TWEETS

OF THE LARGEST WESTERN EUROPE MANUFACTURING COMPANIES $\ldots \ldots \ldots \ldots \ldots . . . . .83$

Fernando Jurado Ramos

Javier Perez-Aranda

THE DIFFERENT APPROACHES FOR THE MARKET SEGMENT B2G (B2A)

COMPARED TO B2B AND B2C, BASED ON A CASE STUDY

FOR INFRASTRUCTURE IN THE PHILIPPINES .......................... 95

Bernhard Alexander Krah

APPLICATION OF ECOSERV MODEL IN SERVICE QUALITY MEASUREMENT:

CASE STUDY OF NATIONAL PARKS IN CROATIA $\ldots \ldots \ldots \ldots \ldots \ldots \ldots \ldots \ldots \ldots \ldots \ldots \ldots$

Iva Valcic

Suzana Markovic

Jelena Kljaic Sebrek 



\section{INDEX OF AUTHORS}

\section{A}

Aleš Kozubík, 61

Andrea Boháčiková, 33, 41

Arianna Tassinari, 1

B

Bernhard Alexander Krah, 95

D

Dušana Alshatti Schmidt, 25

F

Fabrizio Alboni, 1

Fernando Jurado Ramos, 83

G

Giorgio Tassinari, 1

I

Ignazio Drudi, 1

Iva Valcic, 109

\section{J}

Ján Lajda, 41

Javier Perez-Aranda, 83

Jelena Kljaic Sebrek, 109

Josef Polák, 61

\section{M}

Mikhail Pomazanov, 11

\section{S}

Suzana Markovic, 109

T

Tamara Vukić, 71

Tatiana Bencová, 33

Thi Cam Nhung Dao, 53

Thi Hoai Trinh Nguyen, 53

V

Vesna Nikolić, 71

Viet An Kieu, 53
Z

Zuzana Kapustová, 33, 41

Zuzana Kozubíková , 61 



\section{INDEX}

\section{B}

B2A, 95

B2G, 95

Barriers, 71

Biogas, 41

Brand engagement and eWOM, 83

Brand equity, 83

Business-to-Administration, 95

Business-to-Government, 95

Business interests, 1

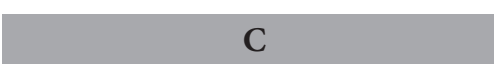

CAP, 33

Competencies, 71

COVID-19, 1, 11, 25

E

Economic growth, 53

ECOSERV, 109

Ecotourism, 109

\section{F}

Factor analysis, 109

Financial decision making, 61

Financial education, 61

Financial management, 61

G

GDP, 25

\section{H}

Higher education, 53

I

Income risk, 33

I

Income stabilisation, 33

Infrastructure, 95

Investment efficiency, 53

\section{L}

Labor market, 25

Lockdown, 1

M

Manufacturing sector, 83

Marketing, 95

\section{Q}

Questionnaire survey, 61

S

Service quality, 109

Slovak agriculture, 33

Slovakia, 41

Social networks, 83

Socio-economic indicators, 11

Statistical methods, 61

Sustainable development, 71

\section{$\mathrm{T}$}

Tangible and intangible, 83

Transformation, 71

\section{$\mathrm{U}$ \\ U}

University, 71
Market segments, 95

Modeling, 11

N

Net present value, 41

\section{O}

Oil, 25

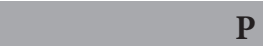

Pandemic, 11

Perceptions, 109

Philippines, 95

Policy, 25

N

- n

\section{P}





\section{PREFACE}

Economic development refers to the improvement of activities in the economy, which leads to progressive changes in the socio-economic structure and the rising of living standards. Given that the objective of sustainable economic development is elimination of poverty, inequality and unemployment - thus leading to social inclusion and improvement of the quality of life; it is necessary in analysis of this important issue apply extremely multidisciplinary approach.

Faculty of Business Studies, Mediterranean University - Podgorica, Montenegro; University of National and World Economy - Sofia, Bulgaria; Faculty of Commercial and Business Studies - Celje, Slovenia; Faculty of Applied Management, Economics and Finance - Belgrade, Serbia, College of Regional Development and Banking Institute - Ambis, Czech Republic and the Association of Economists and Managers of the Balkans have recognized following issue and organized Sixth International Scientific Conference titled: Knowledge Based Sustainable Development - ERAZ 2020 online/virtually (due to the COVID-19 pandemic) on May 21, 2020.

The conference objective was to bring together academic community (experts, scientists, engineers, researchers, students and others) and publication of their scientific papers for the purpose of popularization of science and their personal and collective affirmation. The unique program combined interactive discussion and other forms of interpersonal exchange of experiences and presentation of the latest scientific developments in following areas:

- Microeconomics and macroeconomics,

- Economic policy,

- International Economics and Trade,

- International Business,

- Economic diplomacy,

- Lobbying,

- Globalization,

- European business,

- Modern management and innovation,

- Business and Public Finance,

- Fiscal policy,

- Stock exchange and financial markets,

- Risk management,

- Insurance and reinsurance companies,

- Financial Management and Banking,

- Modern forms of entrepreneurship and investment,

- Investment Management,

- Enterprise and Learning,

- Women and Entrepreneurship,

- Corporate entrepreneurship,

- Agribusiness Strategy,

- Marketing and trade,

- Marketing services,

- Marketing of non-profit sector,

- Research in marketing,
- Marketing in education,

- Marketing in sport,

- Marketing in culture,

- Accounting and auditing,

- Quality management,

- Labor law,

- Business law,

- The role of the rule of law in the country's progress,

- Human rights and protection of minorities,

- Legal aspects of EU integration,

- Intellectual Property Law,

- The reform of corporate law in countries in transition,

- CEFTA,

- Ecology and energy,

- Renewable energy,

- Energetic efficiency,

- Information technology and business intelligence,

- The use and integration of new technologies,

- E-society and E-learning,

- Sustainable tourism,

- Hospitality 
Special emphasis for ERAZ 2020 is given to the key topic: Pandemic Crisis and the Sustainability.

Within publications from ERAZ 2020 conference:

- 11 double blind peer reviewed papers have been published in the International Scientific Conference ERAZ 2020 - Knowledge Based Sustainable Development - Selected Papers,

- 41 double blind peer reviewed papers have been published in the International Scientific Conference ERAZ 2020 - Knowledge Based Sustainable Development - Conference Proceedings,

- 69 abstracts have been published in the International Scientific Conference ERAZ 2020 Knowledge Based Sustainable Development - Book of Abstracts.
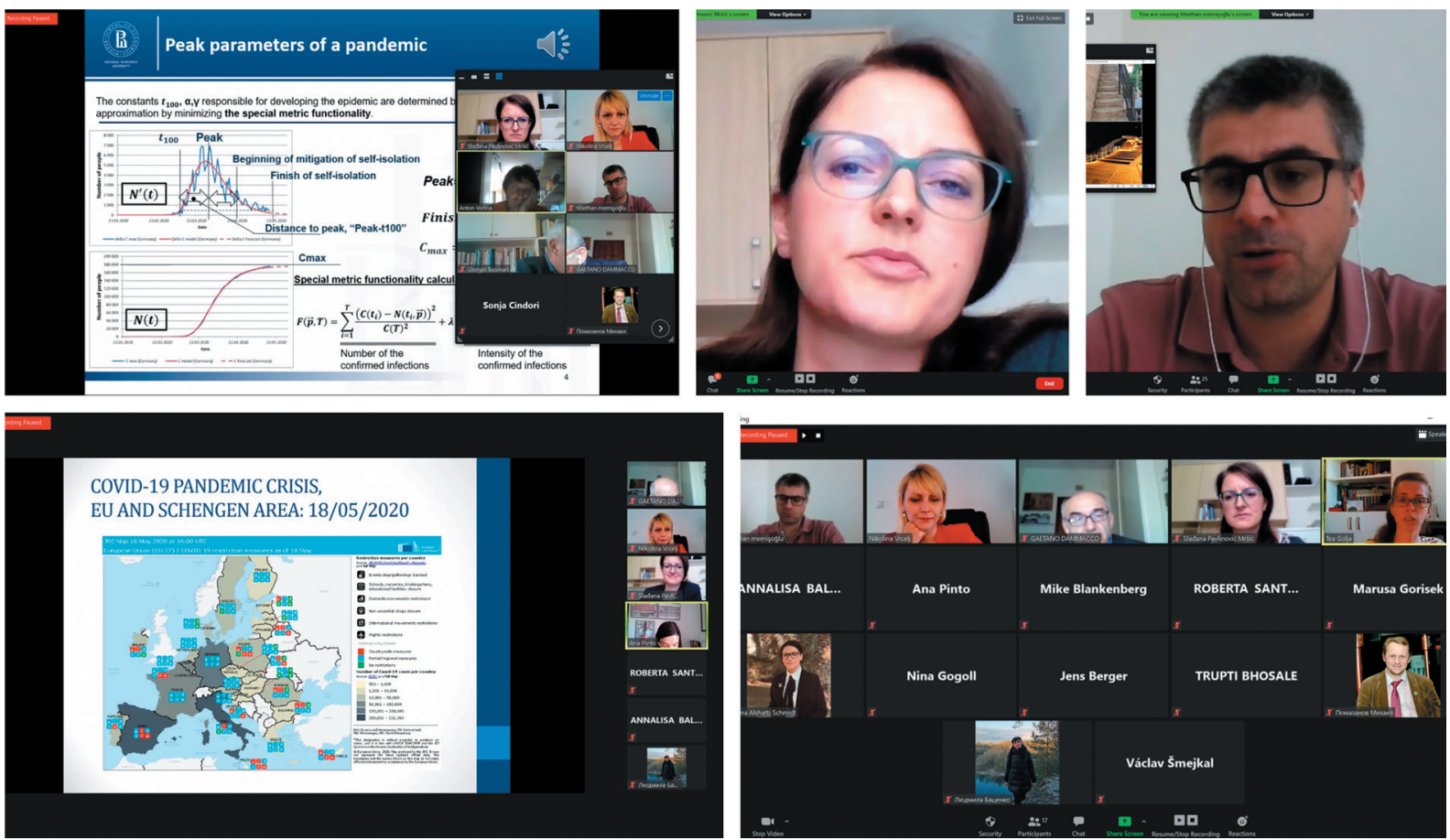

ERAZ 2020 publications have more than 520 pages. Besides that, some papers were accepted for publication in the conference partner journals namely:

- JFEAS is published by the Çukurova University, Faculty of Economics and Administrative Sciences from Turkey twice a year as an open source. This international journal is dedicated to the wide scope of themes of economics, business, public finance, econometrics, international relations, labor economics and the theoretical, methodological and applications between these disciplines, and others in Turkish and English. The journal is indexed in DOAJ, DRJI and Index Copernicus.

- Journal of Sustainable Development (JSD) is an international journal published by the Integrated Business Faculty - Skopje, North Macedonia. JSD area includes three pillars of economic, social and environmental development issues. All these aspects are considered relevant for publishing in the JSD. The journal is officially listed in the respected EBSCO database, CEEOL database, as well as the databases of Business Source Complete and Sustainability Reference Center. All articles published in the journal are also indexed in these databases.

- Journal of Innovative Business and Management is published by the DOBA Faculty, Maribor (Slovenia) and is referred in international scientific journal bases DOAJ, Google Scholar, EconPapers, ResearchGate and RePec. It has been published since 2009 and since then it has been attracting more and more interest among the readers, who predominantly come from academia and business practice. 
- Balkans Journal of Emerging Trends in Social Sciences (Balkans JETSS) is an international scientific journal, published by the Association of Economists and Managers of the Balkans. Aims and scope are economics, management, law and tourism. Balkans JETSS have following indexations: Google Scholar, CEEOL (Central and Eastern European Online Library), ProQuest's Serial Solutions, Summon, Primo Central, Alma, EBSCO's EDS Discovery Service and Knowledge Base, TDNet and OCLC.

Participation in the conference took 123 researchers with the paper representing 19 different countries (Albania, Bulgaria, China, Croatia, Czech Republic, India, Italy, Montenegro, Poland, Portugal, Romania, Russia, Serbia, Slovakia, Slovenia, Spain, Ukraine, United Arab Emirates, USA) from different universities, eminent faculties, scientific institutes, colleges, and various ministries, local governments, public and private enterprises, multinational companies, associations, etc. 



\section{AUTHORS’ AFFILIATION}

\section{Albania}

- University "Aleksandër Moisiu" of Durrës, Faculty of Business, Management Department, Durrës

\section{Bulgaria}

- Faculty of Law and History, Department of Civil Law, South-West University „Neofit Rilski”

- Laboratory of Digitization - Burgas, Institute of Mathematics and Informatics, Bulgarian Academy of Sciences, 8000 Burgas, 5 Demokratsiya Blvd.

- New Bulgarian University, Montevideo St. 21, Sofia 1618

- Technical University of Varna, 9010 Varna, str. Studentska 1

- University of National and World Economy, Sofia 1700, Department of Marketing and Strategic Planning

\section{China}

- Henan Institute of Science and Technology, Henan

\section{Croatia}

- Agro - Honor d.o.o., Vrbaska 1c, Osijek

- College of Applied Sciences "Lavoslav Ružička" Vukovar, Županijska 50, Vukovar

- Faculty of Economics, Business and Tourism, University of Split, Cvite Fiskovića 5, 21000 Split

- Faculty of Law, University of Zagreb, Trg Republike Hrvatske 3, Zagreb

- Faculty of Tourism and Hospitality Management, University of Rijeka, Primorska 42, 51410 Opatija

- Juraj Dobrila University of Pula - Faculty of Interdisciplinary, Italian and Cultural Studies, Pula

- Libertas International University, Trg J. F. Kennedy 6b, HR-10000 Zagreb

- PIK Vrbovec plus d.o.o., Gospodarska zona 20, Antunovac

- Polytechnic of Rijeka, Trpimirova 2, 51000 Rijeka

- University College of International Relations and Diplomacy Dag Hammarskjöld, Trg J. F. Kennedy 6b, HR-10000 Zagreb

- University of Zagreb, Trg Republike Hrvatske 14, HR-10000 Zagreb

- WYG Consulting Ltd.
Czech Republic

- College of Regional Development and Banking Institute - AMBIS, Department of Economics and Management, Lindnerova 575/1, 18000 Praha 8

- Charles University, Faculty of Law, Department of European Law, nám. Curieových 901/7 116 40 Prague 1

- University of Economics, Prague, W. Churchill Sq. 1938/4, 13067 Prague 3 - Žižkov

\section{India}

- Symbiosis Law School, Symbiosis International University, Pune

- Symbiosis School of Economics, Pune

\section{Italy}

- Department of Law, Institute of Legal Medicine, University of Macerata, via Giovanni Mario Crescimbeni 30, Macerata

- Department of Political Science - University of Studies Aldo Moro - Bari

- Dept. of Economics "Marco Biagi", University of Modena and Reggio Emilia

- Dept. of Social and Political Sciences, European University Institute, Fiesole, (FI)

- Dept. of Statistical Sciences "Paolo Fortunati", Alma Mater Studiorum University of Bologna, Italy

- School of Law, Legal Medicine section, University of Camerino, Italy, piazza Cavour 19, Camerino (MC)

- Telematic University Giustino Fortunato, Via Raffaele Delcogliano, 1282100 Benevento

- University of Brescia, Department of Law, via San Faustino, 41, 25122 Brescia

- University of Federico II, Naples

\section{Montenegro}

- Faculty of Business and Tourism, Akademija znanja, Budva

- Faculty of Maritime Studies, Kotor

- Madona Montenegro doo, Kotor

- University Adriatic Bar

\section{Poland}

- University of Economics and Innovation in Lublin, Projektowa str. 4, 20-209 Lublin

\section{Portugal}

- CICE/ESCE/IPS, Campus do IPS, Estefanilha Setúbal 
- Lisbon Law School, Alameda da Universidade, Cidade Universitária, 1649-014 Lisboa

- Rua Saraiva de Carvalho, $149-4^{\circ}$ Dto, Lisbon

- UDI/ESTG/IPG, Avenida Dr. Francisco Sá Carneiro, $\mathrm{n}^{\circ}$ 50, Gab. 21

\section{Romania}

- School of Advanced Studies of the Romanian Academy (SCOSAAR), Romanian Academy, Bucharest

\section{Russia}

- Kemerovo State University, Krasnay st.6, Kemerovo

- Kemerovo State University of Culture, St.Voroshilov, 17 Kemerovo

- Higher School of Economics National Research University, Main campus: 20 Myasnitskaya Ulitsa, Moscow

\section{Serbia}

- Faculty of Agriculture, University of Belgrade, Nemanjina 6, 11081 Belgrade

- Faculty of Business Economics, Educons University, Sremska Kamenica, Vojvode Putnika street no 87

- Faculty of Economics Subotica, University of Novi Sad, Segedinski put 9-11, Subotica

- Faculty of Economics, University of Nis, Trg Kralja Aleksandra Ujedinitelja 11, Niš

- Faculty of Occupational Safety, University of Niš, Čarnojevića 10A, Niš

- Faculty of Philosophy, University of Niš, Ćirila and Metodija 2, Niš

- Faculty of Social Studies Belgrade, Serbia

- ICT College, Zdravka Celara 16, Belgrade

- Innovation Center, University of Niš, University Square 2, 18000 Niš

- JKP Informatika Novi Sad, Bul. cara Lazara 3, Novi Sad

- Megatrend University, Maršala Tolbuhina 8, Belgrade

- University of Pristina in Kosovska Mitrovica

\section{Slovakia}

- Faculty of Economics and Management, Department of Economics, Slovak University of Agriculture in Nitra, Tr. A. Hlinku 2, 94976 Nitra
- Faculty of Management, Comenius University in Bratislava, Odbojárov 10, 82005 Bratislava

- Faculty of National Economic, Department of Finance, University of Economics in Bratislava, Dolnozemská cesta 1, 85235 Bratislava

- Land technologies s.r.o., Hlohovecká 11, 95141 Lužianky

- University of Žilina, Faculty of Managements and Informatics, Dpt. of Mathematical Methods and Operations Research, Univerzitná 8215/1, 01026 Žilina

- University of Žilina, Faculty of Managements and Informatics, Dpt. of Macro and Microeconomics, Univerzitná 8215/1, 01026 Žilina

\section{Slovenia}

- Institute for Developmental and Strategic Analysis, Dunajska 113, 1000 Ljubljana

\section{Spain}

- Faculty of Social Sciences and Communication. Barrio Sarriena, s/n. 48940 Leioa (Vizcaya)

- University of Malaga, Málaga

\section{Ukraine}

- Department of Accounting and Taxation; SHEE "Kyiv National Economic University named after Vadym Hetman", Kyiv

- Department of Public Relations; National University Kyiv-Mohyla Academy, Kyiv

- Sumy National Agrarian University, Kondratieva str., 160/5, 87, Sumy, 40021

- V.N. Karazin Kharkiv National University, Faculty of Economics, 4 Svobody Sq., Kharkiv, 61022

- Vasyl Stefanyk Precarpathian National University, 57, Shevchenko Str., Ivano-Frankivsk, 76018

\section{United Arab Emirates}

- College of Law, United Arab Emirates University (UAEU), Al Ain, P.O. Box No. 15551

\section{USA}

- Pennsylvania State University, Penn State World Campus, 305 Armsby Building, University Park, PA, 16802 


\title{
STRINGENCY OF COVID-19 RESTRICTIONS \\ AMONG ITALIAN REGIONS AND THE ROLE \\ OF REGIONAL ECONOMIC SYSTEMS
}

\author{
Giorgio Tassinari ${ }^{1}$ \\ Fabrizio Alboni ${ }^{2}$ \\ Arianna Tassinari ${ }^{3}$ (C) \\ Ignazio Drudi ${ }^{4}$ (ic)
}

DOI: https://doi.org/10.31410/ERAZ.S.P.2020.1

\begin{abstract}
The diffusion of COVID-19 pandemic among Italian Regions has been very uneven. The intensity of measures introduced to contrast its spread also shows a high heterogeneity among local jurisdiction, but this does not correspond, prima facie, with the intensity of the pandemic. What shapes the stringency of responses across different localities? Various factors could be hypothesised to be at play: factors related to the intensity of the pandemic, to the political and ideological orientation of governing authorities, to the models of growth and development characterising regional economic systems, and to the strength of lobbying groups pushing for more or less stringent responses. To address these questions, we elaborate a regional stringency index and analyse (using CART regression trees and other statistical methods) its relationships with some of these factors. The results show that the main driver of stringency (in an inverse way) is the weight of exports on regional GDP, suggesting that economic interests and business power might play an important role in shaping political responses to pandemics.
\end{abstract}

Keywords: Covid-19, Lockdown, Business interests.

\section{INTRODUCTION}

\begin{abstract}
$\mathrm{A}^{\mathrm{k}}$ key challenge facing policymakers in the formulation of public policy responses to the Covid19 crisis has been how to balance the tension between two competing principles and guiding objectives of governmental activity: on the one hand, the preservation and safeguarding of public health, and on the other, the preservation of economic and business activity to safeguard economic growth and prevent an excessive decline in output. One of the main issue areas where the opposition of these two principles in public policy formulation has played out most evidently is the question of timing and extensiveness of restrictions on economic and productive activity during the lockdown. Which economic sectors should remain operational during the acute phase of the pandemic, and under what conditions? And how fast and extensive should the easing of these restrictions be, once the most acute phase of the pandemic crisis is over?
\end{abstract}

Political tensions over these questions have been at the centre of public policy and political debates in several countries. The heated controversies on the timing and conditions of re-openings of business and commercial activities after the peak of the pandemic in Italy, and the unfolding conflict between the UK government, unions and business groups on the UK government's 'return to work' plans provide illustrative examples in this respect. A key aspect of this debate

1 Dept. of Statistical Sciences "Paolo Fortunati”, Alma Mater Studiorum University of Bologna, Italy

2 Dept. of Economics “Marco Biagi”, University of Modena and Reggio Emilia, Italy

3 Dept. of Social and Political Sciences, European University Institute, Fiesole, (FI), Italy

4 Dept. of Statistical Sciences "Paolo Fortunati”, Alma Mater Studiorum University of Bologna, Italy 
concerns specifically the role that (organized) economic interests have played in shaping public policy responses to the pandemic, with particular regard to the timing, length, extensiveness and stringency of lockdown measures for economic and productive activities. Depending on the national context, European governments have alternatively been accused in media debates of having 'capitulated' to the pressures of powerful business groups when hesitating to implement fast and extensive restrictions on economic activity, or of being 'in the pocket of trade unions' when opting for longer or more extensive preventative measures restricting economic and production activity. This is a pressing challenge for policymakers and political systems, as lack of clarity and transparency about the role and influence that organized economic interests have played in shaping policy responses to the Covid19 pandemic can contribute to an escalation of political and social tensions among social groups, and foster a crisis of public trust arising from a perceived lack in transparency and input legitimacy of governmental activity.

The key hypothesis that we seek to test is that the stringency of public policy responses restricting economic activity to respond to the pandemic is influenced by the structural and instrumental power (cf. Culpepper 2010) that business groups in key economic sectors are able to exercise. In this exploratory paper, we use Italy as an illustrative and crucial case study. The choice of the Italian case is well suited to explore the influence of business interests on the responses to the COVID-19 pandemic. Italy was in the eye of the storm of the Covid-19 pandemic, as one of the European countries that was hit sooner and hardest. However, it displayed considerable regional inequalities in the spread of the pandemic, as it is shown in figure 2. Regional variation in the stringency of the lockdown measures implemented was also considerable, as after the constitutional reform of 2001 Italian regions have enjoyed considerable levels of autonomy on several areas of governance.

The strength and orientation of business and economic interests also varies across regions. The Italian growth model has historically been demand-led, but it has increasingly been dependent on exports since the launch of Euro (Simonazzi, Ginzburg, and Nocella, 2013). This pattern has been deepened by the Great Recession (Bellofiore and Garibaldo, 2019; Perez and Matsaganis 2019). The manufacturing business confederation (Confindustria) is the most powerful business group, and has in recent years been highly influential in orienting government policies in the economic and labour policy fields to push for measures enhancing the external competitiveness of the Italian economy (cf. Pritoni and Sacchi, 2019; Bulfone and Tassinari forthcoming). The 21 Italian Regions display however considerable variation in the degree of economic development (that is reflected in differences in GDP per capita) and in their degree of export orientation. Hence, this makes the Italian case theoretically and empirically apt to investigate whether the strength of export-oriented economic interests at a regional level is correlated with the stringency of pandemic responses, whilst holding other factors (such as the national political system and the overall macroeconomic and fiscal context) constant.

Shedding light on the influence of economic interests on responses to the pandemic has great relevance and potential use for policymakers. Indeed, ascertaining the impact of economic interests and lobby groups on the crafting of policy responses to the Covid19 pandemic helps to illuminate and make legible the forces at work in shaping government policy responses, and in this way contribute to give greater (input) legitimacy to governmental decisions, as well as to introduce greater transparency in political debates over the role of business in politics. 


\section{THE COVID-19 PANDEMIC IN ITALY: A BRIEF CRONICLE}

The official starting point of COVID-19 pandemic in Italy was on the $21^{\text {st }}$ of February, when the first COVID patient was identified in Codogno, (Lodi), 80 kilometres south of Milan. After few days, a red zone was established in the southern area of the Province of Lodi, and from the 24th of February all schools and universities were closed in the entire country. The pandemic quickly spread (see figure 1) and on the 9th of March a total lockdown was established over the entire country. Although most public-facing commercial activities were closed down, most economic activities (such as agriculture, food industry, pharmaceuticals, and so on) remained operational, accounting for around 50\% of the dependent labour force. A more restrictive lockdown of all 'non-essential' activities was implemented from 24th March onwards, following a heated tripartite negotiation between the government, unions and business groups. However, even after this fuller lockdown, several firms in 'non-essential' sectors were able to continue to operate after filing a request for permission (aperture in deroga) to the local government authorities (Prefetture). From the end of April, the diffusion of the pandemic started to decline. Consequently, the Italian Government has progressively reduced the stringency and extensiveness of the lockdown, both for what concerns closures and restrictions on productive activities, and the restrictions on the movement of people.

To fully understand the specificities of the Italian context, it is important to underline that the Italian Constitution grants regional authorities ample powers, first on the subject of health, whose organisation is fully devolved at the regional level, as well on many other issues, including those concerning the authorisation for the execution of productive and commercial activities, and the organisation of local transport. The policies enacted to prevent and contrast the pandemic have been differentiated across Italian regions in terms of timing and stringency. However, these do not co-vary with the intensity of the pandemic (figure 2). This provides the empirical base and rationale for the present research.

\section{RESEARCH HYPOTHESES}

The broad hypothesis we want to test in this work is whether the degree of stringency of lockdown in a given region is related to the strength and composition of economic interests, and to the capacity of economic interests of exercising influence on the political system. Given the political and strategic centrality of export-oriented business groups to the Italian political economy in the post-Great Recession context, we assume that their structural and instrumental power will be higher than those of domestic-oriented business groups. In this regard, we formulate the following hypothesis:

H1: The stringency of lockdown measures is lower in regions where the structural power of export-oriented manufacturing is higher.

We also theorise that regions governed by a centre-right party adopt policies which are more favourable to firms and in defence of the continuity of productive activities, thus adopting a more lenient line in terms of stringency of lockdown measures, whilst the regions governed by the centre-left would adopt more stringent policies prioritising the health interests of the population and the workforce. 
H2: The stringency of lockdown measures is lower in regions where centre-right parties are in power.

It is also important to consider the considerable heterogeneity in the spatial diffusion of the pandemic in Italy. Figure 2 reports the cumulative number of Covid-19 related deaths per 100,000 inhabitants in the middle of the acute phase of the pandemic (18th April), by region. It shows that the hardest hit regions were those of Northern Italy (especially Lombardy). These regions are characterised by high per capita GDP levels and of a high weight of exports on regional GDP if compared to the other regions.

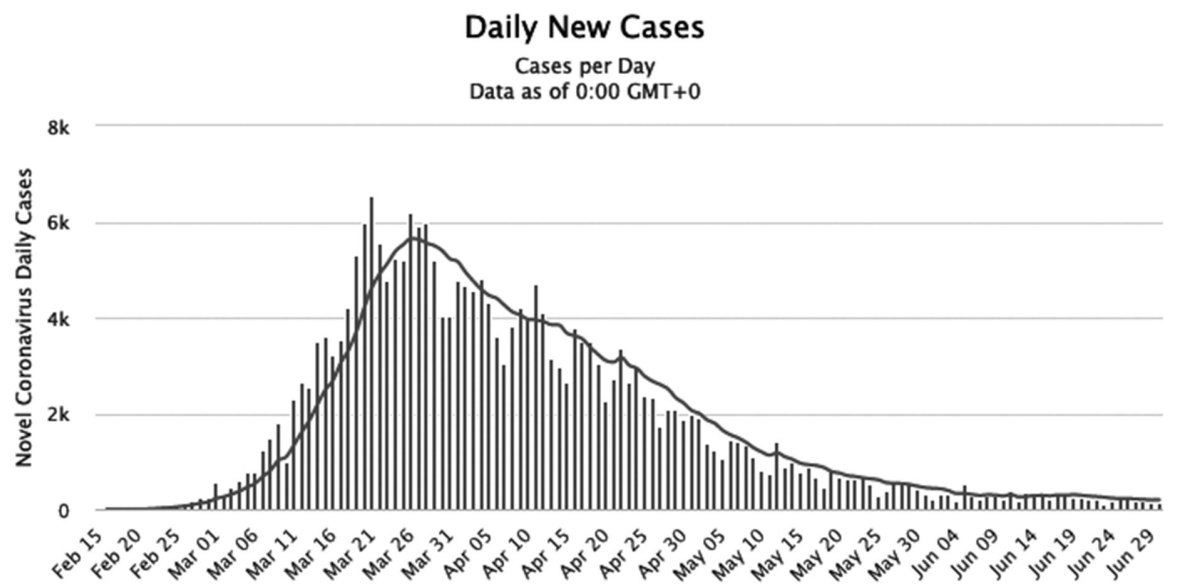

Figure 1. Number of daily new cases of Covid-19 in Italy and 7-days moving average

Source: Worldometer

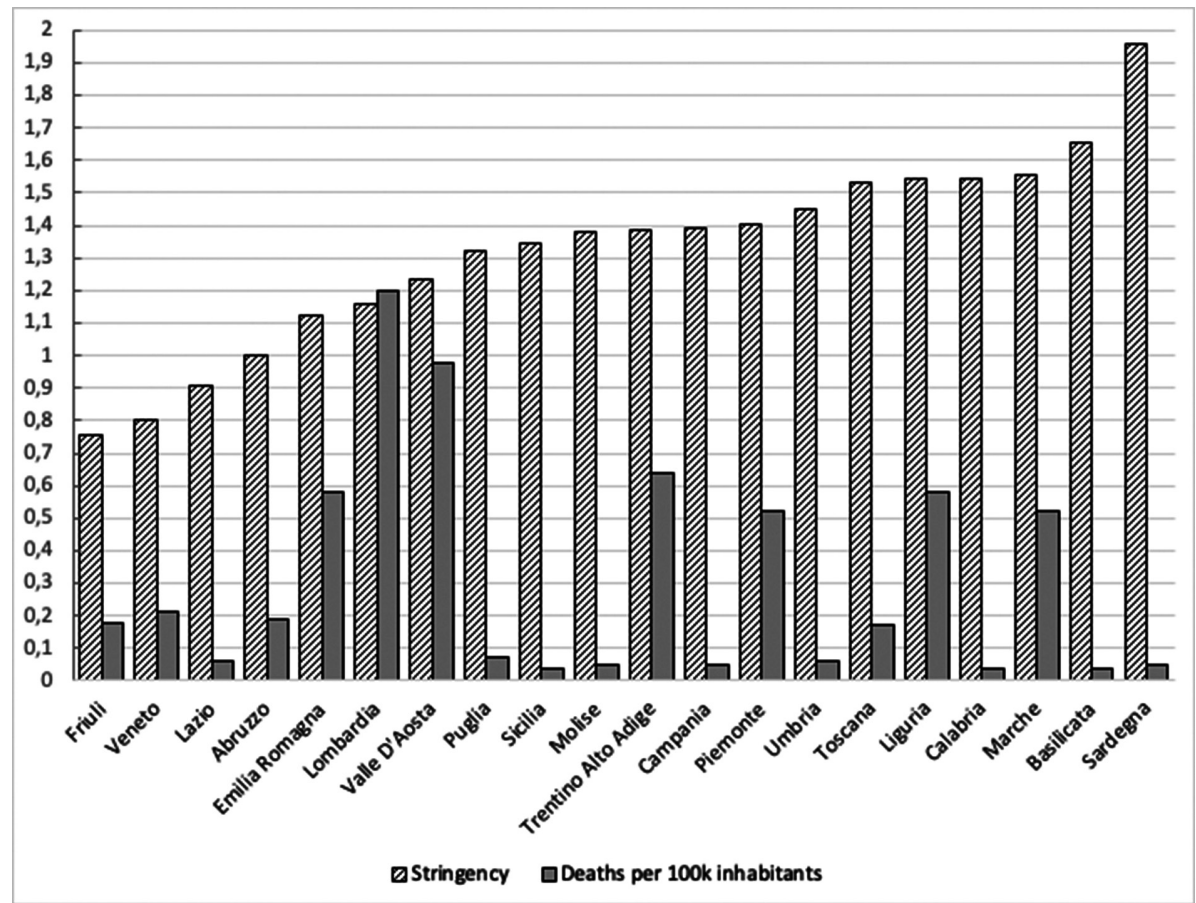

Figure 2. Stringency of lockdown measures and deaths per 100k inhabitants in Italy on $18 / 4 / 2020$, by region

Source: authors' own elaborations on data from Google, Italian Ministry of the Interior and Italian Health Ministry 


\section{THE DATA}

To test our hypothesis, we constructed a 'regional stringency index' to map the stringency of lockdown measures implemented in response to the pandemic across the various Italian regions. This is a preliminary measure that will be further refined in future iterations of this research. ${ }^{5}$ The actual stringency index we use in this exploratory paper (our dependent variable) is given by a sum of two sub-indexes. The first is the $\%$ reduction in mobility in each region compared to the pre-pandemic period (source: Google, 04-26), which is a proxy of the actual extent of closure of productive activities at the height of the lockdown. The second is the percentage of firms in 'non-essential' sectors that obtained the permission to continue running their activities during the lockdown (source Ministry of Interior, 04-24), as a percentage of the overall population of firms in the region. Each regional indicator $\left(x_{i j}\right)$ has been rescaled according to the formula as follows:

$$
1-\frac{x_{i j-} \operatorname{Min}_{j}}{\operatorname{Max}_{j}-\operatorname{Min}_{j}}
$$

The two scaled indicators (each spanning between 0 and 1) have been summed so as to have an overall stringency indicator in the range 0-2 (the lower the value, the less stringent is the policy).

As covariates we include both the strength of pandemic (deaths for 100.000 inhabitants), and the structural components of the regional economy which can act as proxies of the relative structural power of economic interests, and of export-oriented business groups in particular (GDP per capita, $\%$ of export over regional GDP, weight of manufacturing companies over the total number of firms in a region). In the following table each variable is described, and the statistical source is listed.

Table 1. Variables used in the analysis

\begin{tabular}{|l|l|l|}
\hline Variable & Code & Source/Period \\
\hline GDP per capita & Pilpc & Istat, 2019 \\
\hline Deaths for 100 thousand inhabitants & Death & Italian Gov., period from 02-21 to 04-18 \\
\hline Export/GDP & Export & Istat, 2019 \\
\hline \% Manufacture on GDP & Manif & Istat, 2019 \\
\hline $\begin{array}{l}\text { Political orientation of regional } \\
\text { Government (dummy) }\end{array}$ & $\begin{array}{l}\text { CentreLeft, CentreRight, } \\
\text { Other }\end{array}$ & \\
\hline Stringency index & Stringency & Our elaborations \\
\hline
\end{tabular}

Finally, we add a qualitative variable addressing the political orientation of regional governments (Centre-Left, Centre-Right, Autonomist). The rational is that Centre-Right regional governments will foster pro-firms' policies (less stringency), while Centre-Left should be pro-labour and households (more stringency). This variable enters as a dummy one, with the Autonomist category assumed as a basis.

In a subsequent phase of this research, we plan to construct a regional stringency index, similar in inspiration to that constructed by the Oxford Blavatnik School of Government, measuring changes in the relative stringency of lockdown measures at the sub-national / regional level. This will be based on a hand-coding of all relevant regional ordnances restricting or relaxing economic and productive activities and other auxiliary activities (e.g. public transport). 


\section{METHODOLOGY AND RESULTS}

As all variables are rational ones, we first run a standard linear regression by OLS. The specification we used is the following:

$$
\begin{aligned}
\text { Stringency }_{i}= & \beta_{0}+\beta_{1} \text { Pilpc }_{i}+\beta_{2} \text { Death }_{i}+\beta_{3} \text { Export }_{i}+\beta_{4} \text { Manif }_{i} \\
& +\beta_{5} \text { CentreLeft }_{i}+\beta_{6} \text { CentreRight }_{i} \varepsilon_{i}
\end{aligned}
$$

where $i=1, \ldots, 20$ (the twenty Italians regions) and $\varepsilon$ is a white noise.

The results are as follows:

Table 2. Results of standard regression

\begin{tabular}{|c|c|c|c|c|}
\hline Coefficients & Estimate & Standard Error & t value & p-value \\
\hline Intercept & $1.479 \mathrm{e}+00$ & $5.444 \mathrm{e}-01$ & 2.718 & 0.0176 \\
\hline Pilpc & $-2.355 \mathrm{e}-05$ & $1.289 \mathrm{e}-05$ & -1.827 & 0.0908 \\
\hline Deaths & $7.159 \mathrm{e}-01$ & $3.814 \mathrm{e}-01$ & 1.877 & 0.0831 \\
\hline Centre-right govt. & $4,710 \mathrm{e}-01$ & $4.238 \mathrm{e}-01$ & 1.112 & 0.2865 \\
\hline Centre-left govt. & $5.066 \mathrm{e}-06$ & $4.595 \mathrm{e}-01$ & 1.103 & 0.2902 \\
\hline Export & $-5.079 \mathrm{e}-06$ & $3.397 \mathrm{e}-06$ & -1.495 & 0.1588 \\
\hline Manufacturing & $-3.0073-03$ & $1.650 \mathrm{e}-02$ & -0.182 & 0.8582 \\
\hline
\end{tabular}

Residual standard error: 0.2855 on 13 degrees of freedom

Multiple R-squared: 0.3718, Adjusted R-squared: 0.08184

F-statistic: 1.282 on 6 and 13 DF, p-value: 0.3306

The results are not very satisfactory as the F test is not significant, but the coefficients have the expected signs. In order to avoid multicollinearity, we then run a step-wise regression. The results are as follows (table 3).

Table 3. Results of stepwise regression

\begin{tabular}{|c|c|c|c|c|}
\hline Coefficients & Estimate & Standard Error & t value & p-value \\
\hline Intercept & $1.935 \mathrm{e}+00$ & $2.876 \mathrm{e}-01$ & 6.728 & $4.85 \mathrm{e}-06$ \\
\hline Pilpc & $-2.410 \mathrm{e}-05$ & $1.214 \mathrm{e}-05$ & -1.986 & 0.0645 \\
\hline Deaths & $4.672 \mathrm{e}-01$ & $2.922 \mathrm{e}-01$ & 1.599 & 0.1294 \\
\hline Export & $-3,176 \mathrm{e}-06$ & $2.380 \mathrm{e}-06$ & -1.334 & 0.2007 \\
\hline
\end{tabular}

Residual standard error: 0.2697 on 16 degrees of freedom

Multiple R-squared: 0.31, Adjusted R-squared: 0.1807

F-statistic: 2.397 on 3 and $16 \mathrm{DF}$, p-value: 0.1062

The F-statistics is barely significant and the R2 is very low. However, the signs of the coefficients are as expected: the strength of pandemic has a positive effect on the stringency index, while the GDP per capita and the percentage of exports with respect to the regional GDP have negative ones. This can be interpreted as a proxy of the pressure of entrepreneurial associations on the behaviour of the regional governments.

It is difficult, however, to think that the right specification is a simple linear one. Many other mathematical functions are plausible (multiplicative, with interactions and so on). To overcome the difficulties of specification (given that we do not have any theory about the behaviour of 
agents during COVD-19 crisis), we use an explorative method known as CART (Breiman et al. 1984). Classification and regression trees (CART) are a non-parametric decision tree learning technique that belongs to the wide set of data mining methods (Rokach and Maimon, 2008) and that produces either classification or regression trees, depending on whether the dependent variable is categorical or numeric, respectively.

The objective of the CART algorithm is to classify the observations in classes defined in function of the values of the dependent variable. Accordingly, the algorithm will attempt to position the observations among the different classes in the most accurate way possible, disregarding those attributes or those values of attributes that do not lead to a correct classification of the observations. In formal terms, the algorithm in the various phases of the analysis will choose some 'splitter' attributes among those present in the training set, and will try different values of those attributes in order to minimise the impurity function at each node. Minimising the impurity function coincides with finding, in the various phases of the analysis, the attributes and the respective threshold values that lead to the more correct classification and that should thus yield, in that phase, greater information. The process of analysis is iterative and only stops when it is no longer possible to minimise the impurity function at each node by manipulating the choice of the attributes and their threshold values. The impurity of a node is maximum when all the classes of the dependent variable are present in the same proportion, whilst it is minimum when the node contains cases belonging to just one class. The methods commonly used to measure impurity are entropy and Gini index when the dependent variable is qualitative, and the reduction of variance when the dependent variable is quantitative.

In this analysis, we run CART using a dedicated R routine and imposing a number of splits equal to five. The results are shown in figure 3.

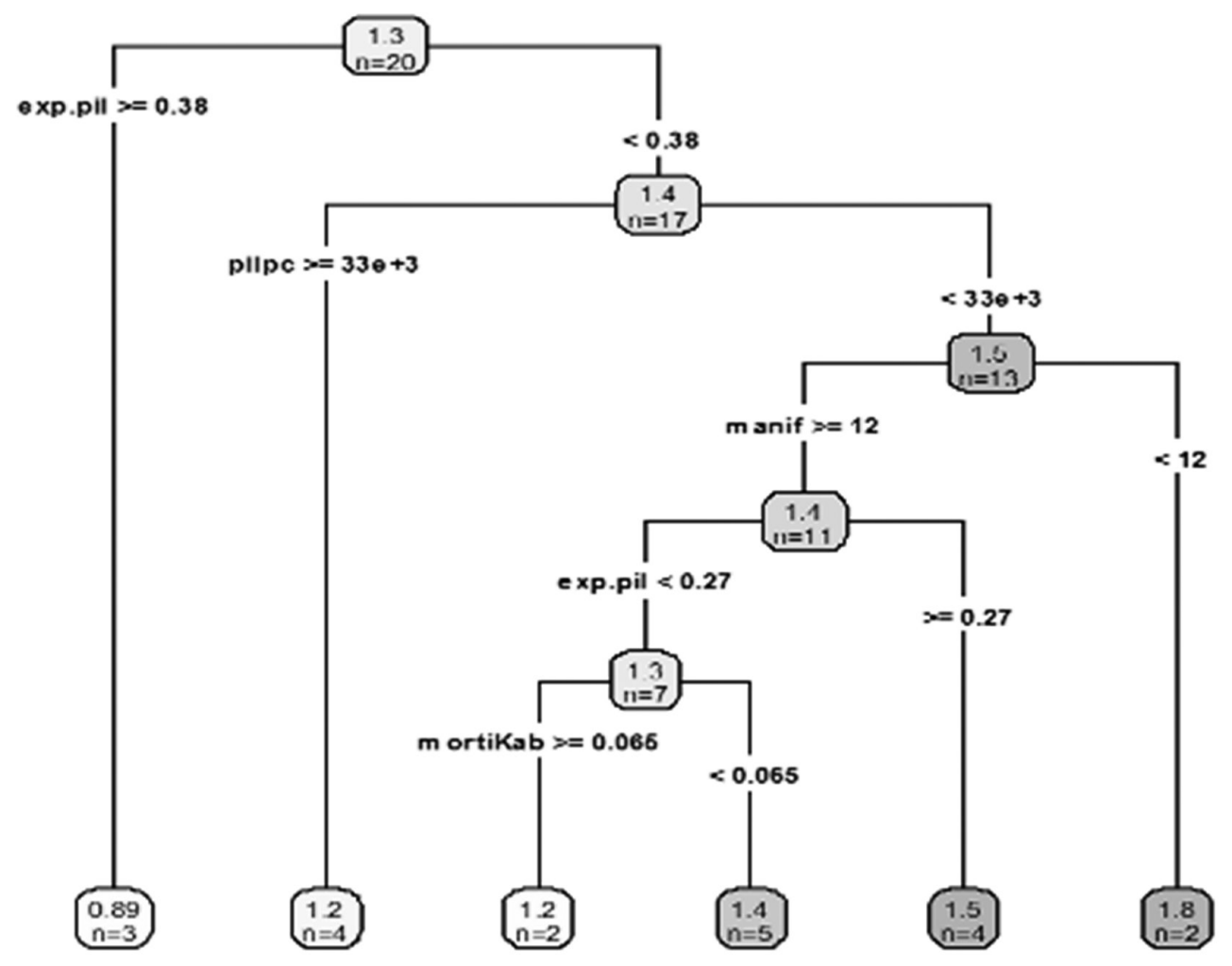

Figure 3. Results of CART regression tree

Source: authors' own elaboration 
As CART is a hierarchical method, the dendrogram should be read from above. The results are very satisfactory. First of all, $\mathrm{R}^{2}$ is about 0,80 , and we have a clear representation of the hierarchy of variables. We get six classes of regions. The first splitting is made according to the weight of exports on GDP. The second partition is made on the basis of GDP per capita. This way we obtain two groups ( 7 regions, Lombardy, Veneto, Emilia-Romagna, Friuli-Venezia Giulia, Piedmont, Lazio) that have the lowest values of the stringency index. The other regions are split on the basis of the weight of manufacturing and again on the basis of exports. The last variable to intervene is the number of corona virus deaths for 100 hundred inhabitants, and this contradicts our expectation that the strength of pandemic was one of the main drivers of regional stringency. Besides, the political orientation of the regional governments seems not to have any influence in the determination of the stringency index.

\section{DISCUSSION AND CONCLUSION}

From the results presented above, we can draw some preliminary observations. First, it appears reasonably clear that the determination of the intensity of stringency of lockdown measures at the regional level is driven by structural features of the regional economic structure, and more specifically by the structural power of export-oriented business groups in a given locality (\% of exports on GDP), and in second place by the strength of the local economic system. Where these indicators are higher, the level of stringency is significantly lower, even though these regions were, on average, also those more exposed to the contagion and more at risk of spread of the disease. To be sure, the weight of exports and manufacturing in the regional economy is a coarse measure of the structural power of business. In future work, more precise proxies will be employed. However, these results are nonetheless indicative that there is some empirical basis to our hypothesis about a correlation between economic interests and the stringency of lockdown measures. The implications of these results are clear. Indeed, it is commonplace to point out that the more lenient the stringency of lockdown measures on productive activities, the higher the chances of diffusion of contagion. In this respect, it is indeed useful to recall that according to the official data from the Italian government (INAIL), around $25 \%$ of all contagions can be traced back to contagions that took place in the workplace.

From our two initial starting hypotheses (effect of the structural power of economic organisations, and effect of the political orientation of regional authorities), only the first is confirmed by our analysis - albeit only indirectly. From the point of view of measures implemented to counter the spread of the pandemic, it appears that regional authorities with a right-wing or a left-wing orientation have implemented similar policies. Or rather: if we divide the regions on the basis of the colour of the local government, we obtain two groups characterised by very strong heterogeneity in terms of stringency and pro-business or pro-people orientation. Hence, the economic characteristics of the regional context seem to play a more important role in shaping responses to the pandemic than political variables.

This preliminary analysis constitutes only a first attempt at testing our hypotheses of interest. There are various directions in which the analysis can be developed. The most important, in our view, is to improve the informational basis of the analysis by elaborating a more accurate regional stringency index that reflects the actual policies and ordnances implemented on a regional basis. The other important next step will be the development of a quantitative content analysis of news coverage at a regional level to identify more directly the lobbying pressures exercised by economic interest groups towards the easing of the lockdown (and vice versa, by unions for a more restrictive approach). 


\section{REFERENCES}

Bellofiore, R. Garibaldo, F (2019), Le dernier metro. Europe and the Edge of the Abyss, Crisis and Critique, 6, 1, pp. 25-46.

Breiman, Leo; Friedman, J. H.; Olshen, R. A.; Stone, C. J. (1984). Classification and regression trees. Monterey, CA: Wadsworth \& Brooks/Cole Advanced Books \& Software. ISBN 9780-412-04841-8.

Bulfone, F. and Tassinari, A. (forthcoming) Under pressure. Economic constraints, electoral politics and labour market reforms in Southern Europe in the crisis decade. European Journal of Political Research.

Culpepper PD (2010) Quiet Politics and Business Power: Corporate Control in Europe and Japan. Cambridge: Cambridge University Press.

Perez SA and Matsaganis M (2019) Export or Perish: Can Internal Devaluation Create Enough Good Jobs in Southern Europe? South European Society and Politics 24(2): 259-285.

Pritoni A and Sacchi S (2019) Interest Groups and the «Jobs Act»: Lobbying with What Effects? Rivista Italiana di Politiche Pubbliche (2/2019).

Simonazzi, A.M., Ginzburg, C. and Nocella, G. (2013), Economic relations between Germany and Southern Europe, Cambridge Journal of Economics, 37, 3, pp. 653-675.

Rokach, L. and Maimon, O. (2008), Data mining with decision trees: theory and applications, World Scientific Pub. Co. Inc. 



\title{
MODELING OF COVID-19 PANDEMIC INDICES AND THEIR RELATIONSHIPS WITH SOCIO-ECONOMIC INDICATORS
}

\author{
Mikhail Pomazanov ${ }^{1}$
}

DOI: https://doi.org/10.31410/ERAZ.S.P.2020.11

\begin{abstract}
This paper presents non-classical models for estimating and forecasting COVID-19 pandemic indices. These models have been successfully tested on country data where the pandemic is nearing completion. In particular, an effective algorithm for mortality index evaluation is also presented. This index is usually replaced by more simple estimates such as, for instance, ,the number of deaths divided by the number of infected"; however, while the virus is at the stage of its rapid distribution, such superficial approaches are incorrect. Model indicators of the infection itself allow us to predict not only the apogee of the epidemic and the end of the quarantine period, but also the maximum number of infected people in some country (continent) during the height of the epidemic.

The second part of the paper is devoted to an attempt to build regression models to explain (with using $100+$ country socio-economic indicators taken from the World Bank data) the behavior of the epidemic spread indices. It is shown that the maximum number of infected people in the country is well predicted (R-square is close to 90\%); and, moreover, migration indicators and the number of international air take-offs are effective regressors. Other indicators, for example, the mortality index, are difficultly modeled; nevertheless, it has a significant relationship with socio-economic factors.
\end{abstract}

The presented paper might be valuable for making effective decisions to forestall some future pandemics or even the ,second wave" of COVID-19.

Keywords: COVID-19, Pandemic, Modeling, Socio-economic indicators.

\section{INTRODUCTION}

mong classical epidemiological models, there are three main types of deterministic (parametric) models for infectious diseases that are spread by direct human-to-human contact in the population. They are presented in Herbert and Hethcote, 1989. The abbreviation ,S. I. R" means the proportion of healthy $S$, the proportion of infected I and the proportion of recovered/deceased $R$ who have immunity, $\mathrm{S}+\mathrm{I}+\mathrm{R}=100 \%$. These three types of models differ in that the first does not take into account the immunity of the SIS-type (,healthy"-"infected"-"healthy”) $S+I=100 \%$, the model SIR (,healthy"-'infected"--"recovered”) is used for diseases where infection gives permanent immunity; the third type of models takes into account natural birth/death in the population, and this type is focused on long-term modeling of epidemics. When a disease modeled by SIR passes through a population in a relatively short time (less than one year), this outbreak is called an epidemic. Since the epidemic occurs relatively quickly, the model does not include birth and death (life dynamics). Epidemics are common in diseases such as influenza, measles, rubella, and chicken pox. An overview, including non-parametric models, is given in Choisy et al., 2007.

Classical parametric models have serious drawbacks in order to model the COVID-19 global pandemic. One of the main issues is the lack of consideration in the model of active disciplinary actions to prevent the development of the epidemic. In the models, the parameters of mutual infection are

Higher School of Economics National Research University, Main campus: 20 Myasnitskaya Ulitsa, Moscow, Russia 
assumed to be constant, i.e. «the diseases are left to themselves». Due to obvious empirical observations boundary conditions on the simulation results are imposed; namely, at the beginning of the epidemic the number of infected as the number of infected (sick at a given time) increases exponentially, starting from a certain conditional ,zero" level, that can be chosen empirically, for example - 100 infected people. The number of infected (patients) at the end of the outbreak can be considered tending to zero or allow a small background level of the growth rate of the total number of infected. The overall level of the total number of infected people covers a small percentage of the population, $\mathrm{S}>\mathrm{I}+\mathrm{R}$, so it does not make sense to incorporate a percentage with immunity in the model (i.e. SIR is not suitable). For the SIS model, the solution of the differential equation in finite functions might exist (the Bernoulli equation in the SIS model), but it has the property of exponential growth (at the beginning of development) only at such a parameter value that the level of infected people does not tend to zero after the peak of the disease. The next paragraph will present an alternative parametric infection model that is being successfully tested in the Ebola virus epidemic (Chapter 3).

During an outbreak of a new or emerging infectious agent such as COVID-19, one of the most important epidemiological quantities to be determined is the mortality rate (indicator), which is the percentage of cases that eventually die from this disease. This ratio is often estimated using the combined number of cases and deaths at one time, such as those compiled daily by the world health organization during the COVID-19 epidemic (WHO. Coronavirus disease, 2019). However, simple estimates of the fatality ratio obtained from these reports can be misleading if the result is unknown for the infected but not recovered proportion of patients at the time of analysis. Estimates obtained during the SARS epidemic by dividing the number of deaths by the total number of reported cases were much lower (3-5 percent during the first few weeks of the global outbreak) than estimates obtained using appropriate statistical methods, and varied significantly across countries. Moreover, as the epidemic progressed, these naive statistical estimates falsely indicated an increase in the death rate, which fueled an already high level of public anxiety among the affected population. Therefore, this assessment requires modeling.

Ghani et al. (2005) propose a method for this, based on the Kaplan-Meyeri survival model, and evaluate its indicators using data from the 2003 severe acute respiratory syndrome epidemic in Hong Kong. In Chapter 4, we will propose an effective and simpler method for estimating the mortality index, which uses the result of approximating the time series of the number of infected, recovered, and deceased patients obtained from the model discussed in Chapter 2. The method defines two indices - the mortality index and the indicative period of recovery (conditional hospitalization).

\section{THE INFECTION MODEL AND PEAK PARAMETERS}

To explain the dynamics of the spread of a short-term epidemic, it is proposed to use the corrected classical Lotka-Volterra model $(\mathrm{L}-\mathrm{V})^{2}$, which describes the interaction of two species, one of which is a predator, and the other is a victim (for example, the ecological system ,carp-pike” or „hares-lynx”).

In the case of an epidemic, the victim is the number(percentage) of the population available for infection $\mathrm{S}(\mathrm{t})$, which at the time of $\mathrm{t}$ is equal to $1, \mathrm{~S}(\breve{\mathrm{T}})=1$. It is assumed that the population takes measures to dissociate the ,victim" by the simplest law

The model arose historically (1931) in connection with an attempt to explain the fluctuations of fish catch in the Adriatic Sea (Volterra, 1976). The same system of differential equations was proposed by Lotka a little earlier (1924), but Volterra much more fully analyzed this system. 


$$
S^{\prime}(t)=-\alpha \cdot S(t)
$$

where $\alpha$ is the constant responsible for the effectiveness of the measures to be taken.

The "predator" in this model is the number of infected $\mathrm{H}(\mathrm{t})$. The predator, similar to the $\mathrm{L}-\mathrm{V}$ model, reproduces by law

$$
N^{\prime}(t)=\gamma \cdot \alpha \cdot S(t) \cdot N(t)
$$

where $\gamma$ is the constant responsible for the scale of infection.

It is obvious that the solution of equations (1) and (2) will be the function responsible for the absolute number of infected, of the form

$$
N(t)=\widehat{N} \cdot e^{\gamma\left(1-e^{-\alpha(t-\hat{t})}\right)}
$$

where $\widehat{N}$ - the number of infected at the time of the conditional beginning of the epidemic $\hat{t}$. It is clear that $\widehat{N}, \hat{t}$ are not independent near the conditional beginning of the epidemic, but can be changed without changing the type of function (3) by rationing taking into account $\alpha, \gamma$. Indeed, for $\alpha(t-\hat{t}) \ll 1$, function (3) will have an exponential development of $N(t) \cong \widehat{N}$. $e^{-\gamma \alpha(t-\hat{t})}$ in which $\mathrm{N} e\{\gamma \alpha \hat{t}\}$ is an invariant. Then it is reasonable to give an obvious meaning, namely, to put empirically $\widehat{N}=100$, and to denote $\hat{t}$ as $t_{100}$. Therefore, for the normalized function of the number of infected (3) $N(t)=100 \cdot \exp \left(\gamma\left(1-e^{-\alpha\left(t-t_{100}\right)}\right)\right)$ three infection constants $t_{100}, \alpha, \gamma$ are subjects to determination. These constants responsible for the development of the epidemic should be determined by the dynamics of infection by approximating by minimizing the distance functional, which will be discussed below.

The next practical step is to determine the peak infection parameters. The first important parameter is the moment of the peak infection rate for the model (3). In other words, we are looking for the moment $t^{*}$, at which the maximum $N^{\prime}(t)$ is reached. The problem is easily solved by solving the equation $N^{\prime \prime}(t)=0$. The solution is the value

$$
t^{*}=\hat{t}+\frac{\ln (\gamma)}{\alpha},
$$

which at the peak gives the maximum increase in the number of cases per day

$$
\dot{N}^{*}=\widehat{N} \cdot \alpha \cdot e^{\gamma-1} \text {. }
$$

the $\widehat{N}$ parameter estimates the maximum level of load on the medical infrastructure.

Further, it is possible to predict the maximum number of infected people for the entire time of the epidemic, which will be

$$
N_{\max }=\widehat{N} \cdot e^{\gamma}
$$

The timing of recovery from the epidemic, which regulates socio-economic decisions to ease quarantine measures, self-isolation, and so on, can be set for simple practical reasons. Namely, by the percentile of growing infections up to $N_{\max }$. I.e., the term $T_{p}$ is calculated from the percentile definition 


$$
p=\frac{N_{\max }-\widehat{N} \cdot e^{\gamma\left(1-e^{-\alpha\left(T_{p}-\hat{t}\right)}\right)}}{N_{\max }}
$$

From (7) follow for small $\mathrm{p}$ a simple formula of benchmarks for the timing of measures to get out of restrictions

$$
T_{p}=t^{*}+\frac{1}{\alpha} \ln \left(\frac{1}{p}\right)
$$

where $t^{*}$ is the peak of the epidemic (4). As a reasonable option, you can take the first forecast of the beginning of easing the restrictions at the level of $\mathrm{p}=10 \%$ (Finish of high security "90\%"), the second - the forecast of removing restrictions at the level of $\mathrm{p}=1 \%$ (Finish of self-isolation "99\%") for (8).

Using the presented elementary formulas, it is possible to predict the most important characteristics of the epidemic during its development, daily updating the parameters based on newly received data.

To determine the best values of the epidemic parameters, an optimizing functional is selected that simulates the distance to the empirical infection curve $\left(C\left(t_{i}\right) \mathrm{i}=1 \ldots \mathrm{T}, \mathrm{T}\right.$ is the period of current observation) in the standard, taking into account the approximation of derivatives (i.e. infection rates) as well. The functionality is offered in the form of:

$F(\vec{p})=\sum_{i=1}^{T} \frac{\left(C\left(t_{i}\right)-N\left(t_{i}, \vec{p}\right)\right)^{2}}{C(T)^{2}}+\lambda \cdot \sum_{i=2}^{T}\left(C\left(t_{i}\right)-C\left(t_{i-1}\right)-\dot{N}\left(t_{i}-\frac{1}{2}, \vec{p}\right)\right)^{2} \cdot \frac{(i-1)^{2}}{C\left(t_{i}\right)^{2}}$

where $\vec{p}$ - vector of parameters $(\alpha, \gamma, \hat{t})$,

$t_{i}$ - daily data publication dates,

$t_{1}=$ the first date when $\widehat{N}$ of infected $\left(C\left(t_{i}\right) \geq \widehat{N}\right.$, e.g., $\left.\widehat{N}=100\right)$,

$C\left(t_{i}\right)$ - number of infected,

$T-$ current rate of infection outbreak.

We suggest to use the following initial values to find the minimum distance:

$\alpha=0, \gamma=\ln (C(T) / \widehat{N}), \hat{t}=t_{1}$

The parameter $\lambda$ is chosen empirically and characterizes weight smoothing rate of infection by function (3). Authors' experience on the basis of empirical calculations suggests $\lambda \in(1 ; 4)$.

\section{TESTING A PARAMETRIC MODEL OF INFECTION ON THE SPIKES OF THE EBOLA EPIDEMIC}

The model (3) is tested on data on the dynamics of Ebola virus infection (WHO Situation Reports. Number of Cases and Deaths in Guinea, Liberia, and Sierra Leone during the 2014-2016 West Africa Ebola Outbreak). Testing is performed on each date T during the development of the epidemic, without using the values (known to date) after the dates. The result is shown in Figure 1. Charts are arranged in a cascade for easy identification of changes in forecast parameters along the abscissa's axis, which is identical for all charts. On the first (top), the current value of the forecast for the peak date of infection for the model is calculated for the dynamic data. The dotted line 
shows the final result (fact). The straight line marked with dots is the current time when the forecast was made. On the second-the forecast value of the maximum number of infected Cmax in the aggregate of foci of infection (African countries). Below the graphs (thin lines and dots) are the infection dynamics: the model (as of the end date) and the fact. On the third (lower) - the number of infections per day: the model and the fact. This is calculated for the end date of the epidemic.

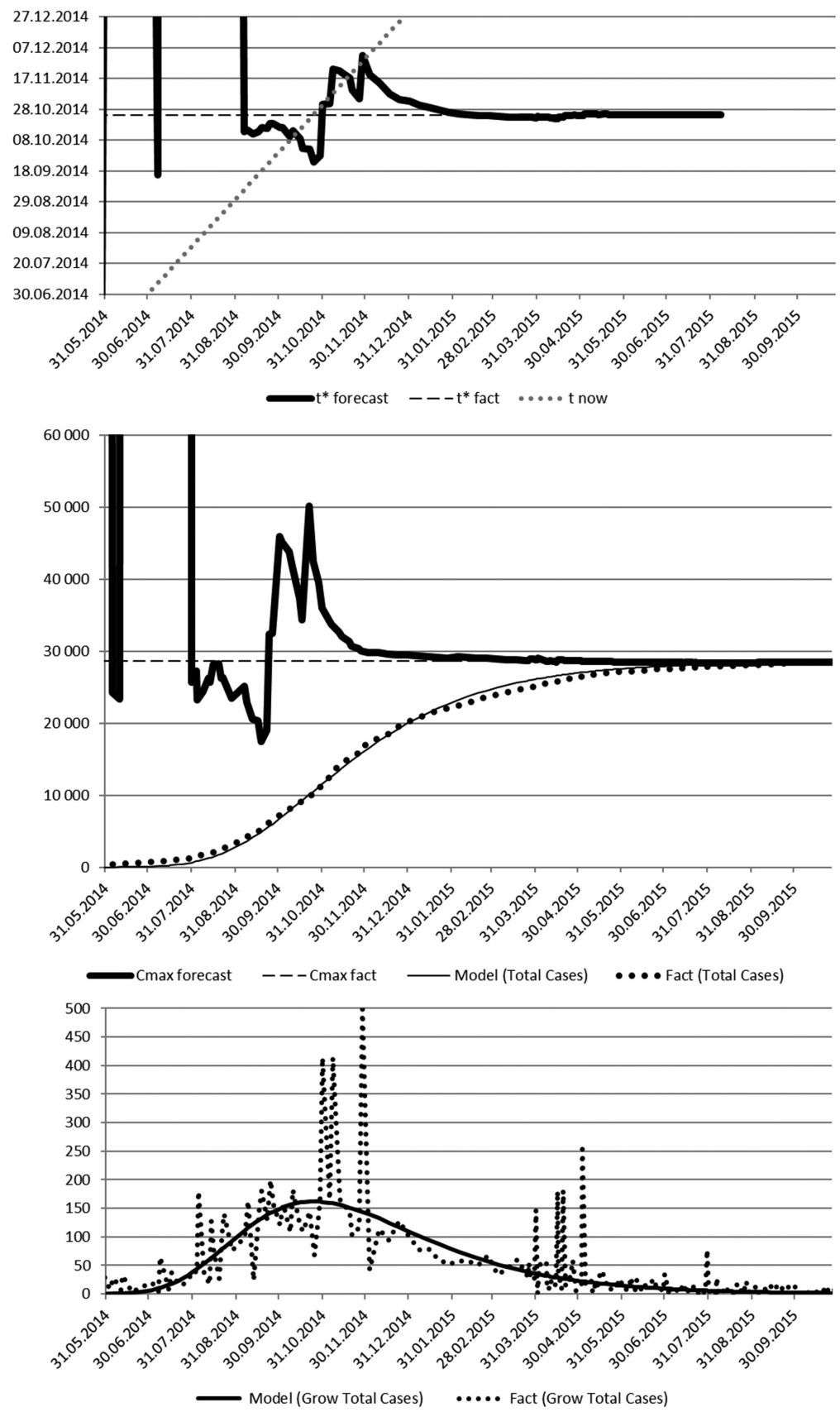

Figure 1. Modeling of peak parameters for the epidemic of the Ebola virus.

Data source: WHO Situation Reports

It can be seen that the infection dynamics is approximated fairly accurately by the model (3). Forecasts of the peak values of the maximum infection rate begin to approach the exact values when the fluctuations in forecasts subside. The approach to the exact values of $+/-10$ thousand people (up to $30 \%$ ) begins with the period of approach of the epidemic period to the peak of infection. Before reaching the peak, forecast values are highly volatile and not significant. 
The first graph shows that the maximum begins to form when the forecast of the peak date intersects with the observation date. On an earlier observation date, the peak forecast is possible, but less reliable.

On empirical observations of the passage of the COVID-19 infection peak, after the formation of the peak date that intersects with the observation date, the final date of the peak recedes back (about a week) and a steady trend begins to decrease the intensity of infection, i.e. the regression of the epidemic.

\section{MODEL INDEX MORTALITY}

There are three parameters for monitoring that are updated daily, at time $t$. This is the number of cases in which the virus is confirmed (Confirmed, C(t)), the number of recovered (Recovered, $\mathrm{R}(\mathrm{t})$ ), and the number of deaths (Deaths, $\mathrm{D}(\mathrm{t})$ ). Up-to-date data and graphs of these parameters can be seen on the Johns Hopkins CSSE University website (Johns Hopkins CSSE, 2019). These parameters are sufficient to determine the death rate as a percentage of patients with RIP(t) and determine the average signal duration of the disease, i.e. hospitalization, $T(t)$. Due to the spread of the disease and the fact that new cases have not yet died, the value of RIP(t) will be greater than the minimum value of low $\mathrm{RIP}(\mathrm{t})=\mathrm{D}(\mathrm{t}) / \mathrm{C}(\mathrm{t})$ and less than the limit of mortality among those who have already been ill or died, equal to up $\mathrm{RIP}(\mathrm{t})=\mathrm{D}(\mathrm{t}) /(\mathrm{D}(\mathrm{t})+\mathrm{R}(\mathrm{t}))$. LowRIP and upRIP parameters are called naive estimates in the literature. If the spread of the epidemic stops and it takes a long time, these parameters will be equal to upRIP $=$ lowRIP $=$ RIP. However, this is not the case during the development of the epidemic, lowRIP $(\mathrm{t})<\mathrm{RIP}(\mathrm{t})<\operatorname{upRIP}(\mathrm{t})$. Therefore, a model is required to evaluate $\mathrm{RIP}(\mathrm{t})$ and $\mathrm{T}(\mathrm{t})$, which will also be significant indicators of the effectiveness of the disease treatment process, a measure of the threat to the life of any person who may become a victim of the epidemic, and a macroeconomic factor that affects the economy and GDP as a whole.

To model the desired parameters, certain simplifying assumptions must be proposed. They should be as natural as possible and preferably simple. So:

- First - the sick patient is hospitalized for a certain time T, the same for all, after this period, he either recovers (Recovered) or is dead (Deaths).

- Second - during the period of illness $s=0 \ldots \mathrm{T}$, the proportion of dying patients is distributed evenly and is equal to $\mathrm{d}(\mathrm{s})=\mathrm{RIP} \cdot \mathrm{s} / \mathrm{T}$, i.e. at the end of the period, this proportion is just equal to $\mathrm{d}(\mathrm{T})=\mathrm{RIP}$.

Then the number of recovered patients at the current (or past) time $t$ can be formed only from those who were infected with the term $\mathrm{T}$ in the countdown back (on the date $\mathrm{t}-\mathrm{T}$ )

$$
\mathrm{R}(\mathrm{t})=\mathrm{C}(\mathrm{t}-\mathrm{T}) \cdot(1-\mathrm{RIP})
$$

This will be the first equation in which $\mathrm{T}$ and RIP are unknown.

On the other hand, the number of deaths will be formed from those who became ill time $\mathrm{T}$ or more ago and from those who became ill recently but die gradually. Then,

$$
\mathrm{D}(\mathrm{t})=\left(\mathrm{C}(\mathrm{t}-\mathrm{T})+\frac{1}{T} \sum_{\mathrm{s}=\mathrm{t}-\mathrm{T}+1}^{\mathrm{t}}(\mathrm{C}(\mathrm{s})-\mathrm{C}(\mathrm{s}-1)) \cdot(\mathrm{t}-\mathrm{s})\right) \cdot R I P
$$


where $\mathrm{C}(\mathrm{s})-\mathrm{C}(\mathrm{s}-1)$ is the number of new cases for each day of the last $\mathrm{t}$ period. This will be the second equation of the model (9-10), which will make it possible to determine the desired two parameters RIP and $\mathrm{T}$ at each moment $\mathrm{t}$ (i.e. RIP(t) and $\mathrm{T}(\mathrm{t})$ ).

As the calculations showed, this problem is uniquely solved and gives the result shown in the graphs figures 2 and 3.

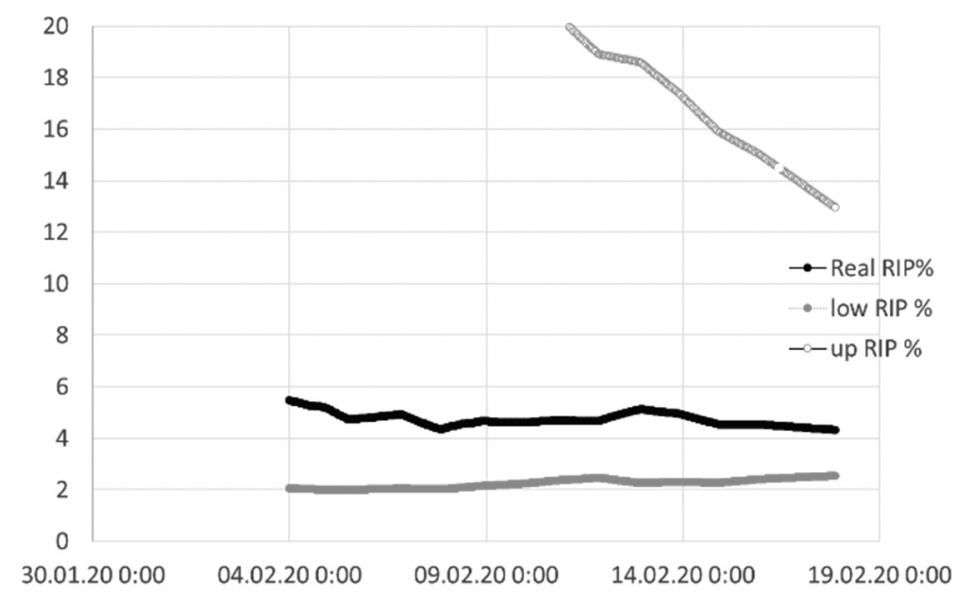

Figure 2. Dynamics of the true mortality rate from coronavirus (as a percentage of cases) for a certain period (in the center) in comparison with the lower and upper bounds obtained from a primitive arithmetic calculation.

Source: author's calculations as of 18.02.2020, given by Johns Hopkins CSSECOVID-19 China

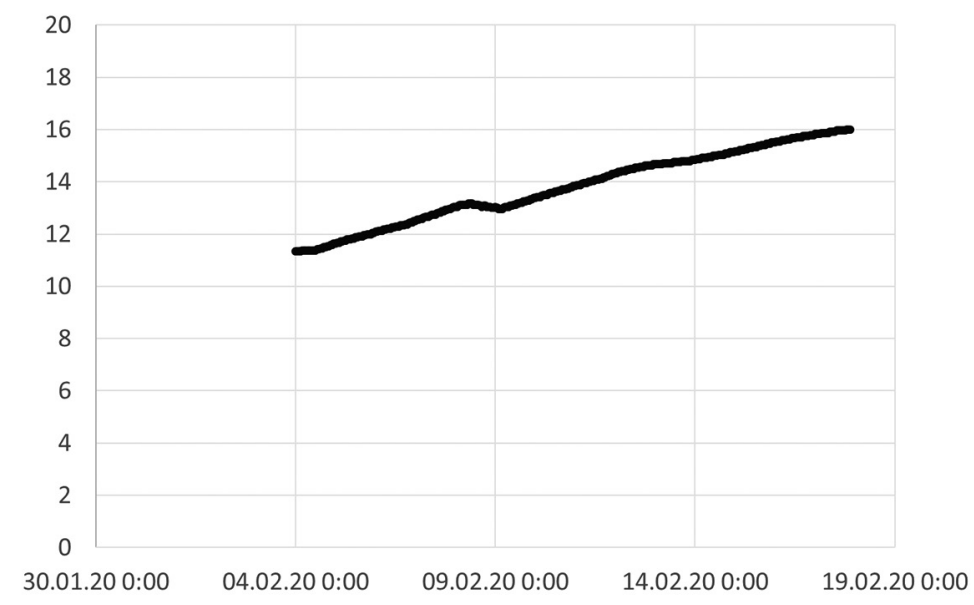

Figure 3. Average calculated dynamics of the duration of hospitalization of a recovering patient (in days).

Source: author's Calculations on 18.02.2020, data from Johns Hopkins CSSE COVID-19 China

From figure 2 it can be seen that there is a tendency to decrease the true mortality rate from $5.5 \%$ to $4.5 \%$, but it is too early to say that it is stable in the presented period of the report. Figure 3 shows an increase in the duration of hospitalization, apparently related to medical policies.

For practical implementation of calculations of mortality indices that are resistant to non-smooth dynamics of recorded cases of infection, recovery and death ${ }^{3}$, it is recommended to switch to the continuous functions $\mathrm{C}(\mathrm{t}), \mathrm{R}(\mathrm{t})$ and $\mathrm{D}(\mathrm{t})$.

3 Data is updated no more than once a day. 
One way is to approximate these functions by smoothing splines (Hastie and Tibshirani, 1990). An alternative and easier-to-implement interpolation possibility in this problem is provided by using a parametric approximation function of type (3) for all three time series $C(t), R(t)$ and $D(t)$, since $\mathrm{R}+\mathrm{D}$ is, in fact, a lagging function of $\mathrm{C}(\mathrm{t})$, D is a fraction of $\mathrm{C}(\mathrm{t})$. In any case, the RIP will be of interest primarily from the point of view of dynamics in the development of the epidemic, and the dynamics will be correctly reflected with a simpler than spline smoothing interpolation. The accuracy requirements for calculating the index are not as high.

When switching to continuous functions, equations (9-10) will be converted to integral relations, the first of which will determine the index $\mathrm{T}(\mathrm{t})$ of the period of recovery/hospitalization/death. $\mathrm{T}(\mathrm{t})$ will be the solution of a nonlinear equation with unknown $\mathrm{T}$ obtained after transformation (9-10):

$$
R(t)=C(t-T) \cdot\left(1-\frac{D(t) \cdot T}{\int_{t-T}^{t} C(s) d s}\right)
$$

After solving equation (11), which is the only one, it is possible to uniquely determine the lethality index using the formula

$$
R I P(t)=\frac{D(t) \cdot T(t)}{\int_{t-T(t)}^{t} C(s) d s}
$$

The proposed (11-12) method of calculating the mortality index from the point of view of practice has an obvious advantage in that it is mainly determined by the last period of the disease and infection/recovery/death of all patients, determined by the index period of hospitalization. This means that the proposed RIP index should respond promptly to changes in the conditions of the disease course, associated with the appearance of effective treatment, mutations of the infection carrier, reaching the limit of medical resources and reducing the quality of treatment, changing the number of patients, etc.

Here are some examples of the dynamics of the RIP, lowRIP and upRIP index calculated for countries with early COVID-19 infection as of the reporting date 20.04.2020, as presented in figure 4.

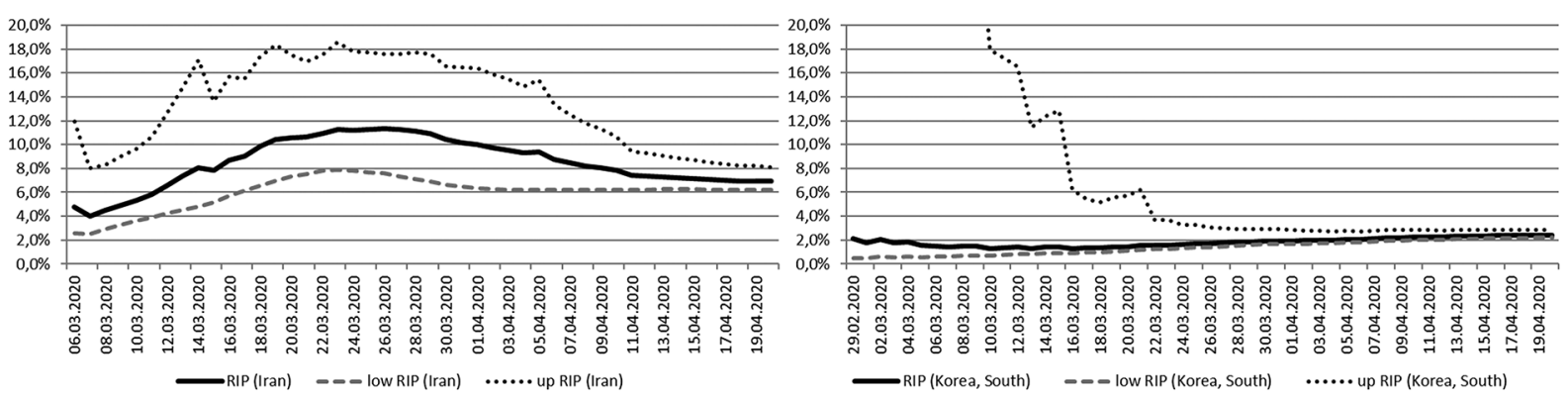

Figure 4. COVID-19 lethality indices for the countries of Iran (left) and South Korea (right).

Source: author's calculations on 29.04.2020, data from Johns Hopkins CSSE COVID-19 Iran, South Korea.

From the presented examples, a significant difference in the behavior of RIP indices in both dynamics and absolute value is visible. So, in Iran, the index first rose, then fell, and in South Korea - the opposite. However, the indices differ by 3-4 times in absolute values. 


\section{EXAMPLES IN TIME-RESULTS OF MODELING OF COVID-19 INDICES IN EUROPEAN COUNTRIES (DATA FROM 15.06.2020)}

In order not to clutter this study with reporting material, the author uses two European countries Italy and the United Kingdom as demonstration examples of COVID-19 propagation modeling, as presented in figure 5 .
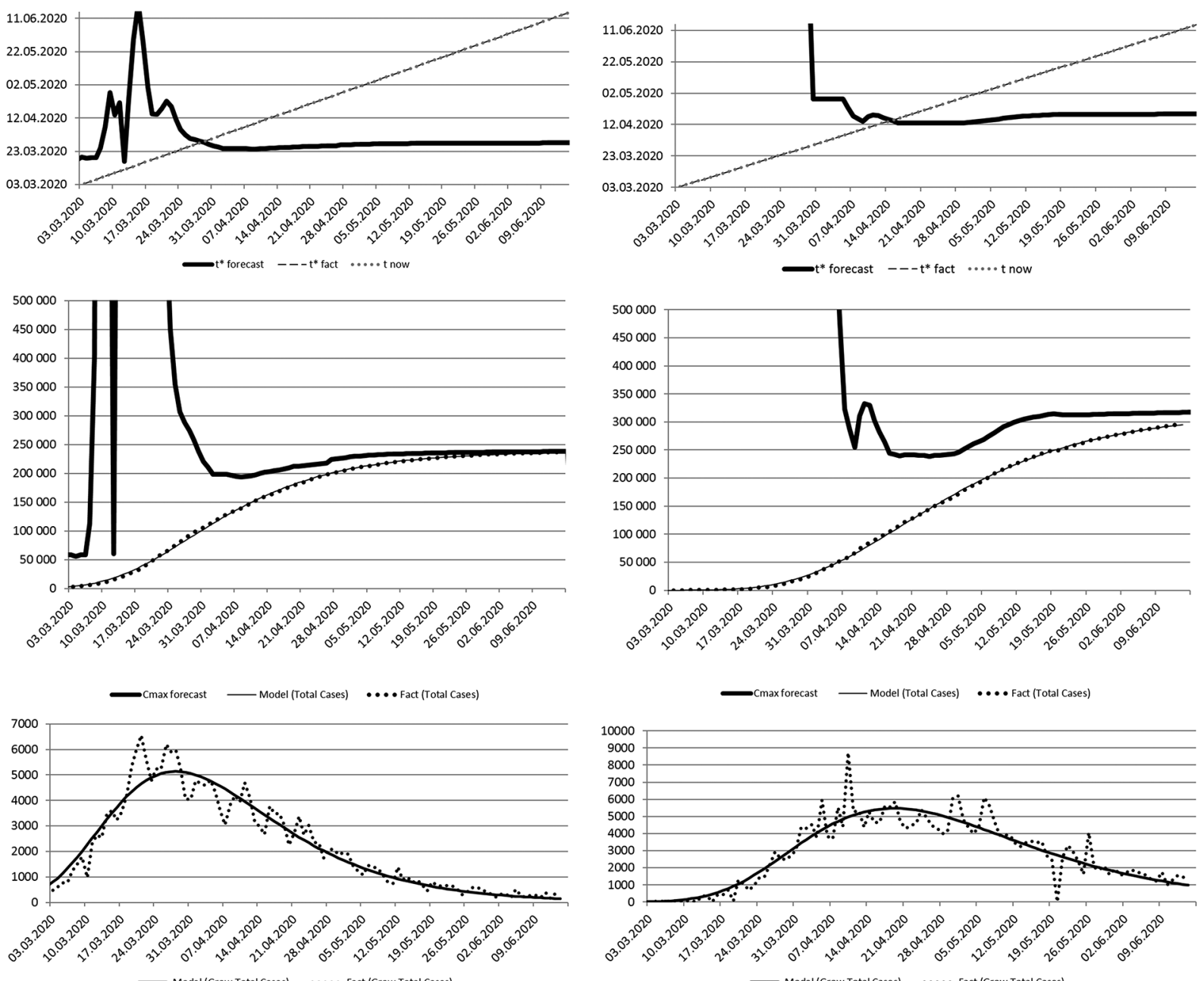

Figure 5. Modeling of peak COVID-19 parameters for Italy (left) and UK (right).

Source: Author's calculations as of 15.06.2020, data from Johns Hopkins CSSE COVID-19

From the first graphs above, it can be seen that the model forecast of peak infection rates becomes relatively stable after the forecast date reaches the date of the peak itself. After this period, the forecast for the peak date is adjusted slightly. Also, the forecast of the maximum number of infected people becomes relatively stable after passing the peak of the epidemic.

However, the presented static model (1), (2) is based on the assumption of a monotonous impact of the socio-economic regime of self-isolation on the containment of the spread of the pandemic. This is not always true, so repeated outbreaks of infection are possible, which are unpredictable and may be the result of mistakes by governments to mitigate the regime, mass riots, natural disasters, etc. The analysis of these processes and their consequences on the dynamics of the spread of the epidemic is the subject of separate scientific research. 
Table 1 shows several important parameters of the COVID-19 pandemic for the largest European countries.

Table 1. Some parameters of COvid-19 in the largest European countries.

\begin{tabular}{|c|c|c|c|c|c|c|c|c|c|}
\hline Country & C now & RIP & $\begin{array}{l}\text { Peak data } \\
\text { forecast }\end{array}$ & $\begin{array}{l}\text { Start: } \\
\text { t_100 }\end{array}$ & $\begin{array}{l}\text { Peak - } \\
\text { t_100, days }\end{array}$ & $\begin{array}{l}\text { Finish of a } \\
\text { high secu- } \\
\text { rity "90\%" } \\
\text { (forecast) } \\
\end{array}$ & \begin{tabular}{|l|} 
Finish \\
self-isola- \\
tion "99\%", \\
(forecast) \\
\end{tabular} & \begin{tabular}{|l|}
$\max C$ \\
forecast in \\
$\%$ of the \\
population \\
\end{tabular} & $\begin{array}{l}\text { Deaths } \\
\text { forecast }\end{array}$ \\
\hline $\begin{array}{l}\text { United } \\
\text { Kingdom }\end{array}$ & 297342 & $26,5 \%$ & 18.04 .2020 & 05.03 .2020 & 45 & 06.06 .2020 & 25.07 .2020 & $0,48 \%$ & 84071 \\
\hline Italy & 236989 & $15,1 \%$ & 28.03 .2020 & 22.02 .2020 & 35 & 06.05 .2020 & 14.06 .2020 & $0,39 \%$ & 36028 \\
\hline France & 194153 & $17,6 \%$ & 03.04 .2020 & 09.03 .2020 & 25 & 02.05 .2020 & 30.05 .2020 & $0,28 \%$ & 34084 \\
\hline Germany & 187518 & $4,8 \%$ & 30.03 .2020 & 03.03 .2020 & 27 & 29.04 .2020 & 30.05 .2020 & $0,23 \%$ & 9074 \\
\hline
\end{tabular}

Source: author's calculations as of 15.06.2020, data from Johns Hopkins CASE COVER-19

From Table 1 it can be seen that the level of true RIP mortality, calculated according to the model of item 4., for the UK is significantly higher than the average level, the minimum is found in Germany. The period of „rampant” pandemic «Peak - t__100» before the peak period is also significantly higher in the UK than in other countries, as well as the percentage of infected people from the population.

The next chapter will present a result on the relationship of pandemic parameters with socio-economic factors in the statistics of countries that have passed the peak of the pandemic on the current date of 15.06.2020.

\section{STUDY OF THE RELATIONSHIP OF SOCIO-ECONOMIC INDICATORS WITH THE PARAMETERS OF THE COVID-19 PANDEMIC}

Before you start presenting research results, you need to make a disclaimer related to the preliminary nature of these results. At the time of writing, the COVID-19 pandemic is far from its final phase in the most countries of the World. Therefore, the study of the relationship with socio-economic indicators is based on the forecast (model) values of COVID-19 parameters. By the time this work is published, certain refinements may be relevant. Nothing stands still, but the value of the research lies, among other things, in the method of building leading conclusions made in «in-time» mode. The value of such conclusions is particularly significant if they can prevent future mistakes in socio-economic containment of the spread of the disease.

Of the 84 countries that were affected by the pandemic, with the number of officially infected more than 1000 people on 15.06.2020, only 60 countries that participate in the statistical study passed the peak of infection. Exogenous variables are the parameters of the pandemic. These parameters are expected to change slightly over time for those countries where the peak of the pandemic has already passed by the time of the study.

\section{Exogenous variables (author's calculations on 17.05.2020)}

- RIP - Fatality (lethality) Index in a given country (model forecast)

- $\boldsymbol{\alpha}$ - The constant is responsible for the effectiveness of the measures taken in a given country (model forecast)

- $\boldsymbol{\alpha} \cdot \boldsymbol{\gamma}$ - Pandemic Rate Index (or detection rate of number of infected) in a given country (model forecast)

- Cmax - Maximum number of infected people in a given country (model forecast) 
- The endogenous parameters for the regression model will be socio-economic indicators presented by the World Bank (The World Bank. Indicators). There are more than 150 of these indicators, and the study involved indicators calculated for the closest date to the present, which is available in the World Bank database.

\section{Endogenous variables (regressors, World Bank):}

- Agriculture \& Rural Development

Agricultural land (\% of land area)

Agricultural methane emissions

etc.

- Climate Change

$\mathrm{CO} 2$ emissions

Disaster risk reduction progress score

Ease of doing business index

Electric power consumption

etc.

- Social Development

Public Sector

Trade

Health

etc.

A nonlinear multiple regression model is constructed, and the minimum number of indicators that are significant for exogenous variables is selected. The quality level of the model is estimated by the R-square coefficient of determination. Additional tests are made, the main of which is the Breusch-Pagan test (Breusch and Pagan, 1979), to check for the presence of heteroscedasticity of random errors in the regression model. Economic consistency is analyzed.

\section{Specifications of regression models}

1. Non-linear multiple regression

$$
Y=A+\sum a_{i} x_{i}+\sum \sum b_{i, j} x_{i} x_{j}+\varepsilon
$$

2. All regressors are statistically significant ( $\mathrm{p}$-value)

3. Regression Quality Level (High $=\mathrm{R}$-square $>90 \%$, Intermediate $=50 \%<\mathrm{R}$-square $<90 \%$, Low $=$ R-square $<50 \%$ )

4. Heteroscedasticity (Yes $=$ Breusch - Pagan test, significance $>10 \%$, No is less $10 \%$ )

5. Economic consistency of model coefficient signs

The aim of the study is to identify factors and their combinations that explain the COVID-19 pandemic parameters, as well as pandemic parameters that cannot be meaningfully explained using World Bank indicators. More than 1 million models of various combinations of regressors are studied.

The results of the study are presented in Table 2 .

For the „True mortality index” parameter, Rip was not able to find any meaningful model. The quality of the regression was low. The economic consistency of signs in variables was ambiguous. To measure the effectiveness of measures taken (to control the pandemic) it was also not possible to find a regression model of any significant quality. 
For the parameter $\boldsymbol{\alpha} \cdot \boldsymbol{\gamma}$, which is responsible for Pandemic Rate (or detection rate of number of infected), we found a satisfactory model with an R-square level of 70\%. Even more success was achieved for the parameter of the maximum number of infected citizens of those countries that were included in the study. We managed to find a whole series of very effective models that have a high determination (R-square of $90 \%$ ), a low level of heteroscedasticity and economic consistency of regressors.

Table 2. General result of regression modeling of covid-19 exogenous parameters

\begin{tabular}{|l|l|l|l|l|}
\hline $\begin{array}{l}\text { Exogenous } \\
\text { variables }\end{array}$ & Interpretation & $\begin{array}{l}\text { Regression } \\
\text { Quality Level }\end{array}$ & Heteroscedasticity & $\begin{array}{l}\text { Economic } \\
\text { consistency }\end{array}$ \\
\hline RIP & Fatality (lethality) Index & Low & Yes & Ambiguously \\
\hline $\boldsymbol{\alpha}$ & $\begin{array}{l}\text { The effectiveness of the } \\
\text { measures taken }\end{array}$ & Low & Yes & Yes \\
\hline $\boldsymbol{\alpha} \cdot \boldsymbol{\gamma}$ & $\begin{array}{l}\text { Pandemic Rate Index (or } \\
\text { detection rate of number of } \\
\text { infected) }\end{array}$ & Intermediate & No & Yes \\
\hline Cmax & $\begin{array}{l}\text { Maximum number of infected } \\
\text { people }\end{array}$ & High & No & Yes \\
\hline
\end{tabular}

Table 3. The most powerful regressors explaining the parameters of the COVID-19 pandemic identified during the active period for 60 countries (15.06.2020)

\begin{tabular}{|c|c|c|c|c|}
\hline Target variable & & Regressor№1 & Regressor№2 & Regressoro3 \\
\hline \multirow{5}{*}{$\begin{array}{l}\text { Pandemic Rate } \\
\text { Index (or detection } \\
\text { rate of number of } \\
\text { infected) }\end{array}$} & \multirow{5}{*}{$69 \%$} & $\begin{array}{l}\text { Railways, } \\
\text { passengers carried } \\
\text { (million passenger- } \\
\text { km) x Specialist } \\
\text { surgical workforce } \\
\text { (per } 100,000 \\
\text { population) } \\
\end{array}$ & $\begin{array}{l}\text { GDP per capita, } \\
\text { PPP (current } \\
\text { international \$) x ln } \\
\text { Hospital beds (per } \\
1,000 \text { people) }\end{array}$ & $\begin{array}{l}\text { Life expectancy at } \\
\text { birth, total (years) } \\
\mathrm{x} \text { International } \\
\text { tourism, number of } \\
\text { arrivals }\end{array}$ \\
\hline & & $\begin{array}{l}\text { GDP per capita, } \\
\text { PPP (current } \\
\text { international } \$ \text { ) x ln } \\
\text { Hospital beds (per } \\
1,000 \text { people) }\end{array}$ & $\begin{array}{l}\text { International } \\
\text { tourism, number } \\
\text { of arrivals x ln } \\
\text { Agricultural land (\% } \\
\text { of land area) }\end{array}$ & $\begin{array}{l}\text { Railways, } \\
\text { passengers carried } \\
\text { (million passenger- } \\
\text { km) x GDP } 2018 \\
\end{array}$ \\
\hline & & $\begin{array}{l}\text { Air transport, } \\
\text { passengers carried } \\
\text { x Agriculture, } \\
\text { forestry, and fishing, } \\
\text { value added ( } \% \text { of } \\
\text { GDP) } \\
\end{array}$ & $\begin{array}{l}\text { Life expectancy at } \\
\text { birth, total (years) x } \\
\text { Life expectancy at } \\
\text { birth, total (years) }\end{array}$ & $\begin{array}{l}\text { International } \\
\text { tourism, number } \\
\text { of arrivals } x \ln \\
\text { Hospital beds (per } \\
1,000 \text { people) }\end{array}$ \\
\hline & & $\begin{array}{l}\text { Railways, } \\
\text { passengers carried } \\
\text { (million passenger- } \\
\text { km) x Specialist } \\
\text { surgical workforce } \\
\text { (per } 100,000 \\
\text { population) }\end{array}$ & $\begin{array}{l}\text { GDP per capita, } \\
\text { PPP (current } \\
\text { international \$) x ln } \\
\text { Hospital beds (per } \\
1,000 \text { people) }\end{array}$ & $\begin{array}{l}\text { International } \\
\text { tourism, number of } \\
\text { arrivals x } \ln \text { Life } \\
\text { expectancy at birth, } \\
\text { total (years) }\end{array}$ \\
\hline & & $\begin{array}{l}\text { Railways, } \\
\text { passengers carried } \\
\text { (million passenger- } \\
\mathrm{km} \text { ) x Specialist } \\
\text { surgical workforce } \\
\text { (per } 100,000 \\
\text { population) }\end{array}$ & $\begin{array}{l}\text { GDP per capita, } \\
\text { PPP (current } \\
\text { international \$) x ln } \\
\text { Hospital beds (per } \\
1,000 \text { people) }\end{array}$ & $\begin{array}{l}\text { International } \\
\text { tourism, number of } \\
\text { arrivals }\end{array}$ \\
\hline
\end{tabular}




\begin{tabular}{|c|c|c|c|c|}
\hline \multirow{3}{*}{$\max C$ forecast } & \multirow{3}{*}{$89 \%$} & $\begin{array}{l}\text { Netmigration } \mathrm{x} \\
\text { Population }\end{array}$ & $\begin{array}{l}\text { CO2 emissions } \\
\text { (metric tons per } \\
\text { capita) x Population }\end{array}$ & \\
\hline & & $\begin{array}{l}\text { Netmigration } \mathrm{x} \\
\text { Population }\end{array}$ & $\begin{array}{l}\text { Air transport, } \\
\text { registered carrier } \\
\text { departures worldwide } \\
\text { x Population }\end{array}$ & $\begin{array}{l}\text { International } \\
\text { tourism, number } \\
\text { of arrivals x } \\
\text { International } \\
\text { tourism, } \\
\text { expenditures (\% of } \\
\text { total imports) }\end{array}$ \\
\hline & & $\begin{array}{l}\text { Air transport, } \\
\text { passengers carried } \\
\mathrm{x} \text { International } \\
\text { tourism, } \\
\text { expenditures ( } \% \text { of } \\
\text { total imports) }\end{array}$ & $\begin{array}{l}\text { Netmigration } \mathrm{x} \\
\text { Population }\end{array}$ & \\
\hline
\end{tabular}

The purpose of this part of the study is not to present «Plug and Play» forecast models, but only to show what socio-economic factors initially determine the scale and speed of the pandemic. And they turned out to be logical, and hypothetically they should have been proposed, without any statistical research. But the value lies in the fact that the determining factors are confirmed by statistical research.

So, we make sure on the statistics COVID-19, which is the number of infected in the country is influenced by uncontrollable factors - population industrial capacity of the country and its production (as expressed in GDP, CO2, etc.)

And managed ones, namely:

- power communication (migration, the number of human exchanges through the travel and transportation including railway transport), tourism, etc.

Including visible factors responsible for the speed of social reaction. These are the country's medical parameters:

- In Hospital beds (per 1,000 people)

- Life expectancy at birth, total (years)

These are the key points that you should pay attention to first of all to prevent consequences. If tourism is harmful (in terms of the risk of epidemics), then this is true. But it is not possible to stop it, it is necessary to strengthen infection control. This is also obvious for the level of development of medicine.

\section{CONCLUSION}

The theoretical part of the presented work offers a very relevant, in our opinion, model that allows us to make adequate predictions about the spread of the epidemic at the moment of its active phase. This is especially relevant for the operational management of the socio-economic risks posed by the epidemic (pandemic). Unlike classic epidemic models, the presented model takes into account socio-economic counteraction to infection, focused on creating restrictions in the form of self-isolation, quarantine measures, etc. The model is static, in the sense that the factor of the reaction of society is assumed to be constant. In those countries where this hypothesis is acceptable, infection dynamics are observed in full accordance with the model. We 
understand that in practice this is not quite true, therefore, second and other subsequent waves that are observed are possible. How and from what they come is a topic of future research. The paper proposes a certain basis for further, more complex modeling.

The practical part of study showed that countries with developed infrastructure for international and domestic movements, as well as high migration, have the maximum number of infected. It clearly demonstrates the need for greater monitoring of these activities to prevent future pandemics.

\section{REFERENCES}

Breusch T. S., Pagan A. R. (1979). A Simple Test for Heteroskedasticity and Random Coefficient Variation". Econometrica. 47 (5): 1287-1294. doi:10.2307/1911963. JSTOR 1911963. MR 0545960.

Choisy M., Guégan J.-F., and Rohani P. (2007) Mathematical Modeling of Infectious Diseases Dynamics. Chapter 22, Encyclopedia of Infectious Diseases: Modern Methodologies, by M. Tibayrenc. Copyright (C) 2007 John Wiley \& Sons, Inc.

Ghani C. et al. (2005) Methods for Estimating the Case Fatality Ratio for a Novel, Emerging Infectious Disease. American Journal of Epidemiology, Volume 162, Issue 5, 1 September 2005, Pages 479-486, https://doi.org/10.1093/aje/kwi230

Hastie T. J., Tibshirani R. J. (1990) Generalized Additive Models. - Chapman and Hall, ISBN 0-412-34390-8.

Herbert W., Hethcote (1989) Three Basic Epidemiological Models. Applied Mathematical Ecology. pp 119-144. Editors Simon A. Levin Thomas G. Hallam Louis J. Gross. Springer-Verlag Berlin Heidelberg DOI https://doi.org/10.1007/978-3-642-61317-3

Johns Hopkins CSSE (2019) Novel Coronavirus COVID-19 (2019-nCoV) Data Repository, https://github.com/CSSEGISandData/2019-nCoV

The World Bank. Indicators. https://data.World Bank.org/indicator?tab=all

Volterra, V. (1976) The Mathematical Theory of the Struggle for Existence. Science, Moscow, 288.

WHO Situation Reports. Number of Cases and Deaths in Guinea, Liberia, and Sierra Leone during the 2014-2016 West Africa Ebola Outbreak, https://www.cdc.gov/vhf/ebola/history/2014-2016-outbreak/case-counts.html

WHO. Coronavirus disease (COVID-2019) situation reports. https://www.who.int/emergencies/ diseases/novel-coronavirus-2019/situation-reports 


\title{
ANALYSIS OF POTENTIAL EMPLOYMENT CONSEQUENCES ASSOCIATED WITH THE NOVEL CORONAVIRUS: \\ CASE OF KUWAIT
}

\author{
Dušana Alshatti Schmidt ${ }^{1}$ (i)
}

DOI: https://doi.org/10.31410/ERAZ.S.P.2020.25

\begin{abstract}
The novel coronavirus (COVID-19) outbreak has already left a mark on the economic activities and labor markets in both advanced and developing countries. While the impacts on the economy vary considerably, the oil dependent economies have been hit harder. Along with the impact of the pandemic disease, they have been contending with a major collapse in oil prices. Kuwait is the world's seventh largest exporter of oil. Falling oil demand might affect the future growth of Kuwait's economy in the long run, and if the crisis continues, possibility to provide employment opportunities will be challenged. The aim of this paper is to analyze potential pandemic's impact on employment in Kuwait in comparison with the financial crisis from 2008-2009, what is of crucial importance for the businesses in the region to understand. The paper is based on a systematic review of the secondary data gathered by international institutions.
\end{abstract}

Keywords: COVID-19, Oil, GDP, Labor market, Policy.

\section{INTRODUCTION}

$\mathrm{O}$ 31 December 2019, the World Health Organization (2020) was notified about pneumonia of an unknown etiology spreading in Wuhan City in China. The number of people infected by an infection, identified as a novel coronavirus, has been escalating worldwide. On 11 February 2020, the World Health Organization (2020) announced COVID-19 as the term for the new infectious disease. One month later, the COVID-19 outbreak was declared a pandemic.

Enforced quarantine, curfew, full lockdown, and other restrictions for disease containment implemented by authorities have had significant impact on the business activities, job securities, and global market as a whole (Sharif et al., 2020). Although, the impact may vary by country and industry as each country is in a different stage of dealing with the pandemic outbreak (Nicola et al., 2020), Kristina Georgieva (2020) emphasized that the global economic outlook for this year is at least as bad as the financial crisis of 2008-2009 and the recovery is expected to begin next year, depending on the virus containment.

According to the International Monetary Fund (2020a), the pandemic is more challenging for the countries in the Middle East that are considered wealthy, mainly due to their large oil resources. Despite their wealth, the pandemic is causing disruption to their economies and labor markets through reduced demand for oil, historic plunge in oil prices along with the suspension of services.

Kuwait is an oil-based economy where an increasing number of COVID-19 cases quickly led to the implementation of the strict containment measures. Further disruption of activities and services, and the drop in oil prices led to the announcement of a series of fiscal and monetary measures to ensure sustainability of the Kuwait's economy and support the survival of small and medium enterprises (SMEs). 


\subsection{Methodology}

The pandemic outbreak, containment measures and lower oil prices raise the following questions: What are the pandemics' consequences for employment in Kuwait?

The paper is based on a systematic review of the external secondary data. The data are obtained from online databases, government statistics, and reports published by international organizations. The paper describes the evolution of the novel coronavirus in Kuwait, the containment and economic measures taken by Kuwait's policymakers, discusses the implications of the coronavirus spread on oil prices and the growth of GDP, and investigates the potential impact of the pandemic on the labor market in Kuwait compared to the global financial crisis from 2008-2009.

\section{EVOLUTION OF THE NOVEL CORONAVIRUS IN KUWAIT}

The first confirmed case of the COVID-19 reported in the Middle East was in Iran (Sharifi et al., 2020). Kuwait announced the first three cases of the COVID-19 on 24 February 2020, when the passengers returning from the Iranian city of Mashad were tested positive (Kuwait News Agency, 2020a). As of 31 May 2020, there were total of 27043 confirmed cases of COVID-19 and 212 deaths (Ministry of Health, 2020).

$\leadsto$ Total diagnosed cases

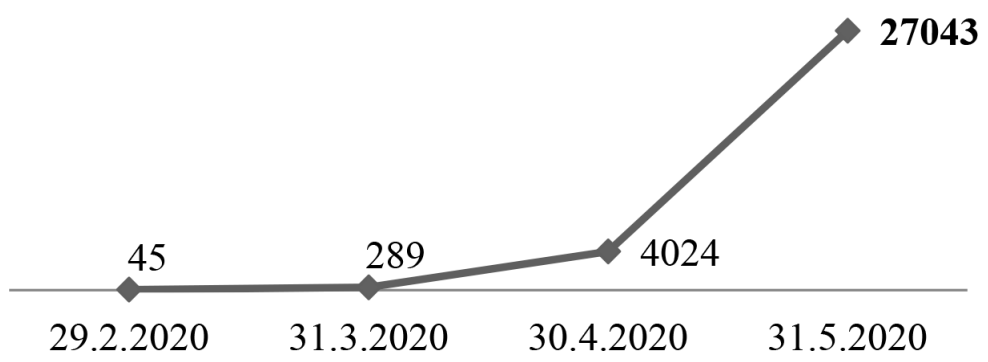

Figure 1. Diagnosed cases of COVID-19 in Kuwait

Source: Ministry of Health, 2020

\subsection{Containment measures}

Kuwait took an uncompromising stand against the novel coronavirus and implemented strict precautionary measures to ensure internal and external security and stability of the state. (See Table 1)

Table 1. Government containment measures

\begin{tabular}{|l|l|}
\hline Date & Measures taken \\
\hline 1 March 2020 & Suspension of schools and universities was implemented. \\
\hline 12 March 2020 & $\begin{array}{l}\text { Kuwait's government suspended work in all ministries, government agencies, public bodies and } \\
\text { institutions excluding vital sectors and emergency services for 2 weeks. }\end{array}$ \\
\hline 14 March 2020 & $\begin{array}{l}\text { All inbound commercial flights to Kuwait International Airport were banned except for arriving } \\
\text { Kuwaiti citizens and their immediate relatives, and travel across the border was restricted. }\end{array}$ \\
\hline 22 March 2020 & $\begin{array}{l}\text { The first partial curfew was implemented between 5pm to 4am, until further notice. Central } \\
\text { markets and shops, except for grocery stores were closed. Kuwait's government extended the } \\
\text { disruption of work in all ministries, government agencies, public bodies and institutions until } 9 \\
\text { April 2020. }\end{array}$ \\
\hline
\end{tabular}




\begin{tabular}{|l|l|}
\hline 7 April 2020 & $\begin{array}{l}\text { The curfew hours were extended from 5pm to 6am until the holy month of Ramadan. Kuwait's } \\
\text { government extended the closure of all ministries, government agencies, public bodies and } \\
\text { institutions until 26 April 2020. }\end{array}$ \\
\hline 24 April 2020 & $\begin{array}{l}\text { The partial curfew was further amended from 4pm until 8am with the suspension of work in the } \\
\text { public sector including at government ministries until 31 May 2020. }\end{array}$ \\
\hline 10 May 2020 & $\begin{array}{l}\text { Kuwait goes into complete lockdown for } 20 \text { days. Workers employed in sectors such as electricity, } \\
\text { oil and workers employed in private sector assisting them were allowed to continue operations. } \\
\text { Private supermarkets and grocery stores remained open. }\end{array}$ \\
\hline $\begin{array}{l}\text { The first phase of easing lockdown restrictions. Kuwait's government started gradually lifting } \\
\text { a lockdown imposed since 10 May 2020. Partial curfew was extended from 6pm until 6am. } \\
\text { Cooperative societies, food retail shops, home delivery services, drive thru services at restaurants } \\
\text { and cafes, public services including maintenance and laundry, industrial activities, company } \\
\text { transport vehicles, patrol stations, private hospitals, private clinics and mosques reopened. }\end{array}$ \\
\hline
\end{tabular}

Source: Kuwait News Agency (2020b, 2020e), PwC (2020), Oxford Business Group (2020), Gulf News (2020), Reuters (2020), Gulf Business (2020)

\subsection{Economic measures}

The Kuwait's government established a committee to help Small and Medium-sized Enterprises (SMEs) and implemented the fiscal measures (see Table 2) to ease the negative effect of the pandemic on their economic activities.

Table 2. Government fiscal measures

\begin{tabular}{|l|l|}
\hline Fiscal & - Budget for ministries and government departments was increased by KD 500 million; \\
measures & $\begin{array}{l}\text { - Social security contributions for organizations in private sector were postponed for } 6 \text { months; } \\
\text { - Full unemployment benefits were provided to Kuwaiti nationals; } \\
\text { - Long-term loans from the SME fund and banks were provided to SMEs. }\end{array}$ \\
\hline
\end{tabular}

Source: International Monetary Fund (2020b), KPMG (2020)

Monetary measures (see Table 3) were implemented by the Central Bank of Kuwait to ensure continuous access to the financial services and stability.

Table 3. Government monetary measures

\begin{tabular}{|l|l|}
\hline Monetary & $\begin{array}{l}\text { - The credit card payments were delayed for } 6 \text { months for all citizens; illegal residents and } \\
\text { children of Kuwaiti women; } \\
\text { - The payment of loans was postponed for } 6 \text { months for all citizens; SMEs and other companies } \\
\text { affected, without interest or fines; } \\
\text { - The interest rate for SMEs financing was set at maximum } 2,5 \% ; \\
\text { - The capital adequacy requirements were reduced by } 2.5 \%, \text { to } 10.5 \% ; \\
\text { - The liquidity requirements were decreased; } \\
\text { - The risk weight of SMEs was reduced from } 75 \% \text { to } 25 \% ; \\
\text { - The maximum funding available was increased from } 90 \% \text { to } 100 \% ; \\
\text { - Net Stable Funding Ratio and Liquidity Core Ratio was reduced from } 100 \% \text { to } 85 \% \text {, and the } \\
\text { - Liquidity Ratio from } 18 \% \text { to } 15 \% \text {; } \\
\text { - Loan-to-Value limits for home constructions were increased from } 70 \% \text { to } 80 \%, \text { for land } \\
\text { purchase for residential projects from } 50 \% \text { to } 60 \% \text {, and for existing homes from } 60 \% \text { to } 70 \% .\end{array}$ \\
\hline
\end{tabular}

Source: International Monetary Fund (2020), PwC (2020)

\section{THE OIL PRICE COLLAPSE AND DROP IN ECONOMIC ACTIVITY}

The economic forecast for Kuwait has changed. A combination of the pandemic and policy responses has caused decline in supply of materials, capital and labor, and decline in demand 
for goods and services (Baldwin \& Weder di Mauro, 2020). Furthermore, the disagreement between members of the Organization of the Petroleum Exporting Countries (OPEC) in early March 2020 led to the fall in the price of oil (Arezki, Yuting Fan \& Nguyen, 2020) by more than $50 \%$ since the beginning of the pandemic crisis (Azour, 2020).

In April 2020, OPEC and high oil exporting non-OPEC countries reached a consensus to cut production of oil by $9.7 \mathrm{mb} / \mathrm{d}$ effective from 1 May 2020 until 30 June 2020 (Blas, Smith \& Ansary, 2020), and from 1 July 2020, the production to be cut to $7.7 \mathrm{mb} / \mathrm{d}$ for another 6 months (Kuwait News Agency, 2020c). According to the National Bank of Kuwait (2020a), country's oil production is estimated to drop on average to $2,46 \mathrm{mb} / \mathrm{d}$ in 2020 , and to $2,42 \mathrm{mb} / \mathrm{d}$ next year, what might have a negative impact on the real GDP. Yet, the real GDP is projected to contract by $1.1 \%$ in 2020 and rise again to 3.4\% in 2021 (International Monetary Fund, 2020d).

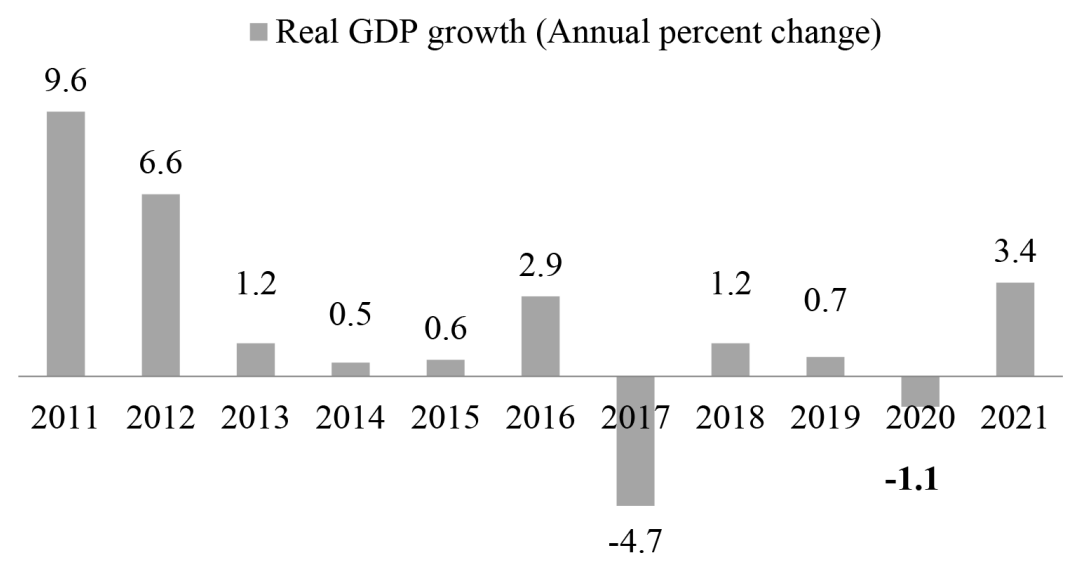

Figure 2. Kuwait's real GDP growth projection

Source: International Monetary Fund (2020c)

Estimated impact of the pandemic on the non-oil GDP growth is uncertain. National Bank of Kuwait (2020a) forecasts the fall by $4 \%$. In addition, Kuwait has estimated budget deficit of about KD 9.2 billion for the current fiscal year 2020/2021 that is larger than deficit estimated last year. A continued decline in oil prices and high government expenditures could widen the actual budget deficit what might affect the future growth of Kuwait's economy, development plan and job creation (World Bank Middle East and North Africa, 2020).

\section{THE PANDEMIC AND LABOR CRISIS IN KUWAIT}

Kuwait has a different labor market than other countries due to its dependence on foreign workers. As of June 2019, the labor force participation rate of non-Kuwaiti was $82.2 \%$, compared to $17,8 \%$ Kuwaiti nationals. The majority of employees working in the public sector are $\mathrm{Ku}$ waiti nationals accounting for $73.75 \%$ while only $26,25 \%$ are non-Kuwaiti. Kuwaiti nationals account for only 3,86\% of the total employed workforce in the private sector and $96,14 \%$ are non-Kuwaiti (National Bank of Kuwait, 2020b). Demographic imbalance in the labor market is one of the most contentious issues. Government has been trying to increase the participation of Kuwaiti nationals in the labor market and adopted the Kuwaitization program that has created more job opportunities for the national workforce in the private sector. Despite better compensation packages, Kuwaiti nationals are discouraged from joining due to job requirements and long working hours (Al-Mutairi, Naser \& Fayez, 2020). 
Coronavirus pandemic and fall in oil prices have further accelerated the situation. The government officials requested to give all government sector jobs to Kuwaiti nationals. Foreign workers holding non-technical jobs will be laid off and employment contracts of foreign workers in the government agencies will not be renewed (Gulf News, 2020). About 135 foreign workers employed in the Public Authority for Housing Welfare were already notified of their termination by 1 July 2020 (Kuwait Times, 2020). In addition, Kuwait Airways, state owned airline provider announced a termination of about 1,500 foreign employees as a result of significant difficulties caused by the coronavirus pandemic (Arab News, 2020b).

In addition, the COVID-19 Kuwait Business Survey conducted by Bensirri Public Relations (2020) in April 2020, prior to the full lockdown, analyzed operational changes caused by the COVID-19 of 498 Kuwaiti SMEs. The survey revealed that $45 \%$ of employers shutdown or suspended their operations and $26 \%$ experienced decline in revenue by $80 \%$ what led to inability of covering fixed cost by $56 \%$ of the employers. Despite the violation of Kuwait's Labor Law, working hours and salaries were reduced by $32 \%$ of employers and $15 \%$ started lying off their employees. The survey also revealed that the sectors most affected by the pandemic are retail, construction, contracting, architecture and professional services.

In 2019, the agricultural sector that includes fishing, forestry, and farming employed only 2,23\% of the total workforce. The industry sector that includes mining, energy production, manufacturing, and construction employed about $25,37 \%$ of the workforce and $72,4 \%$ of the employed population worked in the service sector that covers finance, transportation, government, and other private business activities (Statista, 2020). This means that sectors with the highest number of employees are now at the major risk of job reduction.

The Kuwait's government has temporarily amended the Labor Law for the private sector. The temporary Labor Law allows employers to reduce wages by maximum $50 \%$ during the pandemic crisis (Arab Times, 2020a). To protect the Kuwaiti employees working in the private sector and ensure their job stability in these circumstances, Kuwait's Cabinet approved the disbursement of financial aid to employers in the private sector for 6 months. Furthermore, termination of Kuwaiti employees working in the private sector or reduction of their wages became illegal until the end of June 2021 (Kuwait News Agency, 2020d.).

The pandemic will have an adverse impact mainly on low-skilled and low-income foreign workers, as their jobs are the most vulnerable. Foreign workers who lose their jobs in Kuwait have no access to social protection and inability to find employment leads to loss of Residence Permit making them subject to detention, arrest or deportation. Inequitable access to health insurance and health care increases their risk of becoming infected with the coronavirus. Imposed travel restrictions prevent foreign workers from returning back to their countries what in combination with no income and social security results in poverty (International Labor Organization, 2020). The implication of the pandemic on highly skilled foreign workers occupying different management positions working for reputable organizations is yet unclear (Al-Hashem \& Martin, 2020). Jobs of Kuwaiti employees are the least to be affected (National Bank of Kuwait, 2020a).

\subsection{What past evidence suggests?}

In 2008, the financial crisis spread to the financial markets and real economy in the rest of the world (Tatliyer, 2017). Kuwait is more linked to the financial market; consequently, banking and 
financial services sector were the most affected. The impact on the labor market was limited (Debnath, 2010). The COVID-19 pandemic shock will have a more devastating employment and social impact than the financial crisis. The labor market has changed since then and an expanding informal sector, new forms of employment, such as gig work, and increasing number of foreign workers created and additional problems (International Labor Organization, 2020). Apart from the government's effort to localize workforce, when economy recovers, foreign workers will need to be rehired. Kuwait's labor market has been heavily structurally dependent on the foreign workforce who is its integral part of the labor market and will remain an essential component of the post-crisis economy. This will raise the cost of doing business (National Bank of Kuwait, 2020a).

Considering the experience from the financial crisis, the International Labor Organization (2020) suggested measures that governments should take for economic reactivation:

1. Stimulate the economy and employment by active fiscal and monetary policy, and by providing financial support to sectors most affected.

2. Support enterprises jobs and incomes by providing social protection to all, implementing employment retention measures, and by providing loans or wage support to SMEs.

3. Protect workers in the workplace by enhancing safety measures, providing access to health services, adopting telework, and increasing access to paid leave without discriminating anyone.

4. Rely on an effective social dialogue for formulating and evaluating solutions by collaborating and negotiating at national, sector and enterprise level.

\section{CONCLUSION}

Every worker in the country has been directly affected by the pandemic situation. Those working in the health or public security sector have experienced increase in working hours, on the other side some others have experienced decrease in their working hours, have worked from home or have lost their jobs and income. The real impact of the COVID-19 pandemic on Kuwait's labor market is difficult to predict. Hence, it is important for Kuwait's government to respond to the current challenges by finding new solutions to new problems and protecting the most vulnerable, because for many no income means no security and no future. Finally, the main limitation of this paper is the insufficient data in the published literature about the impact of the pandemic on the highly skilled foreign workers in Kuwait. It should therefore be considered for the future studies.

\section{REFERENCES}

Al-Hashem, S., \& Martin, G. (2020). COVID-19's Implications for Foreign Labour Outflow in Kuwait. Retrieved from https://blogs.lse.ac.uk/mec/2020/05/19/covid-19s-implications-for-foreign-labour-outflow-in-kuwait/

Al-Mutairi, A., Naser, K., Fayez, F. (2020). Factors discourage Kuwaiti employees to participate in the private sector labor force (Kuwaitization). International Journal of Organizational Analysis. https://doi:10.1108/ijoa-07-2019-1839

Arab Times. (2020a). Temporary law permitting salary cuts in private sector. Retrieved from: http:// www.arabtimesonline.com/news/temporary-law-permitting-salary-cuts-in-private-sector/

Arab News. (2020b). Kuwait Airways to lay off 1,500 foreign employees. Retrieved from: https:// www.arabnews.com/node/1681206/business-economy 
Arezki, R., Yuting Fan, R., \& Nguyen, H. (2020). Covid-19 and Oil Price Collapse: Coping with a Dual Shock in the Gulf Cooperation Council. Retrieved from: https://erf.org.eg/publications/ covid-19-oil-price-collapse-coping-dual-shock-gulf-cooperation-council/

Azour, J. (2020). COVID-19 Pandemic and the Middle East and Central Asia: Region Facing Dual Shock. Retrieved from https://blogs.imf.org/2020/03/23/covid-19-pandemic-and-the-middleeast-and-central-asia-region-facing-dual-shock/

Baldwin, R., Weder di Mauro, B. (2020). Mitigating the COVID Economic Crisis: Act Fast and Do Whatever It Takes. Retrieved from: https://voxeu.org/content/mitigating-covid-economic-crisisact-fast-and-do-whatever-it-takes

Bensirri Public Relations. (2020). COVID-19 Kuwait Business Survey. Retrieved from https:// kuwaitimpact.com/

Blas, J., Smith, G., \& Ansary, K. A. (2020). OPEC Meets to Extend Cuts That Trump Says Saved Oil Sector. Retrieved from: https://www.bloomberg.com/news/articles/2020-06-05/opec-meets-toextend-cuts-that-trump-says-saved-oil-industry

Debnath, P. (2010). The Impacts of the Global Economic Crisis in Migration in the Arab World. Retrieved from: https://www.mei.edu/publications/impacts-global-economic-crisis-migration-arabworld

Georgieva, K. (2020). IMF Managing Director Kristalina Georgieva's Statement Following a G20 Ministerial Call on the Coronavirus Emergency. IMF Press statement. Retrieved from: https://www. imf.org/en/News/Articles/2020/03/23/pr2098-imf-managing-director-statementfollowing-a-g20ministerial-call-on-the-coronavirus-emergency

Gulf Business. (2020). Covid-19: Kuwait begins three-week complete lockdown from May 10. Retrieved from: https://gulfbusiness.com/covid-19-kuwait-begins-three-week-complete-lockdown-frommay-10/

Gulf News. (2020). COVID-19: Kuwait to lay off 6000,000 marginal workers. Retrieved from: https://gulfnews.com/world/gulf/kuwait/covid-19-kuwait-to-lay-off-600000- marginal-workers-1.71553943

Gulf News. (2020) Coronavirus: Kuwait to move to 12-hour curfew from Sunday. Retrieved from: https:/gulfnews.com/world/gulf/kuwait/coronavirus-kuwait-to-move-to-12- hour-curfew-fromsunday-1.1590695104779

International Labor Organization. (2020). COVID-19: Labour Market Impact and Policy Response in the Arab States. Retrieved from: https://www.ilo.org/wcmsp5/groups/public/---arabstates/---robeirut/documents/briefingnote/wcms_744832.pdf

International Monetary Fund. (2020a). Confronting the COVID-19 Pandemic in the Middle East and Central Asia. World economic outlook. Retrieved from: https://www.imf.org/en/ Publications/REO/ MECA/Issues/2020/04/15/regional-economic-outlook-middle-east-central-asia-report\#MENAP

International Monetary Fund. (2020b). Policy responses to COVID-19. Retrieved from: https:// www. imf.org/en/Topics/imf-and-covid19/Policy-Responses-to-COVID-19\#K

International Monetary Fund. (2020c). Real GDP Growth. Retrieved from: https://www.imf.org/ external/datamapper/NGDP_RPCH@WEO/OEMDC/KWT?year=2020

International Monetary Fund. (2020d). Regional Economic Outlook. Middle East and Central Asia. Retrieved from: https://www.imf.org/en/Publications/REO/MECA/Issues/2020/04/15/regionaleconomic-outlook-middle-east-central-asia-report

KPMG. (2020). Kuwait: COVID-19 Government relief measures. Retrieved from: https://home. kpmg/ $\mathrm{kw} / \mathrm{en} /$ home/insights/2020/04/kuwait-covid19-government-relief-measures.html

Kuwait News Agency. (2020)a. Kuwait confirms 3 coronavirus cases coming from Iran's Mashhad. Retrieved from: https://www.kuna.net.kw/ArticleDetails.aspx?id=2864385\&language=en 
Kuwait News Agency. (2020)b. Official: Kuwait's schools, universities suspended for 2 weeks starting March 1. Retrieved from: https://www.kuna.net.kw/ArticleDetails.aspx?id=2868841\&language $=$ en $\#$

Kuwait News Agency. (2020)c. Kuwait has already cut oil output voluntarily - minister. Retrieved from: https://www.kuna.net.kw/ArticleDetails.aspx?id=2888349\&Language=en

Kuwait News Agency. (2020)d. Gov't to provide Kuwaiti private sector employees six-month support. Retrieved from: https://www.kuna.net.kw/ArticleDetails.aspx?id=2897013\&language=en

Kuwait News Agency. (2020)e. Kuwait suspends work in gov't departments March 12-26-spokesman. Retrieved from: https://www.kuna.net.kw/ArticleDetails.aspx?id=2876449\&language=en\#

Kuwait Times. (2020). Housing authority terminates 135 expat employees. Retrieved from: https://news. kuwaittimes.net/website/housing-authority-terminates-135-expat-employees/

Ministry of Health. (2020). COVID-19 Updates. Retrieved from: https://corona.e.gov.kw/En/

National Bank of Kuwait. (2020a). Economic impact of Covid-19 on Kuwait. Retrieved from: https://www.nbk.com/dam/jcr:9b8fbb3f-e89f-4dd9-81de-b9285ec0a225/NBKCOVID19ImpactonKuwait20200510.pdf

National Bank of Kuwait. (2020b). Kuwait: Population growth moderates in 1H19; expats employment softens further. Retrieved from: https://www.nbk.com/dam/jcr:d708761b-fca6-45a0-aa94-b0300bb8a737/NBKEUPOP\&LF20191007E.pdf

Nicola, M., Alsafi, Z., Sohrabi, C., Kerwan, A., Al-Jabir, A., Iosifidis, C., Agha, M., \& Agha, R. (2020). The socio-economic implications of the coronavirus pandemic (COVID-19): A review. International journal of surgery (London, England), 78, 185-193. https://doi.org/10.1016/j. ijsu.2020.04.018

Oxford Business Group. (2020). Kuwait's coordinated response to COVID-19. Retrieved from: https:// oxfordbusinessgroup.com/news/kuwait-s-coordinated-response-covid-19

PwC. (2020). Middle East Tax and other measures in response to COVID-19. Retrieved from: https:// www.pwc.com/m1/en/services/tax/me-tax-legal-news/2020/middle-east-tax-other-measures-response-to-covid-19.html

Reuters. (2020) Kuwait expands curfew, extends public sector work suspension. Retrieved from: https:// www.reuters.com/article/us-health-coronavirus-kuwait/kuwait-expands-curfew-extends-public-sector-work-suspension-idUSKBN2222QE

Sharif, A., Aloui, C., \& Yarovaya, L. (2020). COVID-19 pandemic, oil prices, stock market, geopolitical risk and policy uncertainty nexus in the US economy: Fresh evidence from the wavelet-based approach. International Review of Financial Analysis, 70, 101496. https://doi. org/10.1016/j. irfa.2020.101496

Sharifi, H., Jahani, Y., Mirzazadeh, A., Gohari, M. A., Nakhaeizadeh, M., Shokoohi, M., \& Haghdoost, A. A. (2020). Estimating the number of COVID-19-related infections, deaths and hospitalizations in Iran under different physical distancing and isolation scenarios: A compartmental mathematical modeling. https://doi.org/10.1101/2020.04.22.20075440

Statista. (2020). Employment by economic sector in Kuwait 2019. Retrieved from: https://www. statista. com/statistics/438879/employment-by-economic-sector-in-kuwait/\#statisticContainer

Tatliyer, M. (2017). The 2008-2009 Financial Crisis in Historical Context. Contributions to Economics Global Financial Crisis and Its Ramifications on Capital Markets, 3-17. http://doi:10.1007/978-3319-47021-4 1

World Bank Middle East and North Africa. (2020). How transparency can help the Middle East and North Africa). Retrieved from: https://openknowledge.worldbank.org/bitstream/handle/10986/33475/9781464815614.pdf

World Health Organization. (2020). Rolling updates on coronavirus disease (COVID-19). Retrieved from: https://www.who.int/emergencies/diseases/novel-coronavirus-2019/events-as-they-happen 


\title{
THE EFFECT OF INCOME STABILISATION TOOL ON SLOVAK AGRICULTURE
}

\author{
Andrea Boháčiková 1 (i) \\ Tatiana Bencováa \\ Zuzana Kapustová ${ }^{3}$
}

DOI: https://doi.org/10.31410/ERAZ.S.P.2020.33

\begin{abstract}
Managing income risk in agriculture is one of the important issues for farmers and policy makers nowadays. There exist a set of instruments and mechanisms for farmers to face the income volatility, including the individual or public support. Under II Pillar, the Common Agricultural Policy (CAP) offers the support for less favoured farms in the way of insurance, mutual fund, and Income stabilisation tool. The Income Stabilisation Tool (IST) represents the compensation to farmers for a "severe drop" in income, if the farm experienced an income loss of more than $30 \%$ compared to the 3-years average or the Olympic average of the preceding five-year income realizations. However, none of the EU countries has been currently using the tool operationally. The main objective of the paper is to investigate the potential effect of the Income Stabilisation Tool on mitigation of income risk in Slovak agriculture. The results of the paper show the existing possibility to improve financial situation and reduce the income inequality of particular Slovak farms in the future.
\end{abstract}

Keywords: Income risk, income stabilisation, CAP, Slovak agriculture.

\section{INTRODUCTION}

D isk is inherent in all economic activities, but due to external factors that influence the yield and price of agricultural output, farmers particularly are exposed to increased uncertainty (EC, 2017). During the last period, the European farming faced the spectrum of environmental, economic, financial, social and institutional risks. These risks are resulting from the imbalances on the market, that cause volatility of input and output prices, higher probability of extreme weather events, increasing dependence on land owners and financial institutions, ongoing technological progresses such as digitization, organizational changes within the value chains, or changing consumer preferences (Meuwissen, 2018). Uncertainty about prices, and thus income in agriculture increased during the price spikes in 2007-2008 and 2010-2011, followed by a severe drop in prices. When prices for inputs such as fertiliser, seed or feed increase, while the price of the agricultural output remains stable, the profit margin is reduced. Farmers with a low profit margin will therefore be more sensitive to income risk. Income risks do not only refer to income volatility but also to low levels of income, that can result in cash-flow constraints and lead to farmers' bankrupt. Serious impacts on agricultural production, has also the climate change and extreme weather events. The 2017/2018 has been current example, when heat waves and drought in various areas negatively affect EU production. Increased occurrence of risks has been raising farmers' concern and need for an adequate risk management approach. (EC, 2017).

\footnotetext{
$1 \quad$ Slovak University of Agriculture in Nitra, Tr. A. Hlinku 2, 94976 Nitra, Slovakia

2 Slovak University of Agriculture in Nitra, Tr. A. Hlinku 2, 94976 Nitra, Slovakia

3 Slovak University of Agriculture in Nitra, Tr. A. Hlinku 2, 94976 Nitra, Slovakia
} 
In the CAP, risk management instruments have become more important over the time. Since 1998, the European Community has been intensively investigating the possibilities of how to assist farmers in stabilizing their incomes (Meuwissen et al., 2008). With the 2008 Health Check, a risk management layer was introduced for the first time. It provided targeted risk coverage instruments such as subsidised insurance schemes and mutual funds in the operational programmes for the fruits, vegetables and wine sector. In order to support farmers in coping with income risks, several instruments have been proposed (see e.g. Cafiero et al., 2007; Meuwissen et al., 2008; Meuwissen et al., 2013; Bielza Diaz-Caneja et al., 2008; European Commission, 2008). The policy-makers finally introduced the support for risk management, after the 2013 reform in the Pillar II for the period 2014-2020 (EC, 2013). Risk management tools proposed in the Regulation (EU) $n^{\circ} 1305 / 2013$ allowed the Member States to allocate funds of the European Agricultural Fund for Rural Development (EAFRD) to provide financial contributions to income stabilization by 3 instruments: insurance premiums, mutual funds and a newly introduced Income stabilisation tool (Cordier, 2015; Pigeon et al., 2014; DG Agri, 2011).

Income from farming refers to the sum of revenues the farmer receives from the market, including any form of public support, deducting input costs (EC, 2013). The Income Stabilisation Tool, defined in the Article 39 (1305/2013) is a risk management tool for compensating farmers for severe income lost. A severe income drop in this proposal is defined as a decrease of $30 \%$ of the average annual income of the individual farmer in the preceding three-year period or a threeyear average based on the preceding five-year period excluding the highest and lowest entry (Olympic average). Independent of the source of this income reduction, farmers should receive compensation payments for less than $70 \%$ of the income lost in the year the producer becomes eligible to receive this assistance (EC, 2013; El Benni et al., 2016). Even if the compensation of income lost has been offered, under the 2014-2020 only two countries, Italy and Hungary and one region (Castilla y Leon) in Spain planned expenditure of EUR 130 million for the IST. However, none of the EU countries has been currently using the tool operationally.

The new risk management tools have been assessed by scientists to consider the feasibility and potential positive effect on the agricultural sector. One of the first ex-post studies of the EU Commission (EC, 2009) tested the concept of an income policy that would compensate $70 \%$ of a $30 \%$ minimum income loss due any reason, using the FADN data. The $23 \%$ of the EU- 25 farmers in 2006 had an estimated loss greater than $30 \%$ with a required compensation of $\$ 11.2$ billion (€9.7 billion per year as an average for the last decade, EU-15 and variations from $€ 8.5$ to 11.4 billion). The ex-ante research on the IST focusses on actuarial evaluations of a potential income compensation, governmental costs, impacts on optimal farm programmes, and identification of potential beneficiary groups of farms (Zgajnar, 2017; Pigeon et al., 2012; Liesivaara et al., 2012; Mary et al., 2013; El Benni \& Finger, 2014). The authors El Benni et al. (2016) noted, that in the ISTs ex-ante analyses two basic approaches are employed. First, farm level optimization models are used to investigate how the IST affects a specific farm and how farmers react to the provision of such tool (e.g. Turvey, 2012; Mary et al., 2013; Liesivaara et al., 2012). These approaches can reveal insights in farm-level decision making but are focused on a limited number of farms. Second, bookkeeping data across a large set of farms and years are used to set up simulation models and investigate income risks of farms to specify potential indemnification within the IST (e.g. Kimura \& Anton, 2011; Pigeon et al., 2012). Zgajnar (2017) added that the third approach is the analysis of data series with the regression-based econometric models (Pigeon et al., 2014; El Benni et al., 2016). 
In the Slovak agriculture, the potential effect of IST on individual farms has not been evaluated yet. Therefore, we firstly focus the research on the identification of farms, that suffered more than 30\% lost in the period 2009 - 2017 and could have been indemnified since the 2014 year, when risk management tools in the second Pillar of CAP have been introduced. The main objective of the paper is to examine the potential effect of the Income Stabilisation Tool in compensating the farms in the income lost and mitigating the income risk in Slovak agriculture.

\section{METHODOLOGY}

The data used for the analysis are obtained from the Ministry of Agriculture and Rural Development of Slovak republic. After outliers exclusion, the data set consists of financial statements of 654 individual farms in the years 2009 - 2017. The outliers are companies that did not exist during the whole observed period and had negative reference gross farm income. Farms are divided and examined separately according to their size, legal form and production orientation. Based on the size are farms divided to the group of micro (1 - 9 employees), medium (10 - 49 employees) and large (50 - 250 employees). From the legal forms are selected only farms with the legal form cooperative or business company (Limited liability company and Join-stock company). Based on the production orientation, the companies are divided into crop and animal farms. The classification criterion is more than 50\% share of sales from crop production or livestock production to the total sales of own products and services.

The ability to receive indemnification from Income Stabilisation Tool's fund have the farms, that recorded greater than $30 \%$ loss compared to the average annual income of the previous three year or to the ,Olympic' average of the previous five years. In the paper we use the first condition for identification of farms instead of 5-years Olympic average, as it is considered to be more specific (El Benni et al., 2016; Cordier, 2015). The payments by the IST mutual fund to farmers shall compensate a maximum of $70 \%$ of lost income. One of the obstacles in data selection is how to calculate the income. According to the European Commission proposition (EC, 2011) the income is defined as the sum of revenues the farmer receives, including any form of public support, deducting input costs. However, the authors have used different income categories for IST assessment, for example Net farm income (Hausheer Schnider, 2011; El Benni et al., 2016), profit margin (Liesivaara et al., 2012), farm net value added (Pigeon et al., 2012), gross margin (Zgajnar, 2017). In the paper we decided to identify the farms that could have receive the indemnification based of the Gross farm income calculation (Figure 1). Gross farm income refers to the sum of Sales from products and services (Total output), including Sales from crop production, Sales from animal production and Sales from agrotourism, plus the Subsidies of non-investment character, deducting the Input costs. Input costs refer to the FADN data categories called Total specific costs and Total farming overheads, and in Slovak financial statements are recorded in the account Consumption of material, energy and other non-storable supplies (fuels, electricity, seeds and seedlings, fertilizers and pesticides, crop protection products, purchased feeds for animals) and total intermediate consumption. The total external factors such as wages, rent and interest paid have not been taken into account. We considered 6 different periods covering data in the years 2009 - 2017, concretely $2009-2011,2010-2012$, $2011-2013,2012-2014,2013-2015,2014-2016$. The first three years are used to specify reference income levels and the fourth year is used to specify the level of indemnification, if the loss is greater than $30 \%$. Because we investigated hypothetical IST coverage, we calculated the maximal possible indemnification of $70 \%$ from the more than $30 \%$ loss. 


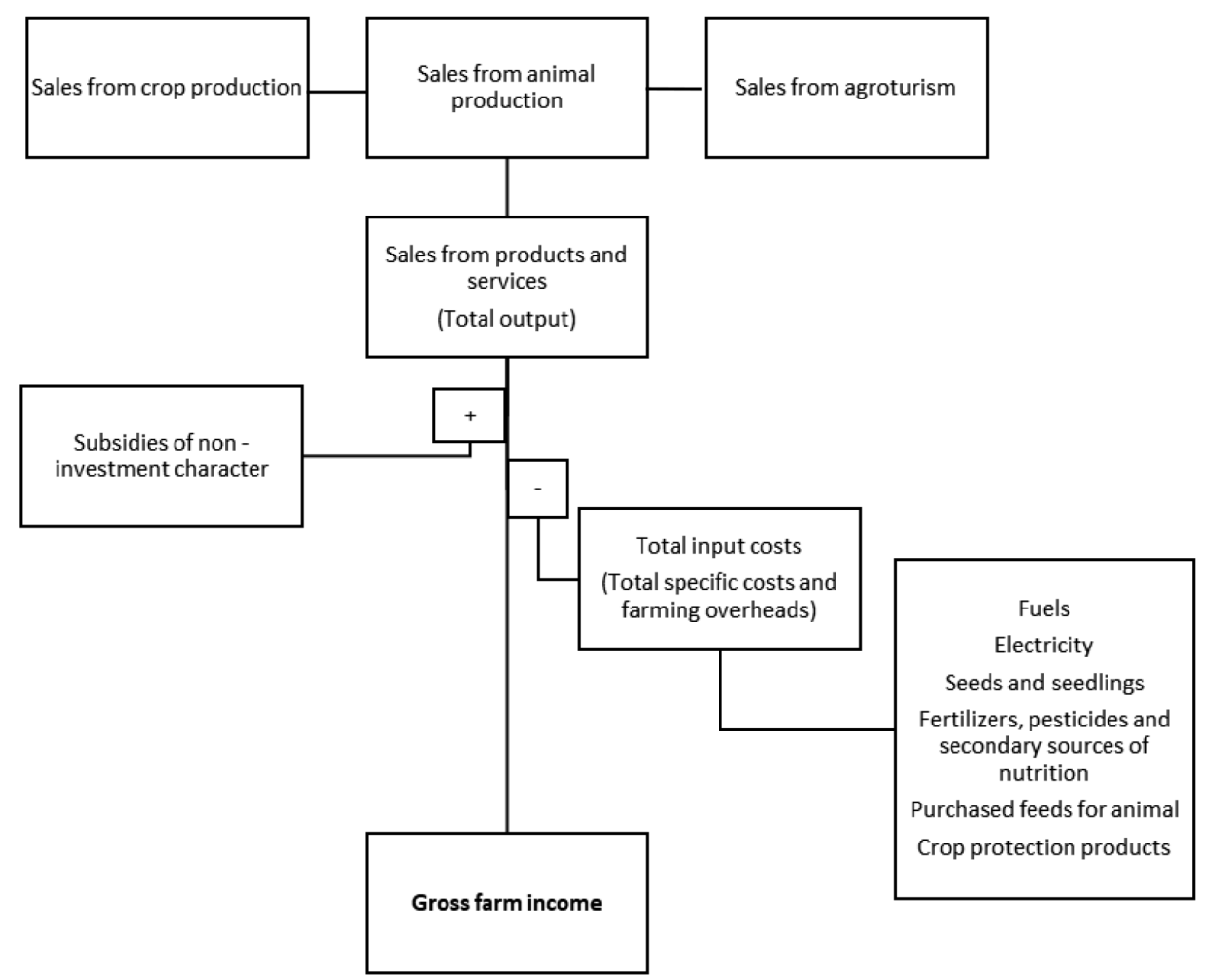

Figure 1. Gross farm income scheme

Source: own processing

\section{RESULTS}

Information from the financial reports of Slovak agricultural companies are used to analyse, which farms in the recent years suffered the loss adequate for the indemnification from the funds of Income Stabilization Tool. The government of Slovak republic has not implemented the IST yet, therefore the calculations show hypothetical scenarios of the ex-post analysis in the years 2009 - 2017. We used the 3-years average to calculate the reference income according to the variable "Gross farm income". The final data set consists of 654 agricultural companies from all regions of Slovakia. The removed outliers are the companies with insufficient information (missing data) in the observed period, and companies with negative reference income (3-years average of Gross farm income). We classified and individually examined the agricultural companies according to their production orientation (crop and animal farms), size (micro, medium, large) and legal form (cooperatives and business companies - Limited liability company and Join-stock companies). The structure of the data set is presented in the Table 1.

The results show that in the year 2012, 15\% of Slovak farms could have received the indemnification in the total amount of 19653040 EUR, if the $70 \%$ of loss would have been covered. The majority of identified farms were focused on the animal production (68\%), had the medium size (57\%) and legal form of business company (59\%). Only $9 \%$ of farms were eligible for compensation in year 2013 (12.97 mill EUR) and according to characteristics had similar farm types as in the previous year.

The difference is remarkable since the 2014, after the new CAP programming period, mainly in the case of production orientation, where the difference between groups is smoothened. In the year 2014 the greatest compensation could have been paid, amounted to almost 27.42 million EUR, although the percentage of indemnity farms is the same as in the year 2012. Even if, the 
same share of farmers in 2015 and 2016 experienced the loss more than 30\%, the potential indemnification refers to different amounts (approximately 5,5 million EUR more in 2016). The smallest number of farms (only 52), could have been indemnified in 2017, with the total amount of 11.07 million EUR. According to the characteristics, there is a changing structure of indemnity farms from the point of size. The lowest share had the large companies with more than 50 employees, instead of micro farms as it was in all previous years.

Table 1. Structure of agricultural companies

\begin{tabular}{llcc}
\hline Classification criterion & \multicolumn{1}{c}{ Category } & Absolute value & \% share \\
\hline \multirow{2}{*}{ Production orientation } & Crop farm & 278 & $43 \%$ \\
& Animal farm & 376 & $57 \%$ \\
\hline \multirow{2}{*}{ Legal form } & Cooperative & 337 & $52 \%$ \\
& Business company (Ltd. JSC) & 317 & $48 \%$ \\
\hline \multirow{2}{*}{ Business size } & Micro (1-9) & 107 & $16 \%$ \\
& Medium (10-49) & 342 & $52 \%$ \\
\hline \multirow{2}{*}{ Sum } & Large (50-250) & 205 & $32 \%$ \\
\hline
\end{tabular}

Source: own processing

Table 2. Structure of agricultural companies

\begin{tabular}{|c|c|c|c|c|c|c|}
\hline & 2012 & 2013 & 2014 & 2015 & 2016 & 2017 \\
\hline All farms & $15 \%$ & $9 \%$ & $15 \%$ & $8 \%$ & $8 \%$ & $7 \%$ \\
\hline Cooperatives & $41 \%$ & $44 \%$ & $42 \%$ & $43 \%$ & $42 \%$ & $49 \%$ \\
\hline Business company & $59 \%$ & $56 \%$ & $58 \%$ & $57 \%$ & $58 \%$ & $51 \%$ \\
\hline Micro & $19 \%$ & $14 \%$ & $26 \%$ & $20 \%$ & $17 \%$ & $25 \%$ \\
\hline Medium & $57 \%$ & $59 \%$ & $48 \%$ & $60 \%$ & $56 \%$ & $67 \%$ \\
\hline Large & $24 \%$ & $27 \%$ & $26 \%$ & $20 \%$ & $27 \%$ & $8 \%$ \\
\hline Crop farms & $32 \%$ & $37 \%$ & $54 \%$ & $49 \%$ & $54 \%$ & $49 \%$ \\
\hline Animal farms & $68 \%$ & $63 \%$ & $46 \%$ & $51 \%$ & $46 \%$ & $51 \%$ \\
\hline $\begin{array}{l}\text { The sum of potential } \\
\text { indemnification }(€)\end{array}$ & 19653040 & 12971121 & 27419940 & 12125918 & 17721008 & 11069947 \\
\hline
\end{tabular}

Source: own processing

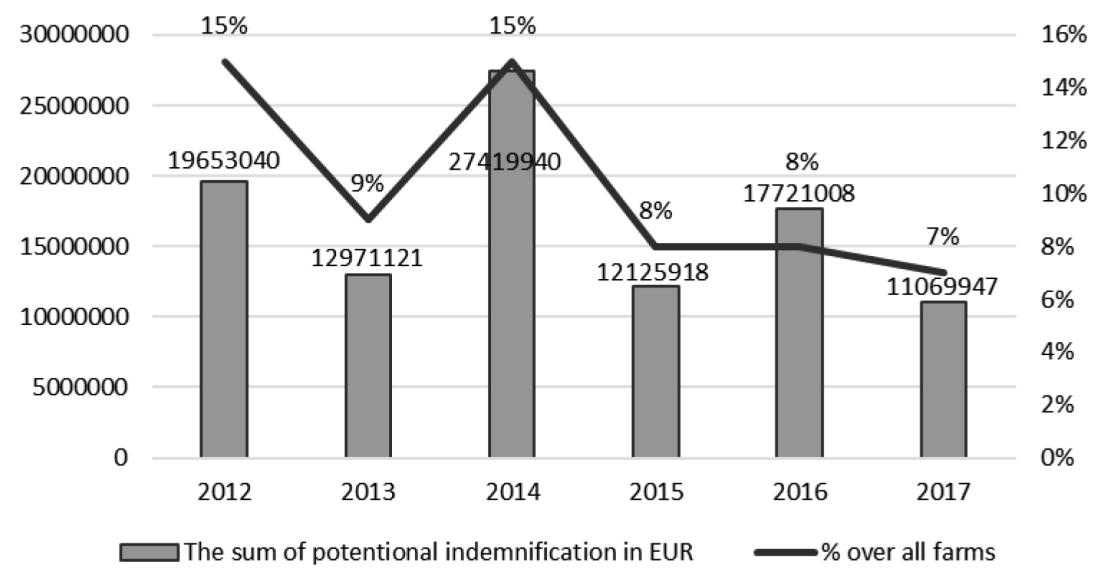

Figure 2. Potential indemnification of Slovak farms in 2012-2017

Source: own processing

The Figure 2 shows the development of share of farmers experiencing an income loss of more than $30 \%$, and the amount of compensation that would have been required if the Income Stabilisation tool would have been in implemented place between 2012 and 2017 in the Slovak 
agriculture. The line indicates the \% share of farmers eligible for compensation, and the bars indicate the budget necessary for indemnification in the same years. For better assessment of the potential effect of IST, we examined also the scenarios in 2012 and 2013, although the IST belongs to the 2014-2020 CAP regulation.

Undoubtedly, the Income Stabilisation Tool enlarges the risk management opportunities for farmers, and our results show that each year millions of Euros could have been used for loss coverage, but the future implementation in the national policy remains questionable. The CAP gives the Member states opportunity to define the own rules for the constitution and management of the mutual funds, in particular for the granting of compensation payments to farmers. Therefore, it is necessary to prepare administration and monitoring of farms, methodology for arrangement of funds, penalties in case of negligence on the part of the farmer and other steps, that might be costly.

\section{FUTURE RESEARCH DIRECTIONS}

The Income stabilisation tool seems to be an effective instrument in the mitigation of income risk in agriculture. Therefore, its questionable, why none of the European countries has implemented the tool in the national agricultural policy so far. The critics of the IST consider as negative that the risk management tools in the Article 36 of Regulation (EU) $n^{\circ} 1305 / 2013$ are optional and not obligatory, given the farmers rather suggestion with very vague guidelines than effective programmes (Cordier, 2015). Questions that arise by governments and farmer organisations are how to organise, initiate and govern the mutual fund. What should happen when funds have to be paid in one of the starting years when the capital stock is still very small is also a problem. Moreover, the budgetary needs of the IST can be very volatile and quite demanding. If the scheme is implemented in all Member States, the maximum budget needs for one year are estimated at 22 billion EUR. Another obstacle of the IST is that funds may only be used in case of income losses larger than $30 \%$. Furthermore, the programming of ISTs is hampered as it is not allowed to specific sectors, although there are large differences between agricultural sectors in terms of the risks faced and the chance that payments are received (EC, 2017). The selection of income category and its correct calculation is found to be another problem. The income definition that is used influences compensation. For example, if decoupled payments are not included the scheme is triggered more often. The accounting systems in European countries differ, what might cause misleading in income consideration, when necessary data is not available. Moreover, it is hard to accurately assess farmer income and revenue, especially for small farms that do not have an adequate accounting system. The potential problem in the future could also be purposely adjustment of financial statements in order to obtain funds for the farms. These issues are very challenging for the policy makers, because the improvements and specifications of IST, as well as other risk management tools in the CAP after 2020 are expected. In the future, we would like to extend our research and examine more deeply the effects of the IST implementation in Slovak agriculture.

\section{CONCLUSION}

The Common Agricultural Policy 2014-2020 has been mainly aimed at compensating farmers for the negative effects of price volatility and tackling income volatility. Member States have the possibility to support three risk management tools (insurance schemes, mutual funds and an Income Stabilisation Tool) through their rural development programs. As the CAP offers the tools to mitigate the agricultural risk connected with income volatility, it should be important for each country to open the question of risk in agriculture in the scientific research. 
Income Stabilization Tool (IST) can be implemented by EU-Member States to provide up to 70 $\%$ compensation to farmers who experienced more $30 \%$ loss. In the paper we examined the potential indemnification for 654 agricultural companies in the years 2012 - 2017. During the observed period, the compensation would have amounted, on average to 16.8 mill. EUR per year for, varying between a minimum of 11.07 mill. EUR in 2017 to a maximum of $27.42 \mathrm{mil}$. EUR in 2014. The majority of indemnity farms are the business companies with the medium size. The production orientation seemed to be an important characteristic in years 2012 and 2013, when more than $60 \%$ of farms suffering the loss were focused on animal production, however since 2014, when the new CAP programming period started, the differences has been smoothened.

Although, the additional funds for covering the loss of farmers and stabilizing their income are a great option, a lot of questions arises with the implementation of IST in Slovakia. These have not only the methodological character (insufficient guideline, problematic income definition, inconsistent accounting systems, necessity for appropriate monitoring, etc.), but also the problem with prevention of negligence on the part of farmers, who can adjust the financial statements in order to receive funds. Therefore, the CAP should specify and improve the risk management tools implementation in the new programming period after 2020.

\section{ACKNOWLEDGMENT}

This paper was supported by the project VEGA: Impact of the Common Agricultural Policy on the mitigation of income risk in Slovak agriculture and factors determining the level of risk of agricultural companies. Project registration number 1/0338/18.

\section{REFERENCES}

Agri, D. G. (2017). Risk management schemes in EU agriculture; dealing with risk and volatility. European Commission, Brussels.

Agri, D. G. (2011). Evaluation of effects of direct support on farmers' income - Common Agricultural Policy Evaluations, European Commission, Brussels, May, 16 p.

Cordier, J. (2015). Comparative analysis of risk management tools supported by the 2014 US Farm Bill and the CAP 2014-2020.

El Benni, N., Finger, R., \& Meuwissen, M. P. (2016). Potential effects of the income stabilisation tool (IST) in Swiss agriculture. European Review of Agricultural Economics, 43(3), 475502. https://doi.org/10.1093/erae/jbv023

European Commission. (2008). CAP Health Check - Impact Assessment Note No. 8, Brussels, DG Agriculture and Rural Development.

European Commission. (2009). Income variability and potential cost of income insurance for EU, Directorate-General for Agriculture and Rural Development, European Commission, Brussels, Belgium.

European Commission. (2011). Impact Assessment - Common Agricultural Policy towards 2020, Commission Staff Working Paper, Annex 6: Risk Management, SEC(2011), 1154, European Commission, Brussels, Belgium.

European Commission. (2011). Proposal for a Regulation of the European Parliament and of the Council on support for rural development by the European Agricultural Fund for Rural Development (EAFRD). COM(2011), 627/3, European Commission, Brussels, Belgium. 
European Commission. (2013). Regulation (EU) No 1305/2013 of the European Parliament and of the Council of 17 December 2013 on support for rural development by the EAFRD and repealing EC No 1698/2005. OJ L (Official Journal European Union L 347/487), 347, 487-548.

Finger, R., \& El Benni, N. (2014). A note on the effects of the Income Stabilisation Tool on income inequality in agriculture. Journal of Agricultural Economics, 65(3), 739-745.

Garrido, A., \& Bielza, M. (2008). Evaluating EU risk management instruments: policy lessons and prospects for the future. W: MPM Meuwissen, MAPM Van Asseldonk, RBM Huirne (red.), Income stabilisation in European agriculture. Design and economic impact of risk management tools. Wageningen: Wageningen Academic Publishers.

Kimura, S., \& Anton, J. (2011). Farm income stabilization and risk management: Some lessons from AgriStability program in Canada (No. 726-2016-49783), August 30-September 2. Zurich, Switzerland.

Liesivaara, P., Myyra, S., \& Jaakkola, A. (2012). Feasibility of the income stabilisation tool in Finland (No. 706-2016-48385), February 23rd-24th. Dublin, Ireland.

Mary, S., Santini, F., \& Boulanger, P. (2013). An ex-ante assessment of CAP Income Stabilisation Payments using a farm household model (No. 355-2016-18185).

Meuwissen, et al. (2018). Report on resilience framework for EU agriculture: Sustainable and resilient EU farming systems (SureFarm) project report, work package D1. 1. Wageningen University \& Research.

Meuwissen, M. P., Assefa, T. T., \& van Asseldonk, M. A. (2013). Supporting insurance in European agriculture: Experience of mutuals in the Netherlands. EuroChoices, 12(3), 10-16.

Meuwissen, M. P., Van Asseldonk, M. A., \& Huirne, R. B. (Eds.). (2008). Income stabilisation in European agriculture: design and economic impact of risk management tools. Wageningen Academic Publishers.

Pigeon, M., de Frahan, B. H., \& Denuit, M. (2014). Evaluation of the EU proposed farm income stabilisation tool by skew normal linear mixed models. European Actuarial Journal, 4(2), 383-409.

Pigeon, M., Frahan, B. H. D., \& Denuit, M. (2012). Actuarial evaluation of the EU proposed farm income stabilisation tool (No. 706-2016-48370). Paper presented at the 123rd EAAE Seminar Price Volatility and Farm Income Stabilisation, February 23rd-24th. Dublin, Ireland.

Turvey, C. G. (2012). Whole farm income insurance. Journal of Risk and Insurance, 79(2), 515540.

Zgajnar, J. (2017). Analysis of indemnify cation of income risk at sector level: the case of Slovenia. Studies in Agricultural Economics, 119(2), 70-76. 


\title{
THE ECONOMIC VIABILITY OF THE ENERGY PRODUCTION FROM BIOMASS VIA ANAEROBIC DIGESTION
}

\author{
Zuzana Kapustová ${ }^{1}$ \\ Andrea Boháčiková ${ }^{2}$ (D) \\ Ján Lajda ${ }^{3}$
}

DOI: https://doi.org/10.31410/ERAZ.S.P.2020.41

\begin{abstract}
Anaerobic digestion is a microbial process that occurs in the absence of oxygen where a community of microbial species breaks down both complex and simple organic materials, ultimately producing methane and carbon dioxide. Biogas refers to a secondary energy carrier that can be produced out of many different kinds of organic materials and its options for utilization can be equally versatile - biogas can be used to generate electricity, heat and biofuels. It is clear that introduction of the subsidies in 2009 for BGPs initiated usage of the AD technology for generating electric energy. The sharpest increase in number of BGPS was recorded in 2013; however, there was a major downsizing in their installation in 2014 due to change in the subsidy system. The main aim of the paper is to forecast economic viability of biogas plants in Slovakia based on the net present value indicator, estimation of payback period of the technology and assessment of the maximum economic price of input material.
\end{abstract}

Keywords: Biogas, Net present value, Slovakia.

\section{INTRODUCTION}

66 naerobic digestion is a microbial process that occurs in the absence of oxygen. In the process, a community of microbial species breaks down both complex and simple organic materials, ultimately producing methane and carbon dioxide" (Engler et al., 2013). European Biomass Association (2013) defines biogas as a secondary energy carrier that can be produced out of many different kinds of organic materials and its options for utilization can be equally versatile. Biogas can be used to generate electricity, heat and biofuels. Also, the fermentation residues, called digestate, can be used for example as a fertilizer. Pepich et al. (2010) describe biogas as a product of transformation of biomass into energy via an anaerobic digestion (AD), where the resulting product is a biogas, serving as fuel for cogeneration units and it reaches about $70 \%$ of the energy content of natural gas. $2178 \mathrm{kWh}$ of electricity or $11.4 \mathrm{GJ}$ of heat can be obtained by burning $1000 \mathrm{~m}^{3}$ of biogas. Additionally, $1 \mathrm{~m}^{3}$ of biogas contains as much energy as 0.6 to $0.7 \mathrm{dm}^{3}$ of fuel oil for heating. Compared with conventional heat and electricity, up to $40 \%$ of fuel can be saved. Compressed and adjusted biogas can be supplied to the grid as natural gas and only additional costs for treating biogas are the barrier, even though there are already developed technologies for such treatment (Holm-Nielsen et al., 2008). Baxter (2014) points out that there are many ways how to realise flexible output produced by biogas plants. It is possible to store biogas with storage capacity locally and also via pipelines connecting more biogas plants. Excess capacity cogeneration or combined heat and power (CHP) units might be used in times of deficit irregular renewable electricity generator or of the highest demand.

Slovak University of Agriculture in Nitra, Faculty of Economics and Management, Department of Economics, Tr. A. Hlinku 2, 94976 Nitra, Slovakia

2 Slovak University of Agriculture in Nitra, Faculty of Economics and Management, Department of Economics, Tr. A. Hlinku 2, 94976 Nitra, Slovakia

3 Land technologies s.r.o., Hlohovecká 11, 95141 Lužianky, Slovakia 
There is a concept of many biogas plants linked together for flexible operation created already. Another alternative is to upgrade biogas to natural gas quality.

Braun et al. (2014) believe that economic viability of the energy production from energy crops is possible only if we achieve high crop and biogas yields while keeping investments, raw material and production costs low. In addition, other incentives are provided like subsidies and feedin-tariffs to increase economics of the process. Gebrezgabher et al. (2010) underline that the financial viability of the system also depends on transport of input materials. Some researchers indicate that maximum economical distance is of $15-25 \mathrm{~km}$. Logistics of inputs and outputs are crucial indicator for biogas system to be economically, environmentally, and socially viable. Long distance transportation generates transportation cost as well as environmental costs in form of GHG emissions, odour and noise. Therefore, these externalities of the transport should be managed to their minimums. Wellinger (2014) states that biogas plant operators have to deal with security of sustainability of producing biomass and its higher yields per hectare via catch crop or multiple cropping on arable land. Other possibilities are permanent grasslands. There are also mechanical, physical and biochemical pre-treatment techniques to raise efficiency of biomass degradation. On the other hand, Dollhofer (2014) reminds that these mechanical and chemical pre-treatment techniques come hand in hand with significant energy loses as they require high energy input.

The paper intends to forecast economic viability of biogas plants in Slovakia based on the net present value indicator, estimation of payback period of the technology and assessment of the maximum economic price of input material. The contribution of the paper is twofold. First, the paper provides analysis of biogas sector over specific time period in Slovakia. Second, the paper gives an empirical evidence of the economic viability of the biogas sector and its benefits for investors by using simplified model of a biogas plant scenario as a representing sample.

\section{MATERIALS AND METHODS}

In order to forecast economic viability of biogas plants in Slovakia, the following steps are done:

Step 1: Biogas plant model is constructed on the basis of analysis of Slovak biogas sector and literature review.

Step 2: Grain maize annual price (EUR) forecast is performed. In order to predict the values, the VECM model is performed based on the long run relationship between grain maize annual prices (EUR) and amount of maize production (tonnes) in Slovakia from 1993 to 2018; data were used from Food and Agriculture Organization of the United Nations (FAOSTAT). Anderson et al. (2002) explain that VECM is a policy-oriented vector autoregressive model that is anchored by long-run equilibrium relations suggested by economic theory and VECM forecasts are considerably more accurate than simple random-walk alternative. Gangopadhyay et al. (2016) suggest that VECM indicates a $\mathrm{nx}_{1}$ vector of stationary time series $\left(\mathrm{y}_{t}\right)$ in terms of constant, lagged values of itself and error correction term. The standard VECM model can be expressed as follows:

$$
\Delta y_{t}=c+\varphi_{1} \Delta y_{t-1}+\varphi_{2} \Delta y_{t-2}+\ldots+\varphi_{p} \Delta y_{t-p}+E C T_{t}+\varepsilon t
$$


where ECT refers to the Error Correction Term - a product of an adjustment factor $(\alpha)$ and the cointegrating vector $(\beta)$. The cointegrating vector shows the long-term equilibrium relationship between the examined variables while the adjustment factors indicate the speed of adjustment towards equilibrium in case there is any deviation.

Step 3: Prediction of grain maize annual yields (tonnes/hectare) for following calculation of grain annual yields of grain maize (bushels/tonne). Sample Mean method is used to forecast grain maize annual yields. The formula is as follows:

$$
F_{t+1}=\frac{1}{n} \sum_{1}^{n} Y_{t}
$$

where $\mathrm{F}$ is a forecasted value in year $\mathrm{t} ; \mathrm{n}$ is number of observations and $Y_{t}$ is an actual value in year t. The data were taken from Food and Agriculture Organization of the United Nations (FAOSTAT).

Step 4: Annual grain yields of grain maize (bushels/tonne) are estimated on the basis of its relationship with grain maize annual yields (tonnes/hectare) given by approximate bushels of grain content in a tonne of corn silage (Lauer, 2005; as cited in Lippert, n.d.). Table 1 depicts approximate bushels of grain contained in a tonne of corn silage. Data were used from Food and Agriculture Organization of the United Nations (FAOSTAT).

Table 1. Approximate bushels of grain contained in a tonne of corn silage

\begin{tabular}{|c|c|}
\hline $\begin{array}{c}\text { Maize Yield } \\
\text { Bu/A }\end{array}$ & $\begin{array}{c}\text { Grain Yield } \\
\text { Bu/T }\end{array}$ \\
\hline 25 & 3,5 \\
\hline 50 & 5,5 \\
\hline 75 & 6,8 \\
\hline 100 & 7,5 \\
\hline 125 & 7,9 \\
\hline 150 & 8 \\
\hline 175 & 7,9 \\
\hline
\end{tabular}

Source: Lauer, 2005 (as cited in Lippert, n.d.)

Step 5: Calculation of future maize silage annual prices derived from grain maize prices and grain yield of grain maize forecast. The formula is as follows:

$$
\text { Maize silage price } \left._{t}(\text { EUR / tonne })=M_{t}(\text { EUR / bushel }) * C_{t} \text { (bushels / tonne }\right)
$$

where $\mathrm{M}$ is a price of grain maize in year $\mathrm{t}$ and $\mathrm{C}$ is a grain yield in one ton of maize in year $\mathrm{t}$.

Step 6: Net present value (NPV) is used as valuation criteria in order to forecast economic viability of biogas plants and Payback Period is performed as a tool that compares revenues with costs and determines the expected number of years required to recover the original investment. NPV determines the present value of an investment and represents sum of estimated future cash flows in today's value of money (Mészáros and Jašňák, 2014). The formula is as follows (Patinvoh et al., 2017): 


$$
N P V=-\mathrm{I}+\sum_{t=1}^{n} \frac{\mathrm{CF}_{\mathrm{t}}}{(1+r)^{t}}
$$

and

$$
C F_{t}=p_{t} o_{t}-c_{t} m_{t}-F C_{t}
$$

where $\mathrm{CF}$ is estimated cash flow in year $\mathrm{t}, \mathrm{r}$ is discount factor and $\mathrm{I}$ is the initial investment. $\mathrm{CF}$ is a function of income, variable cost and fixed costs in year t. $\mathrm{P}$ is price of output, o is amount of output produced at time $\mathrm{t}, \mathrm{c}$ is cost of input and $\mathrm{m}$ is amount of input in year $\mathrm{t}$. FC are fixed cost including annuity, labour costs, G-component, manipulation with materials services, maintenance and service costs.

The following formula for Payback Period (PBP), that calculates the time required for the payback of investment, can be used for even cash inflows of a project (Santadkha and Skolpap, 2017):

$$
\text { Payback Period }=(\text { Original Investment }) /(\text { Annual } C F)
$$

However, if the cash flows of a project are uneven, the payback period is computed by adding the annual cash flows until such time as the original investment is recovered.

Step 7: To find out the ceiling price of the maize silage as the input for AD, Break Even Analysis was used. The ceiling price of the input is calculated at the point when total costs equal total revenues. The formula is as follows (Weil and Maher, 2005):

$$
T R=V C+F C
$$

and

$$
T R=A * C+F C
$$

where TR (Total Revenues) = cumulated quantity of electricity produced during lifetime of the project MW * guaranteed selling price of the electricity EUR / MW; VC (Variable Costs) $=$ cumulated amount of maize silage used for $\mathrm{AD}$ during lifetime of the project $(\mathrm{A})$ in tones * price of maize silage (C) EUR / ton; FC (Fixed Costs) = cumulated fixed costs during lifetime of the project including investment, capital costs, labour costs, G-component, service and maintenance costs and manipulation services costs. Then the final formula is derived as follows:

$$
C=\frac{(T R-F C)}{A}
$$

where $\mathrm{C}$ is ceiling price (EUR) of one ton of maize silage at which the biogas plant does not generate any profit nor loss.

\section{3, RESULTS}

In case of Slovakia, the sharpest increase in number of biogas plants (BGPs) was recorded in 2013. An increasing trend was experienced in the development of the biogas sector until 2014; 
however, there was a major downsizing in their installation in 2014. It is clear that introduction of the subsidies in 2009 for BGPs initiated usage of the AD technology for generating electric energy. The trend in subsidies was slightly decreasing with stable values since January 2012 until December 2013. During this period, the majority of BGPs were lunched. In January 2014 the new subsidy policy was introduced that broke down biogas sector into 4 groups. The most popular scale of BGP (1 MW of capacity) lunched in 2014 were granted with lowest amount of purchasing price. The change in policy reflects trends in other countries with more developed biogas industry and also problems and negative externalities connected with BGPs of larger size. On the other hand, the change of subsidy policy for year 2014 highlights its volatility which means uncertainty in the sector which could be the main factor why there was not any new BGP lunched in 2014. 111 biogas stations with a total capacity of 103 MW were established in Slovakia by the end of July 2015 (109 installations in operation at the end of 2018) ("EnergiePortal", 2017). The average installed capacity of a biogas plant is $0.943 \mathrm{MW}$ in Slovakia (for comparison, the average installed capacity is $0.4 \mathrm{MW}$ in Germany) and the majority of them focus on the production of electricity from maize silage processing.

\subsection{Forecast of economic viability of biogas plants in Slovakia}

Considering the fact that there are not exactly the same BGPs, due to the fact that each BGP is tailored to a specific environment, capacity, location and etc., a general model was constructed, according to literature and analysis of biogas sector and its development, which represents majority of BGPs in Slovakia.

\section{a. Scenario description}

The plant is located nearby a farm to minimize transport cost for input and output materials. To simplify model, the plant is considered as economically autonomous entity. The plant uses $100 \%$ maize silage as an input material for wet anaerobic fermentation and was launched in 2013 due to the fact that in the very same year the most BGPs were activated. Its size is $1 \mathrm{MW}$ of electric energy capacity. The input material is bought from the farm at market prices and the final output is electricity that is sold at guaranteed prices for 15 years, heat is used only for internal needs and digestate is provided to the farm for free as a fertilizer which is transported to the fields at the expenses of the farm. Manipulation with input and output materials are provided by the farm and the plant covers the costs which are estimated 500 EUR per month. The lifetime of the project is 15 years.

The project involves the initial investment of 3.5 million EUR, where $30 \%$ is financed by own capital and $70 \%$ is financed with debt with interest rate $3.2 \%$, with maturity 10 years in monthly payments. $55 \%$ of the investment costs cover technology included in the second depreciation group with accelerated depreciation for the first two years then the technology is included in the third group (depreciation period of 8 years) with accelerated depreciation since 2015. The rest $45 \%$ of the investment is included into fourth depreciation group with accelerated depreciation and since 2015 it is included into fifth group with linear depreciation.

Operation costs cover all elements that are inevitable to keep the BGP running. Total labour costs including two personnel operators with average wage in the energetic sector in Slovakia are 1174 EUR monthly per person. There are estimated 50 tonnes of input material each day, 335 days per year. 30 days per year the plant is out of service. Service and maintenance cost 
are estimated 60 thousand EUR each year. Operation costs also include expense for connection to the grid so called G-component (since 1.1.2014), which is estimated to 18270 EUR per year. The plant operates 8040 hours per year at $95 \%$ of its total capacity. Guaranteed price per one megawatt is 134.08 EUR.

\section{b. Forecast of grain maize prices, grain maize yields in Slovakia and calculation of future maize silage prices}

Forecast of grain maize prices for years from 2019 till 2027 is shown in Figure 1. The prices were predicted on the basis of relationship between annual price of grain maize and volume of production of grain maize in Slovakia. The forecast estimates steadily increasing trend for the grain maize price over the next years. There is also shown that the 95 percent intervals include relatively wide range of values and the actual future values may differ significantly from estimated ones and in that case following calculations might bring inaccurate deductions.

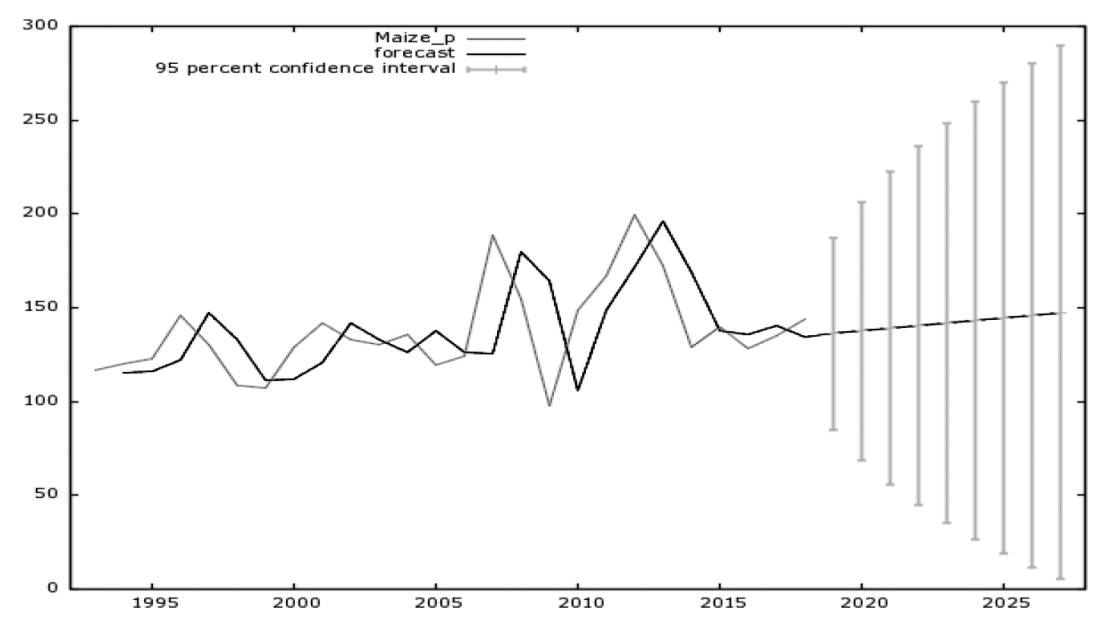

Figure 1. Grain maize prices forecast for years 2019 - 2027

Source: authors' processing

Historical values and Simple Mean method were used to forecast yields of grain maize in Slovakia because these yields are mainly affected by weather conditions, fertilizers and pesticides usage, and technology of production. The mean value of the used data is $6.051 \mathrm{~T} / \mathrm{ha}$ which is transformed into $96.39 \mathrm{Bu} / \mathrm{A}$ for next calculations (Figure 2).

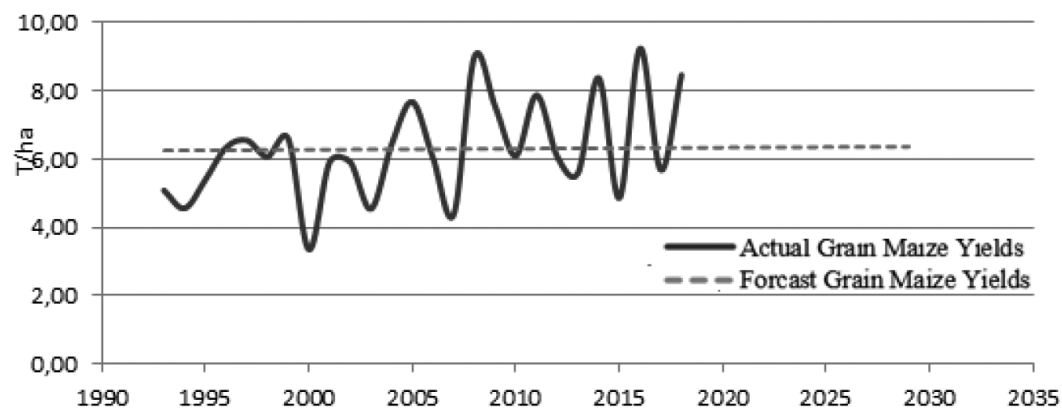

Figure 2. Actual and forecasted values of grain maize yields (T/ha) in Slovakia

Source: authors' processing, FAOSTAT

Using Table 1 of approximate bushels of grain content in a ton of corn silage, we found out relationship from which we derived a formula to calculate grain yields of grain maize to project 
prices of silage maize. From the data in Table 1 the relationship was derived as it is show in Figure 3. Grain yields are estimated according to maize yields per hectare and the formula is as follows:

$$
y_{t}=-0.0003 x_{t}^{2}+0.0927 x_{t}+1.5286
$$

where $\mathrm{y}$ is grain yield in bushels per one tone of grain maize silage in year $\mathrm{t}$ and $\mathrm{x}$ is grain maize yield in bushels per one acre in year $t$.

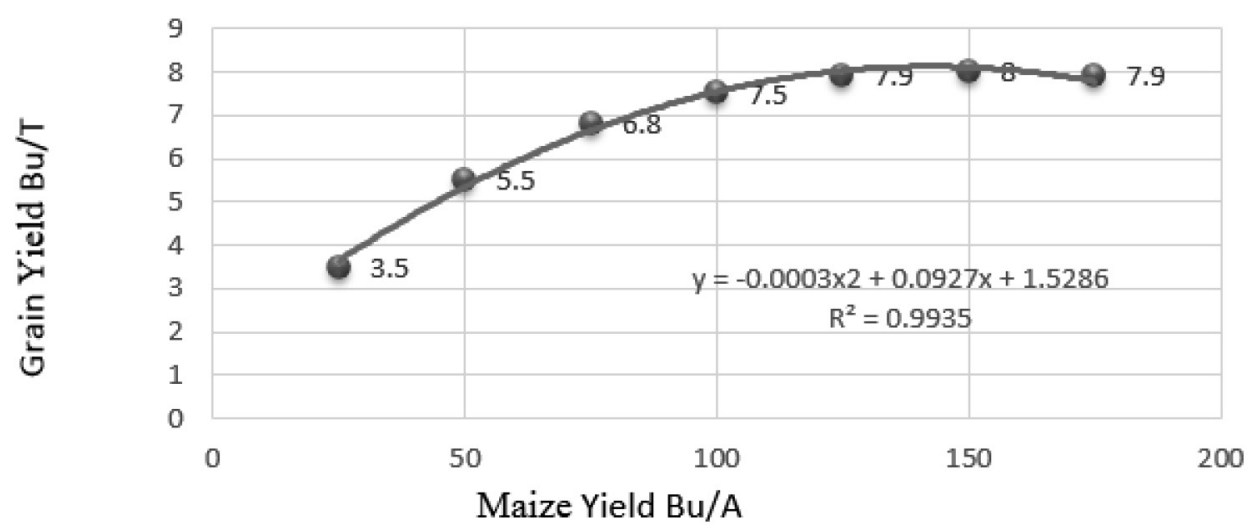

Figure 3. Relationship between grain yield of maize bushel per ton of silage and grain maize yield bushel per acre

Source: authors' processing

\section{c. Determining NPV of the project and estimation of payback period of biogas plants in Slovakia}

To forecast economic viability of biogas sector NPV tool was used. The model of a biogas plant was constructed the way it represents as many BGPs in Slovakia as possible and contains general similarities. The scenario does not count with any other income than the one from sale of electricity and only one single input is used. Some BGPs benefit from using different types of inputs that are less costly than maize silage even though may not be as effective as the maize silage or there are also options of selling heat and fertilizers; however, these investments are costly and extremely difficult to generalize.

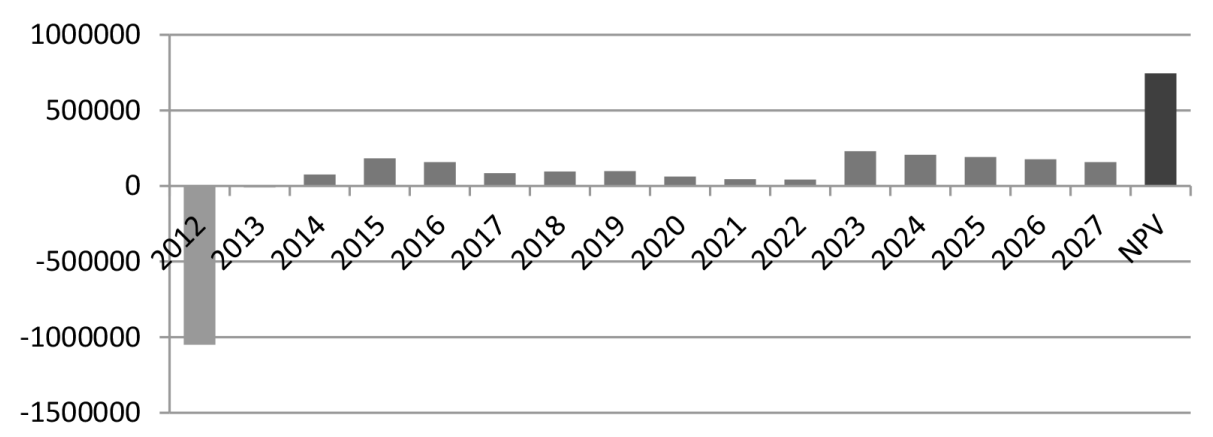

Figure 4. Discounted cash flow with final NPV value (in EUR)

Source: authors' processing

According to Figure 4, the sum of all discounted cash flows is 745048.01 EUR. NPV value for the project is positive which means, it is worth investing and Slovak biogas industry is economically vital. However, the result is as accurate as the silage maize price forecast, which is the 
most questionable element apart from technical conditions of BGPs. Even though we can easily estimate cash inflow due to guaranteed prices of electricity for 15 years, government can still interfere and decrease or increase cash inflow. An example is implementing G-component in 2014 the effect of which is as a tax levied on electricity produced from RES.

Payback period was calculated to 10 years and the initial investments including cost of capital is estimated to be regenerated by the time their maturity as the debt is to be paid by the $10^{\text {th }}$ year. The BGP starts to generate profit in the $11^{\text {th }}$ year of the project life with the cumulative profit in the last projected year 1375251.19 EUR (Figure 5).

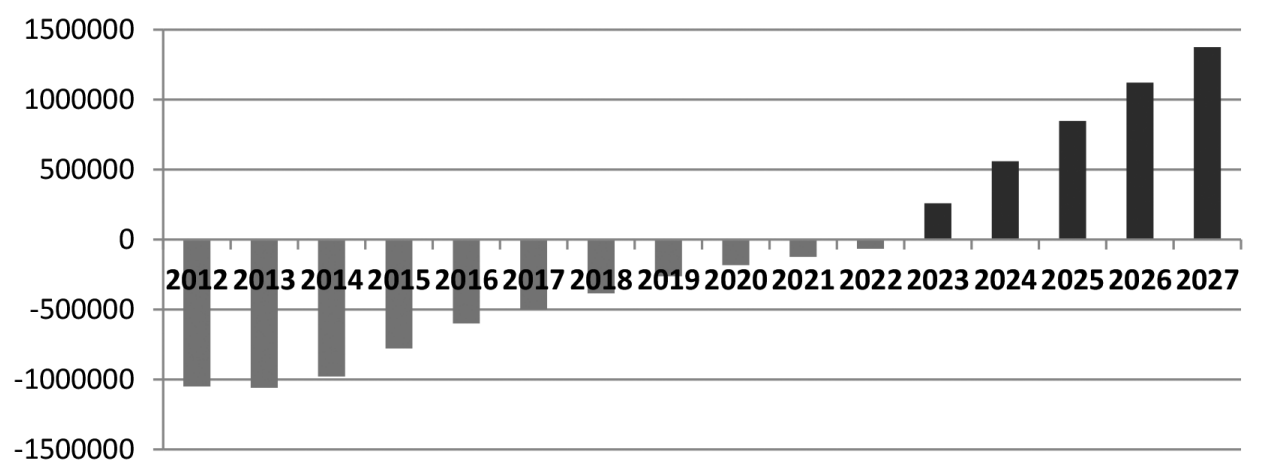

Figure 5. Cumulative cash flow (in EUR)

Source: authors' processing

One of the most criticized week spot of the payback period tool is the fact that it does not take into account time value of money. To overcome this drawback, payback period was calculated also on the basis of discounted cash flow. The result is very similar to the previous one and it estimates 10 years for the investments to be recovered and since $11^{\text {th }}$ year it starts to generate profit as it is shown in Figure 6. The cumulative profit generated in the $15^{\text {th }}$ year in today's value of money is 745049.01 EUR.

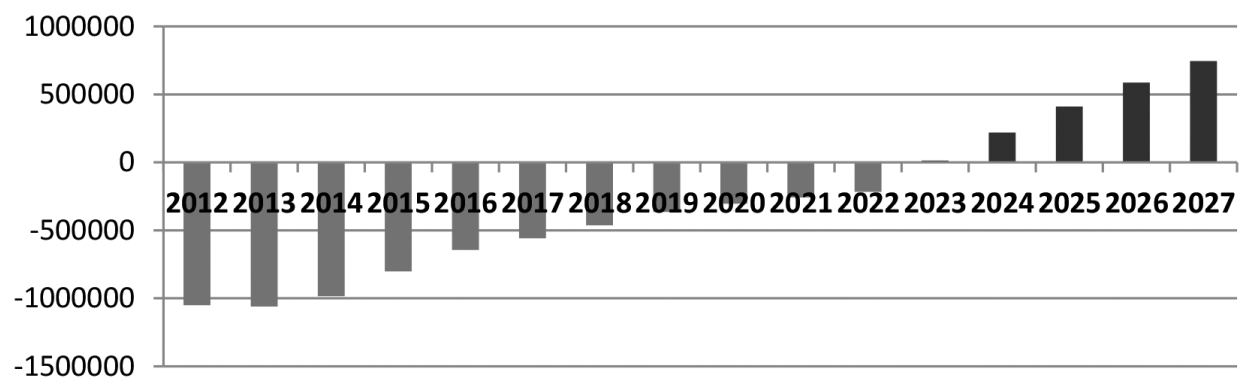

Figure 6. Discounted cumulative cash flow (in EUR)

Source: authors' processing

\subsection{The ceiling price of main input for $\mathrm{AD}$ - maize silage}

Using the calculation to determine ceiling price of input for AD we discovered that if the one ton of maize silage costs 38.913 EUR in selected period, the model biogas plant generates zero profit. If the price is less, the plant becomes profitable, the lower the price is, the more profitable the plant is. On the other hand, any price above $38.913 \mathrm{EUR} / \mathrm{T}$ makes whole project unprofitable. According to these findings the average price of maize silage during lifetime of BGPs needs to be lower than calculated ceiling price to keep the sector profitable. Risk of increasing maize silage price endangers majority of biogas plants not only in Slovakia but also in whole Europe. 
The finding is confirmed by reports from year 2013 when the price of maize silage went up to $40 \mathrm{EUR} / \mathrm{T}$ and biogas plants were generating loss as some of them admitted so. However, they were making loss, the price was not too high so they kept on production electricity to lower the loss. It can be concluded that the economic viability of biogas sector in Slovakia highly depends not only on subsidies but also on the price of maize silage which recorded significant variations over the past years. The Figure 7 shows how profitable are most of the biogas plants in Slovakia at any given price of the input - maize silage. When the revenues and other than input costs are fixed, we can estimate economic condition of biogas sector and its financial benefits for farms or firms according to price development of the maize silage.

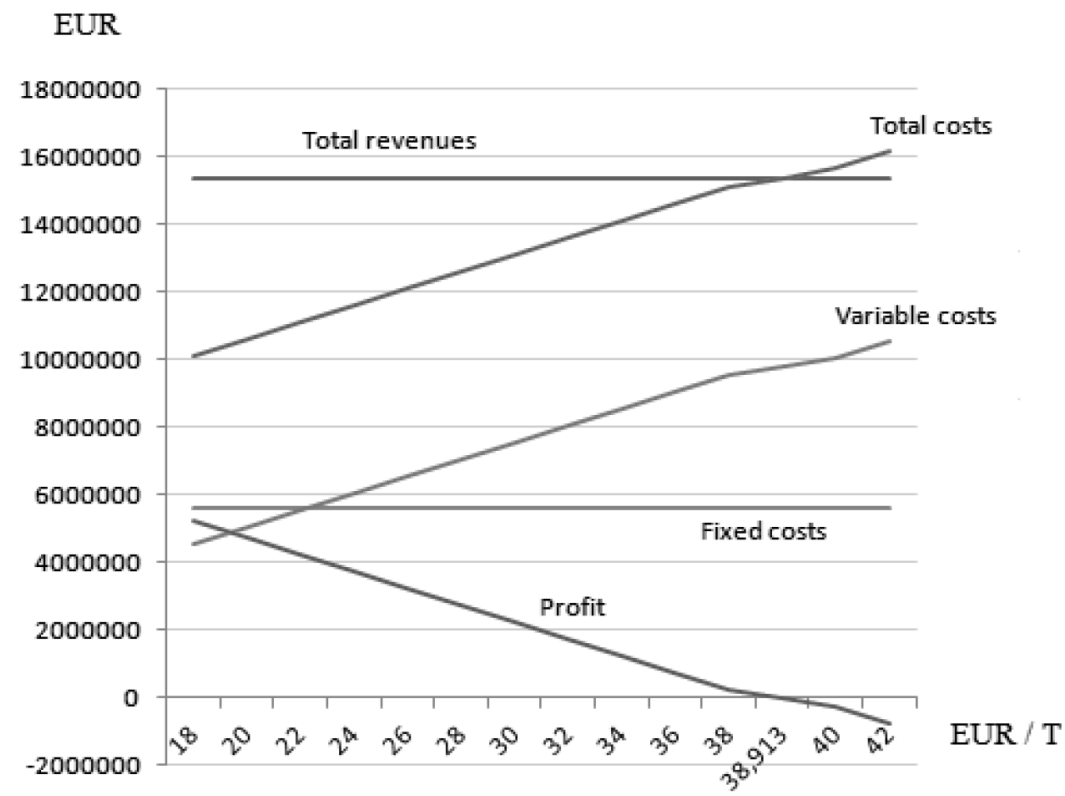

Figure 7. Profitability of BGPs in Slovakia at different prices of maize silage

Source: authors' processing

\section{CONCLUSION}

The economic viability of the sector and its benefits for investors were examined using simplified model of a biogas plant scenario as a representing sample. BGP is not only an electric power source, but most importantly, it is supposed to be a stable source of income for farmers designed to help financially as their core business is extremely dependent on weather conditions and therefore very risky. Economically vital biogas sector in Slovakia is thus critical for the investors - farmers.

According to literature and biogas sector development analysis, the biogas plant model was constructed to match the majority of Slovak BGPs to have a representative sample of the biogas sector in Slovakia - BGP lunched in 2013 with legislation support from the very same year applying fixed subsidies for the next 15 years, with however later changes in legislation (G-component) included. Scale of the plant is $1 \mathrm{MW}$ electric capacity, life time is 15 years and input material is silage maize bought for market prices. The prices were estimated on the basis of grain maize annual prices and its grain content in a ton of corn silage outlook. Calculation based on silage maize forecast predicts positive net present value. More accurately the investment since 2013 of about 3.5 million EUR with additional operation costs is supposed to be worth 745049.01 EUR in 15 years. The payback period of 10 years is estimated according to cumulated cash flow and also cumulated discounted cash flow. 
The analysis indicates economic viability of the sector, which is however, based on the accuracy of the silage maize price outlook. Such a long-term price prediction tends to be unreliable due to the too many random factors effecting the price development. The critical price of silage maize is calculated at the level of 38.92 EUR per ton. Former subsidy system was established when price of one silage ton was about 26 EUR per ton, while in 2013 the price went up to 40 EUR per ton and BGP were generating loss. In the case that the average price of silage maize is over 38.92 over the next 12 years, users of average Slovak BGP and overall Slovak biogas sector will be unprofitable, burden for farmer and the whole concept unsuccessful, waste of money and resources. In that case it will be a question if to let farmers to deal with unfavourable market conditions alone or more subsidize the sector. Moreover, it is also necessary to look for suitable substitutes for standardly used corn silage.

\section{ACKNOWLEDGEMENTS}

This paper is supported by the project VEGA no. 1/0338/18 with the title Impact of the Common Agricultural Policy on the mitigation of income risk in Slovak agriculture and factors determining the level of risk of agricultural companies.

\section{REFERENCES}

Anderson, R. G., Hoffman, D. L., \& Rasche, R. H. (2002). A vector error - correction forecasting model of the US economy. Journal of Macroeconomics, 24 (4), 569 -598. https://doi.org/10.1016/S0164-0704(02)00067-8

Baxter (2014). Biogas integration into future energy supplies. In G. M. Gübitz (Author), Conference proceedings for the international conference: BiogasScience 2014. Vienna, Austria: University of Natural Resources and Life Sciences.

Braun, R., Weiland, P., \& Wellinger, A. (2015). Biogas from Energy Crop Digestion. Retrieved from: http://www.iea-biogas.net/files/daten-redaktion/download/energycrop_def_ Low_Res.pdf

Dollhofer, V. (2014). Pretreatment with anaerobic fungi, a solution to improve digestion of recalcitrant substrates? In G. M. Gübitz (Author), Conference proceedings for the international conference: BiogasScience 2014. Vienna, Austria: University of Natural Resources and Life Sciences.

EnergiePortal (2017). Biogas plants in SR (Bioplynové stanice v SR). Retrieved from: https://www. energie-portal.sk/Dokument/bioplynove-stanice-v-sr-100191.aspx

Engler R. J., Jordan, E. J., McFarland, M. J., Lacewell, R. D. (2013). Economics and environmental impact of biogas production as a manure management strategy. 109-114. Retrieved from: $<$ https://www.agmrc.org/media/cms/Engler2_F05E9EA9371B6.pdf $>$

European Biomass Association (2013). A Biogas Road Map for Europe. Retrieved from: $<$ http://www.aebiom.org/IMG/pdf/Brochure_BiogasRoadmap_WEB.pdf $>$

Food and Agriculture Organization of the United Nations (FAOSTAT). Crops. [statistics]. Retrieved from: http://www.fao.org/faostat/en/\#data/QC

Gebrezgabher, S. A., Meuwissen, M. P. M., Prins, B. A. M., \& Oude Lansing, A. G. J. M. (2010). Economic analysis of anaerobic digestion - A case of Green power biogas plant in The Netherlands. NJAS - Wageningen Journal of Life Science, 57, 109-115.

https://doi.org/10.1016/j.njas.2009.07.006

Gangopadhyay, K., Jangir, A., \& Sensarma, R. (2016). Forecasting the price of gold: An error correction approach. IIMB Management Review, 20 (1), 6 - 12.https://doi.org/10.1016/j.iimb.2015.11.001 
Holm-Nielsen, J. B., Al Seadi, T., \& Oleskowicz-Popiel, P. (2009). The future of anaerobic digestion and biogas utilization. Biosource Technology, 100 (22), 5478-5484. https://doi.org/10.1016/j.biortech.2008.12.046

Lippert, M. (n.d.). Calculating Grain Yield Utilizing a Corn Silage Forage Test. Retrieved from < https://fyi.uwex.edu/forage/files/2016/10/GrainYieldfromCornSilageII.pdf>

Mészáros, A., \& Jašňák, P. (2014). Economic efficiency of the biogas plant (Ekonomická efektívnost' bioplynovej stanice). Elektroenergetika, 7 (2), 9-14.

Patinvoh, R. J., Osadolor, O. A., Horváth, I. S., \& Taherzadeh, M. J. (2017). Cost effective dry anaerobic digestion in textile bioreactors: Experimental and economic evaluation. Bioresource Technology, 245, 549-559. https://doi.org/10.1016/j.biortech.2017.08.081

Pepich, Š. et al. (2010). Usage of agricultural biomass for energy purposes and its impact on sustainable development (Využitie pol’nohospodárskej biomasy na energetické účely a jej vplyv na trvalo udržatel'ný rozvoj).

Retrieved from: <http://www.tsup.sk/files/vyuzitie_poln.biomasy_na_energet.ucely.pdf $>$

Santadkha, T., \& Skolpap, W. (2017). Economic Comparative Evaluation of Combination of Activated Carbon Generation and Spent Activated Carbon Regeneration Plants. Journal of Engineering Science and Technology, 12 (12), 3329-3343.

Weil, R.M., \& Maher, M.W. (2005). Handbook of Cost Management (2nd ed.). Hoboken, New Jersey: JohnWiley \& Sons, Inc.

Wellinger, A. (2014). Challenges and opportunities. In G. M. Gübitz (Author), Conference proceedings for the international conference: BiogasScience 2014. Vienna, Austria: University of Natural Resources and Life Sciences. 



\title{
THE EFFICIENCY OF PUBLIC HIGHER EDUCATION INVESTMENT ON ECONOMIC GROWTH IN VIETNAM
}

\author{
Thi Hoai Trinh Nguyen ${ }^{1}$ (D) \\ Viet An Kieu ${ }^{2}$ (iD \\ Thi Cam Nhung Dao ${ }^{3}$ it
}

DOI: https://doi.org/10.31410/ERAZ.S.P.2020.53

\begin{abstract}
The purpose of this article is to evaluate the efficiency of public higher education investment in Vietnam's economic growth through data reports from the Ministry of Education and Training, Ministry of Finance, the General Statistics Office, and the primary investigation of the authors. The paper focuses on an in-depth analysis of the costs of investing in higher education, such as state budget spending on higher education, the impact of budget expenditure on growth, individual investment (household) investment in public higher education, social costs for higher education public study, and average social cost for one learner. From the above analysis, the authors will present employment status and the impact of the problem on both economic growth and the average income of workers by technical expertise.

Besides, the authors will compare the situation of investment in higher education and the economic growth rate of Vietnam to some countries in Southeast Asia. From there, the authors will determine the limitations of this impact process. Based on that, the authors will propose some solutions to improve the efficiency of investment in public higher education for Vietnam's economic growth.
\end{abstract}

Keywords: Investment efficiency, Higher education, Economic growth.

\section{INTRODUCTION}

$\mathrm{E}$ conomic growth and development is always the top goal of many countries in the world, including Vietnam. In order to have a developed economy, a civilized society requires a developed human resource in both physically and intellectually. In the context of the knowledge economy, the human element plays a significant role. Higher education is the critical force to shoulder that task, and also a breakthrough division of high-quality human resources in the country's socio-economic development strategy.

Determining the importance of higher education, Vietnam has many investment policies for higher education. This paper focuses on the effectiveness of higher education investment in economic growth in Vietnam.

\section{LITERATURE REVIEW}

Education in general and higher education in particular, is a form of investment (investment in developing human capital) (Hien, 2016). Investment efficiency is an economical category expressing a comparative relation between socio-economic results, objectives achieved from investment activities, and the costs to obtain those results in a certain period (Phuong \& Hung, 2013).

\footnotetext{
$1 \quad$ Bucharest University of Economic Studies, Bucharest, Piața Romană 6, Romania

2 Technical University of Civil Engineering of Bucharest, Bulevardul Lacul Tei 124, Bucharest, Romania

3 Hue College of Economics - Hue University, Hue City, Thua Thien Hue Province, Vietnam
} 
Higher education is a long-term and profitable investment guaranteed in the form of highly skilled labor resources and geared to the needs of social development, promoting economic growth and society quality improvement (Yogish, 2006). Discussing the relationship of education to economic growth, many studies such as Hong, 2019 assessed the level of education's contribution to Vietnam's economic development since the 2005 Education Law came into effect. The research results show a particular impact of education and policies to encourage education on economic growth. Alternatively, (Hung N. T., 2015) has affirmed that policies on investment in education and economic growth are positively related to each other. (Daiva , 2015) asserts in a study that economic growth and social welfare depend mainly on the quality of human resources. Thus, education policy is considered to have a significant impact on economic development. (Long \& Nhan, 2018) validated the impact of education on economic growth by applying a neoclassical growth model with expanded Cobb-Douglas production function. The results show that a group of factors: the average number of years of schooling of the labor force, the budget expenditure for education, physical capital, labor force, have a statistically significant impact on economic growth. (Hung, 2016) studied the impact of human resources on Vietnam's economic growth. The study used the ARDL self-regression delay distribution method and Eviews software to process the data. (Tho, 2019) proposes major solutions and suggests macro policies to mobilize and effectively use resources to promote economic growth. (Vu, et al., 2012) discusses the impact of vocational and higher education on economic growth by using SGMM dashboard data and Estimations of simultaneous equations FE3SLS. The results show both types of higher education and vocational education have a two-way causal relationship with economic growth, but vocational education seems to have a more significant impact on economic growth than higher education. (Yan, et al., 2009) used unified analytic theory and the Granger experiment to test the relationship between higher education and economic growth. The results show that from 1978 to 2006, the relationship between the two sides was stable and lastingly equilibrium. Moreover, it shows that economic growth is the main reason for the development of higher education, but no significant figures are showing how important educational development contributes to economic growth. (Yu, et al., 2014) using the Johansen test, the Granger causality test, the impulse response function, variance analysis, and other empirical methods based on the spontaneous vector model. The results show a long-term and stable relationship between higher education investment, human capital investment, and economic growth. Specifically, higher education investment and human capital investment have a significant positive impact on economic growth. Higher education investment is the cause of economic growth, and investment in higher education can promote economic growth. (Stevanovic, et al., 2018) also shows a positive and statistically significant correlation between per capita GDP and national intellectual capital measures.

\section{METHODOLOGY}

In this article, in order to get an overview of the context of Vietnam in the issue of higher education investment efficiency for economic growth, the authors will conduct the study in the following steps.

Step 1. Aggregate data from the General Statistics Office and government information on the respective websites

Step 2. Collect and research the previous research documents to compare and draw out the research direction.

Step 3. Calculate state budget expenditure and the impact of state budget expenditure on higher education on GDP 
State budget $=$ Central budget + Local budget
Proportion of state budget
Proportion of state budget expenditure for higher education

$$
=\frac{\begin{array}{c}
\text { Proportion of state budget } \\
\text { expenditure for higher education }
\end{array}}{\text { Total state budget }} \times 100 \%
$$

Step 4. Calculate social costs for higher education

Step 5. Present the status of employment by qualification.

Step 6. Compare Vietnam's average labor income and GDP with other countries.

Step 7. Present limitations and propose solutions that, according to the authors, are appropriate and highly practical to solve research problems.

\section{RESULT \& DISCUSSION}

Vietnam is a country that attaches great importance to education, as in party congress and government documents resolutions, ,investment in education is an investment for development.” In particular, in the era of technology 4.0, when the demand for high-quality human resources is always high, the Vietnamese government gradually focuses on investment in higher education.

Table 1. State budget expenditure and impact of state budget expenditure on higher education on economic growth

\begin{tabular}{|l|r|r|r|r|}
\hline & \multicolumn{1}{|c|}{$\mathbf{2 0 1 6}$} & $\mathbf{2 0 1 7}$ & $\mathbf{2 0 1 8}$ & $\mathbf{2 0 1 9}$ \\
\hline $\begin{array}{l}\text { Total state budget balance } \\
\text { (billion USD) }\end{array}$ & $\mathbf{5 4 , 6 3}$ & $\mathbf{5 9 , 6 7}$ & $\mathbf{6 5 , 3 6}$ & $\mathbf{7 0 , 0 9}$ \\
\hline $\begin{array}{l}\text { Total state budget expenditure } \\
\text { for education }\end{array}$ & $\mathbf{8 , 4 0 6 7}$ & $\mathbf{9 , 2 4 7 4}$ & $\mathbf{9 , 8 4 7 0}$ & $\mathbf{1 0 , 5 2 4 5}$ \\
\hline Budget spending for higher education & 0,84 & 0,89 & 0,98 & 1,05 \\
\hline $\begin{array}{l}\text { The ratio between the budget } \\
\text { expenditure on higher education } \\
\text { and education }\end{array}$ & 9,99 & 9,62 & 9,95 & 9,97 \\
\hline GDP (billion USD) & 205,3 & 223,9 & 240,5 & 266,5 \\
\hline $\begin{array}{l}\text { The ratio of budget expenditure } \\
\text { for higher education to GDP }\end{array}$ & 0,41 & 0,40 & 0,41 & 0,39 \\
\hline
\end{tabular}

Source: the author's calculations based on Government Final Report

In the expenditure structure by the level of education, the proportion of expenditure on higher education is approximately $10 \%$, which is only $0.39-0.41 \%$ of GDP. This low percentage directly affects the quality of training of higher education and vocational education, making it difficult to compete with other countries in the region and around the world. Meanwhile, the human resource from higher education are the ones directly playing an essential role in the economy, because it is responsible for well-trained human resources, with high efficiency (productivity) in companies (Naros, M-S; Simionescu, M; 2019)

The assumption that the social costs of investment in higher education made up of two main sources: state budget investment and household investment, the average social investment for a learner is as follows: 
Table 2. Social costs for higher education

\begin{tabular}{|l|r|r|r|}
\hline & $\mathbf{2 0 1 7}$ & $\mathbf{2 0 1 8}$ & $\mathbf{2}$ \\
\hline $\begin{array}{l}\text { Average state budget expenditure } \\
\text { per learner (USD) }\end{array}$ & 630 & 594 & 627 \\
\hline Proportion (\%) & 49 & 43 & 45 \\
\hline $\begin{array}{l}\text { Average household expenditure } \\
\text { per learner (USD) }\end{array}$ & 656 & 787 & 766 \\
\hline Proportion (\%) & 51 & 57 & 55 \\
\hline Total & 1286 & 1381 & 1393 \\
\hline
\end{tabular}

Source: the author's calculations based on the data of the Ministry of Finance, government website information.

The capital structure for higher education also shows the effort of government support through state budget spending in the context of the limited state budget. The low proportion of state investment in higher education compared to households reflects that the state focuses on investment in low levels of education, such as high school, preschool, and primary school. In general, compared with advanced countries, the social investment cost for higher education in Vietnam is still low.

The primary purpose of higher education is to train high-quality human resources, fully meet the criteria of the business, and create jobs for workers.

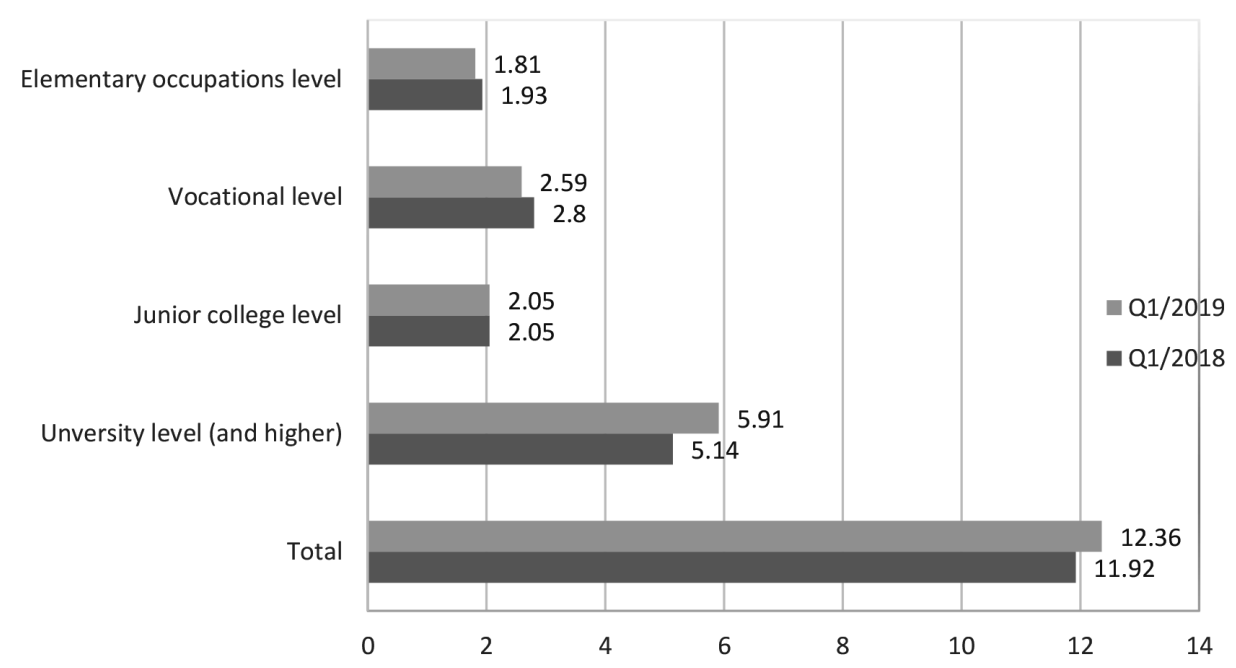

Chart 1. Employment status of employees. Unit: million people

Source: The Ministry of Labour Invalids and Social Affairs

Considering the statistics in the first quarter of 2019 and the same period in 2018, the author found that, among the total of 12.36 million people of working age, the highest number of employees belongs to people with university degrees. This number shows that market demand still prioritizes people with university degrees and above. At the same time, university graduates have a higher chance of employment than others.

On the other hand, the final result of higher education is the average income of the laborers. The following chart shows employees income as of 2019 


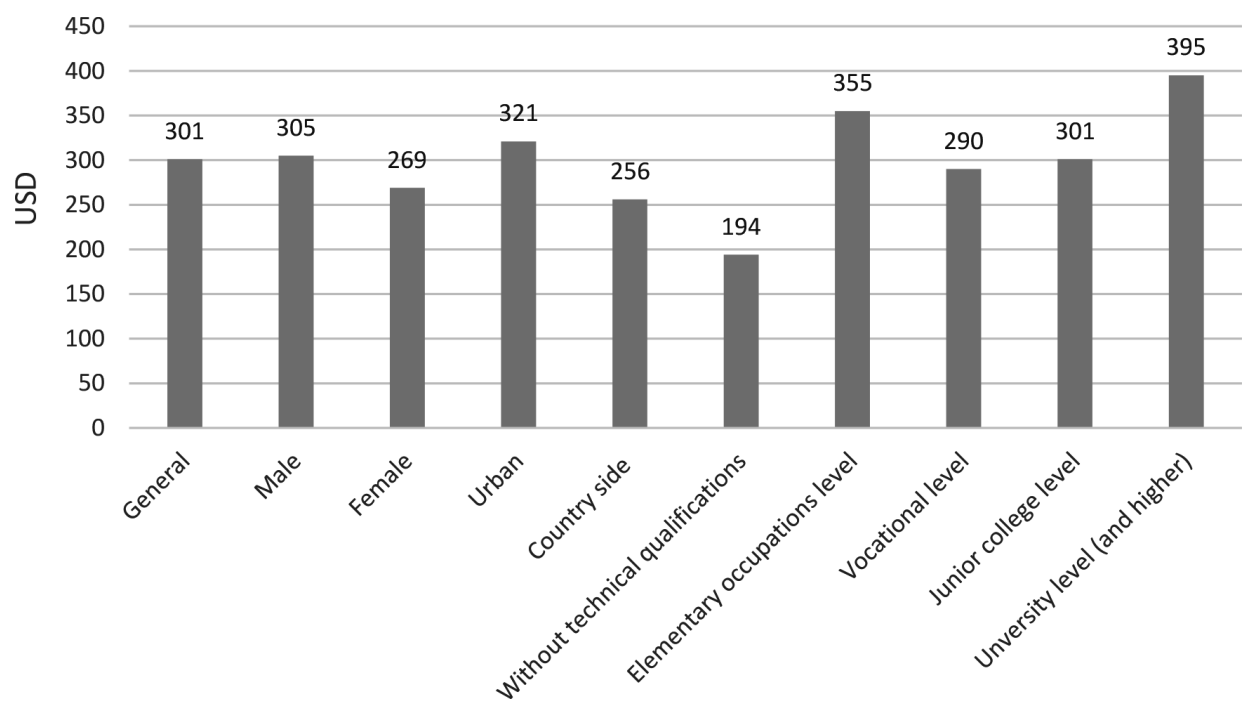

Chart 2. Average income of Vietnamese employees

Source: the author's calculations based on data of the Ministry of Labor - Invalids and Social Affairs

In terms of gender structure, the average income of men is higher than that of women. In terms of the regional structure, urban areas have higher incomes than rural areas with a difference of approximately 60 USD. In terms of technical qualifications, people with university-level (or higher) have higher incomes than lower levels, and people without technical qualifications have a stunted income (194 USD). However, from an international perspective, the income of Vietnamese workers compared to other countries in Southeast Asia is lower as shown in the following table:

Table 3. Comparison of average income of workers in countries in Southeast Asia

\begin{tabular}{|c|c|}
\hline Country & Basic salary (USD) \\
\hline Vietnam & $384-582$ \\
\hline Singapore & $2087-2927$ \\
\hline Malaysia & $959-1417$ \\
\hline Philippines & $502-725$ \\
\hline Indonesia & $397-571$ \\
\hline
\end{tabular}

Source: the author's calculations based on street.com data

Except for Indonesia, which has a salary similar to Vietnam, employees in Singapore, Malaysia, and the Philippines are remarkably well paid. For example, the salary in the Philippines is currently about 1.5 times higher than Vietnam. The differences are even higher in the case of Malaysia (nearly three times) and Singapore (nearly six times).

This difference also varies by position, most prominently among graduates and staff. Specifically, the average salary of a newly graduated student in Vietnam is 250-387 USD, while this number in Singapore is 1,337-1,879 USD.

Human resource is a decisive factor in the realization of socio-economic goals, and it also determines the process of accelerating industrialization and modernization of the country in order to quickly integrate the Vietnamese economy with the region and the world. After all, it is people that are the most basic and essential element of the entire production force. 


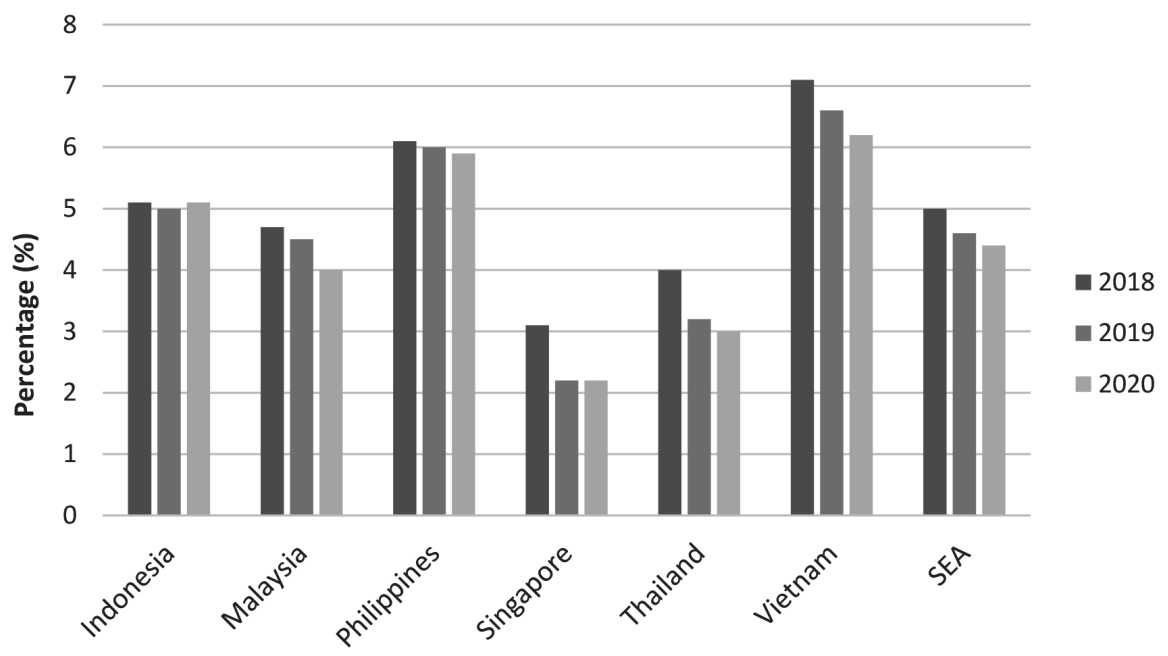

Chart 3. Vietnam's economic growth rate and regional countries

Source: Oxford Economics/Haver Analytics

According to the chart, the overall economic growth of Southeast Asia in the first half of 2019 only reached $4 \%$ compared to $4.5 \%$ in the same period of 2018 . Only Vietnam and Philippines have a remarkable economic growth rate compared to the region.

\section{CONCLUSION}

\section{Limitations}

a. Through the research process, the authors found that the effectiveness of investment in higher education and economic growth is not in the positive direction. Low investment in higher education does not entail slow growth. The role of human resources for higher education has not fully developed its capacity.

b. The average income of laborers is still low compared to other countries in the region. The main reasons come from two factors: skills and attitude (discipline, lack of passion) (WB, 2012). The causes are:

i. Firstly, individual and household investments are formal, focusing on degrees instead of investment efficiency.

ii. Secondly, the training program has not yet adapted to the capacity of the learners; the schools are still not autonomous in terms of the curriculum; the content is theoretical and far from reality.

iii. Thirdly, the universities have not focused on vocational education and professional ethics for students.

c. Higher education still depends too much on capital coming from the state budget and households and has not expanded to attract outside investment, and lacks autonomy.

\section{Solutions}

Based on the above limitations, the author proposes the following main solutions:

a. Innovate investment in higher education towards cost-sharing, burden-sharing with the state through increasing tuition fees step by step. Change the method of funding to ensure quality and fairness. 
b. Increase the attraction of capital sources for higher education through the form of student credit, calling for investment from businesses, investment from the form of linking abroad advanced programs.

c. Enhance the autonomy and accountability of universities. The university should be self-reliant in terms of personnel to have a qualified faculty of ethics. Promote academic autonomy to take the initiative and develop curricula suitable for students as well as international standards. Promote financial autonomy to determine tuition fees and reasonable allocation of the state budget.

d. Develop the learners' capacity, focus on vocational education, and improve professional ethics for students, meeting the needs of socio-economic development.

e. Study to adjust reasonable wage policy for employees because salary will be the primary motivation to promote the creative capacity and dedication of employees. At the same time, an excellent salary policy will retain talents and avoid brain drain.

\section{REFERENCES}

Daiva , D. (2015). The Impact of education policy to country economic development. Procedia - Social and Behavioral Sciences, (pp. 2427-2436).

Hien, D. T. (2016). Investment efficiency for public higher education in Vietnam in the direction of access to cost benefits. PhD thesis in Economics, National Economics University.

Hung, N. N. (2016). The impact of human resources on Vietnam's economic growth. Financial Magazine.

Hung, N. T. (2015). The relationship between economic growth and education budget in Vietnam during 2000-2012. Journal of Development \& Integration.

Long, P. D., \& Nhan, L. T. (2018). Impacts of education on economic growth of provinces in the central Vietnam. Journal of Science and Technology of Danang University.

Naros, M-S; Simionescu, M;. (2019). The role of education in ensuring skilled human capital for companies, Theoretical and Empirical Researches in Urban Management., (pp. 77-84).

Phuong, T., \& Hung, P. (2013). Report on investment economics. National Economic University.

Stevanovic, T., Ivanovic-Dukic, M., Radenovic, T., \& Radovic, O. (2018). The impact of national intellectual capital on the economic growth in the South-Eastern European Countries. ZBORNIK RADOVA EKONOMSKOG FAKULTETA U RIJECI-PROCEEDINGS OF RIJEKA FACULTY OF ECONOMICS.

Tho, T. B. (2019). Roles and solutions regarding human resources for the situation of economic growth in Vietnam. Journal of Industry and Trade.

$\mathrm{Vu}, \mathrm{T} .$, Hammes, D., \& Im, E. (2012). Vocational or university education? A new look at their effects on economic growth. Economics Letters, 426-428.

Yan, W., Zeng, P., \& Yang, D. (2009). Co-integration Analysis between Higher Education Investment and Regional Economic Development in Guangxi Province. VOL 2: ECONOMIC POLICIES, PLANNING AND ASSESSMENT. PROCEEDINGS OF THE 2009 INTERNATIONAL CONFERENCE ON PUBLIC ECONOMICS AND MANAGEMENT ICPEM 2009.

Yogish, S. N. (2006). Education and Economic Development. Indian Journal of Social Development.

Yu, H., Zhao, S., Xu, X., \& Wang, Y. (2014). An Empirical Study on the Dynamic Relationship between Higher Educational Investment and Economic Growth using VAR Model. SYSTEMS RESEARCH AND BEHAVIORAL SCIENCE. 



\title{
FINANCIAL LITERACY OF UNIVERSITY STUDENTS MEASURED BY P-FIN INDEX
}

\author{
Josef Polák ${ }^{1}$ \\ Zuzana Kozubíková2 ${ }^{10}$ \\ Aleš Kozubík ${ }^{3}$
}

DOI: https://doi.org/10.31410/ERAZ.S.P.2020.61

\begin{abstract}
Financial literacy belongs to the most important competences of all members of the modern 21-st century society. The authors present results of the research based on the personal finance index that is recently developed an innovative measure of knowledge. The questionnaire research that has been conducted among the students of two universities in the Czech and Slovak republic. It focused on full-time and part-time students with the aim to verify the suggestion that practical experience of distance learning students has a significant impact on the level of their financial literacy. Statistical analysis of the data shows, that part-time students have achieved better results in all functional areas of the personal finance index. Based on these findings authors also drew some conclusions for improving education in this field.
\end{abstract}

Keywords: Financial education, Financial management, Financial decision making, Statistical methods, Questionnaire survey.

\section{INTRODUCTION}

$\mathrm{T}$ he growing development of new technologies accompanies our lives at the beginning of the $21^{\text {st }}$ century. On the one hand, these technologies help us, but at the same time, they make our lives more complicated. We need much more knowledge and technical skills to master and use them effectively. In today's modern world, the classic notion of literacy as the ability to read and write is no longer sufficient, but new types of literacy with different adjectives are needed. We can mention, for example, computer literacy, which is frequently extended to digital literacy, informational literacy, and similar. Last but not least, we can also include financial literacy here. Financial markets offer many new products that are difficult to understand. The digital environment has simplified access to new products, which are increasingly attracting small investors. Financial literacy is therefore a key factor in maintaining financial stability in professional and as well in personal life.

We make the most important, long-term financial decisions (such as pension plans or choosing the most suitable way of financing housing) only a few times in our lives. Moreover, these decisions are often made by people at a young age, when they do not yet have enough experience. Teaching financial literacy in schools is a tool to help young people understand financial matters and orient themselves in increasingly complex financial instruments and services.

1 College of Regional Development and Banking Institute - AMBIS, Department of Economics and Management, Lindnerova 575/1, 18000 Praha 8, Czech Republic

2 University of Žilina, Faculty of Managements and Informatics, Dpt. of Macro and Microeconomics, Univerzitná 8215/1, 01026 Žilina, Slovakia

3 University of Žilina, Faculty of Managements and Informatics, Dpt. of Mathematical Methods and Operations Research, Univerzitná 8215/1, 01026 Žilina, Slovakia 
The importance of financial literacy is also confirmed in the current post-COVID era which tested the knowledge and skills of individuals, companies and government institutions in areas such as risk management, investment decisions and cash flow management. It is also essential to orient oneself correctly in all protective measures and government support programs. In the event of indebtedness, it is necessary to make the right decision on the deferral of payments and evaluate the future financial burden. Also, in the banking services market, a number of new programs for merging loans at new interest rates and the like are emerging. This can be a financial trap for an insufficiently financially literate individual.

In this article, we present the results of our research on financial literacy among the university students of the full-time and combined study. Our research aimed to verify whether the everyday practical experience of distance learning students has a positive impact on the level of their financial literacy when compared with the full-time students. Based on the results of our abbreviated preliminary research, which we published (Polák, Kozubíková, \& Kozubík, 2018) and (Kozubík, Kozubíková, \& Polák, 2019), we formulated our research hypothesis

H1: Part-time students achieve a better level of financial literacy than full-time students.

If we take into account the fact that overall financial literacy includes several functional areas, it is natural to assume that knowledge is unevenly distributed between these areas. However, we wanted to verify whether practical experience tends to reduce these differences. We have formulated the second research hypothesis:

H2: Differences in results in individual areas of financial literacy are not as significant for parttime students as for full-time students.

These results are then important in the process of improving the quality of teaching in order to increase financial literacy and contextual thinking.

\section{LITERATURE SURVEY}

Financial literacy is generally understood as the ability to comprehend finance. We can illustrate it with the simple definition given by Kim. Financial literacy is the basic knowledge that people need in order to survive in a modern society. (Kim, 2001) According to Mandell, it is the ability to evaluate the new and complex financial instruments and make informed judgments about both: choices of instruments and extent of use that would be in their own best long-run interests. (Mandell, 2007) Here are also approaches that refer to the set of competencies that allow an individual to make informed and effective decisions through their understanding of finances. We can mention for example the following: The ability to understand how money works in the world: how someone manages to earn or make it, how that person manages it, how he/she invests it (turn it into more) and how that person donates it to help others. (Giesler \& Veresiu, 2014) For the purposes of our research, we have adopted the definition of a financially literate individual as: A person who uses his ability to make a qualified judgment on the basis of the knowledge, skills and experience gained thus enabling him to smooth financial security throughout life. (Kozubíková, 2015).

In the past, several papers have been published dealing with the relationship of financial literacy with various factors. A strong positive relationship between financial literacy and household wealth is reported in (van Rooij, Lusardi, \& Alessie, 2012). As well (Behrman, Mitchell, Soo, 
\& Bravo, 2012) argued that investments in financial literacy could have large positive effects on household wealth accumulation. A strong association, between small business success and financial literacy, was found in (Dahmen \& Rodríguez, 2014). The relationship between financial literacy and retirement planning was proven in (Klapper \& Panos, 2011). These authors have shown financial literacy is significantly and positively related to retirement planning involving private pension funds. All mentioned works undoubtedly confirm the enormous importance of financial literacy and the importance of financial education.

\section{METHODS AND DATA}

To measure students' financial literacy, we used an innovative tool introduced in (Lusardi, Yakoboski, \& Oggero, The TIAA Institute-GFLEC Personal Finance Index: A New Measure of Financial Literacy, 2017) as a personal finance index (shortly P-Fin index). This tool measures the knowledge and level of comprehension that enables effectively manage personal finances and financial decision-making. It is designed to completely cover the eight areas of financial literacy that an individual commonly encounters in managing personal finances. These areas are:

- earnings, determinants of wages and income,

- consuming, budgeting and spending,

- saving, comprehension the accumulation factors,

- investing, understanding the types and risks of investments,

- borrowing and debt management,

- risk management, comprehension the uncertain outcomes,

- insurance and the understanding of coverages,

- accessing and working with information sources.

This approach enables us to interpret the P-Fin index either as the total score (percentage success rate) of the whole knowledge test or as an ordered 8-tuple, where each component corresponds to one area of financial literacy, mentioned above. In this way, we can then effectively detect possible inequalities in knowledge.

We obtained data for our analysis in the form of a questionnaire survey. Our questionnaire consisted of 30 questions, three or four of them focused on individual areas of financial literacy. Respondents entered the answers as a choice of four options, one of which was correct, and one option was „I don't know” answer. In addition to knowledge questions, the questionnaire contained questions on the survey of socio-demographic data such as age, gender, education, size of residence, etc., as well as questions on the self-reflexive evaluation of respondents and their experience with financial services.

We conducted our survey at two universities, one in the Slovak Republic and the other in the Czech Republic. In our research, we focused on students of management, where we can assume that in the future, in addition to personal finances, they will frequently decide on corporate or public finances, which increases the need for their adequate financial literacy.

In total, we have distributed the questionnaire among 540 respondents. After removing the maliciously completed questionnaires (we discarded the questionnaires, which contained more than 50 percent of „I don't know” answers), we obtained 449 answer sheets, which represents a relatively high response level of approximately $83 \%$. The obtained sample contained 145 respondents of the part-time form of study and 304 respondents of full-time study. Thus, both 
subsamples had sufficient size to apply methods of the statistical analysis, especially the descriptive statistics and hypotheses testing. All direct calculations have run in a specialized open statistical environment R.

\section{RESULTS}

From the obtained demographic information, we can present some basic characteristics of our dataset. Our sample contained $42.6 \%$ women and 57.4\% men. So it was gender-balanced concerning the ratio of men and women among students, where, especially in connection with informatics, there is an increased interest in studying from men. In terms of age, our sample is dominated by young people aged 18 to 25 years. They represent almost $74 \%$ of respondents, which is natural in terms of the focus of the survey. In our sample, the inhabitants of rural settlements, small towns, and large agglomerations were relatively uniformly represented in shares of $34 \%, 36 \%$, and $30 \%$.

We have summarized the descriptive statistics of the final P-Fin index values in Table 1. There we present the results for the whole sample, as well as in the breakdown for individual forms of study. Here we can notice that the part-time students achieved better values than full-time students. This is especially clear for the average value of the P-Fin index and all quartiles. Only the weakest results and best results do not differ much.

Table 1. Descriptive statistics of the P-Fin scores for whole sample and separately for full-time and part-time students

\begin{tabular}{|c|c|c|c|c|c|c|}
\cline { 2 - 7 } \multicolumn{1}{c|}{} & Min. & 1-st Quartile & Median & Mean & 3-rd Quartile & Max \\
\hline Whole & 0.10 & 0.43 & 0.53 & 0.52 & 0.60 & 0.93 \\
\hline Full-time & 0.10 & 0.40 & 0.50 & 0.48 & 0.57 & 0.90 \\
\hline Part-time & 0.17 & 0.53 & 0.60 & 0.61 & 0.73 & 0.93 \\
\hline
\end{tabular}

\section{Source: Own elaboration}

We have verified the higher average P-Fin scores in the group of part-time students by one-sided two sample Welch's $t$-test of the equality of means hypothesis. The results of the test we summarized in Table 2. It is obvious that the hypothesis can be rejected with a very high confidence level. Similar to the total scores of the P-Fin index, we performed the appropriate statistical tests of hypotheses for its individual components. In all eight cases, the hypothesis of equality of mean values could be rejected. To save space, instead of an extensive table, we only mention the fact that the respective $p$-values ranged from $210^{-16}$ to 0.018 . This statistical test result is a confirmation of our research hypothesis that part-time students achieve better results than full-time students. This hypothesis proved to be true not only for the P-Fin index as a whole but also for all its functional areas.

Table 2. Results of the two sample Welch's t-test for the means of P-Fins scores of the full-time and part-time students

\begin{tabular}{|c|c|c|c|}
\cline { 2 - 3 } \multicolumn{1}{c|}{} & Mean & $\boldsymbol{t}$-statistics & $\boldsymbol{p}$-value \\
\hline Full-time & $48.4 \%$ & -8.4789 & $1.15 \cdot 10^{-15}$ \\
\hline Part-time & $60.9 \%$ & \\
\hline
\end{tabular}

Source: Own elaboration

Figure 1 graphically illustrates the distribution of correct and incorrect answers across the PFin index functional areas. While Figure 1 presents the distribution in the whole sample, Figure 2 and Figure 3 illustrate the results for the full-time and part-time students respectively. One can easily observe a positive shift of the part-time students' answers. Here we see a reduced portion of the „I don't know answers". Moreover, this shift increases the portion of the correct answer. 


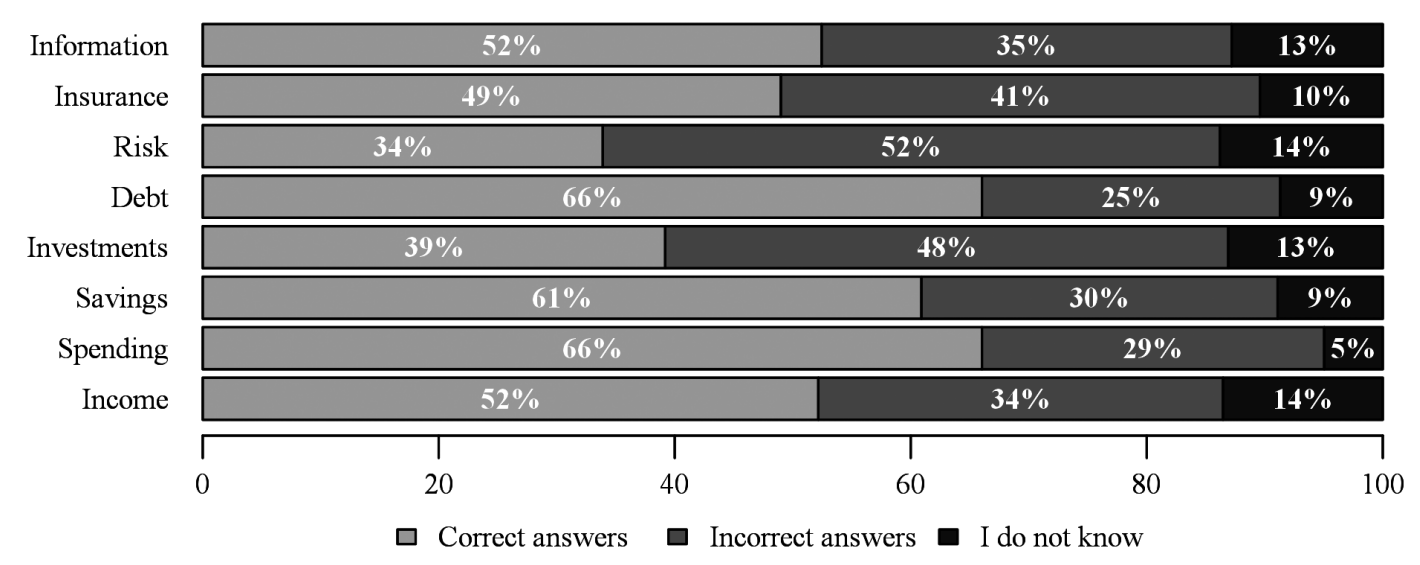

Figure 1. Percentages of correct and incorrect answers and „don’t know” answers

Source: Own elaboration

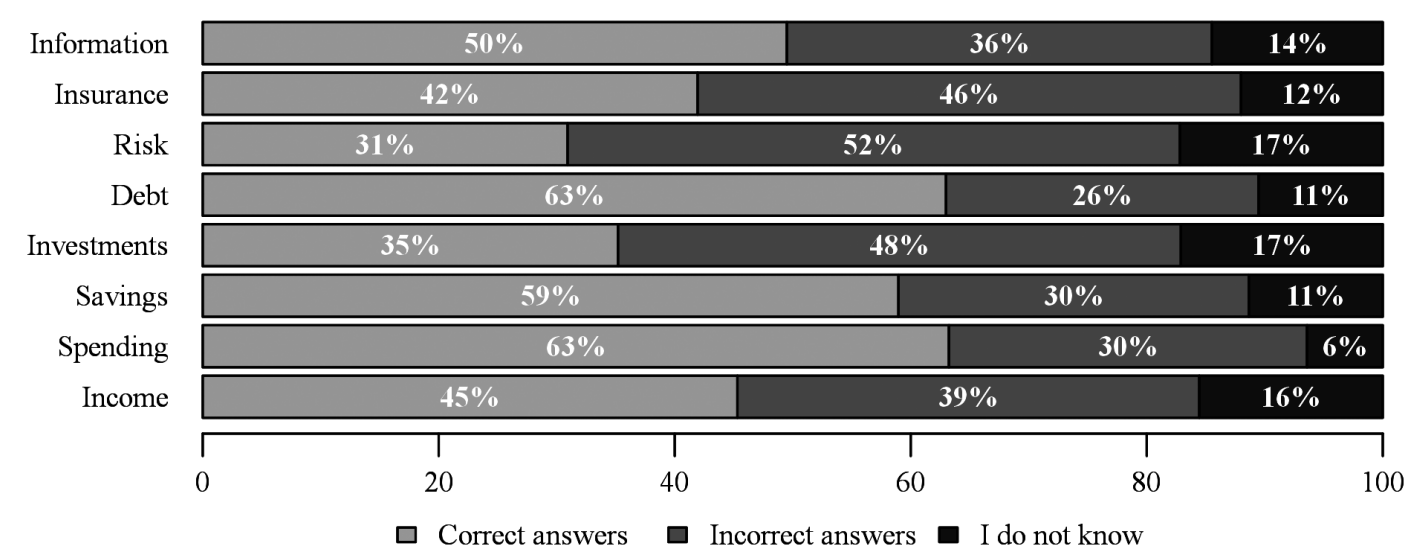

Figure 2. Percentages of correct and incorrect answers and „don't know” answers of full-time students

Source: Own elaboration

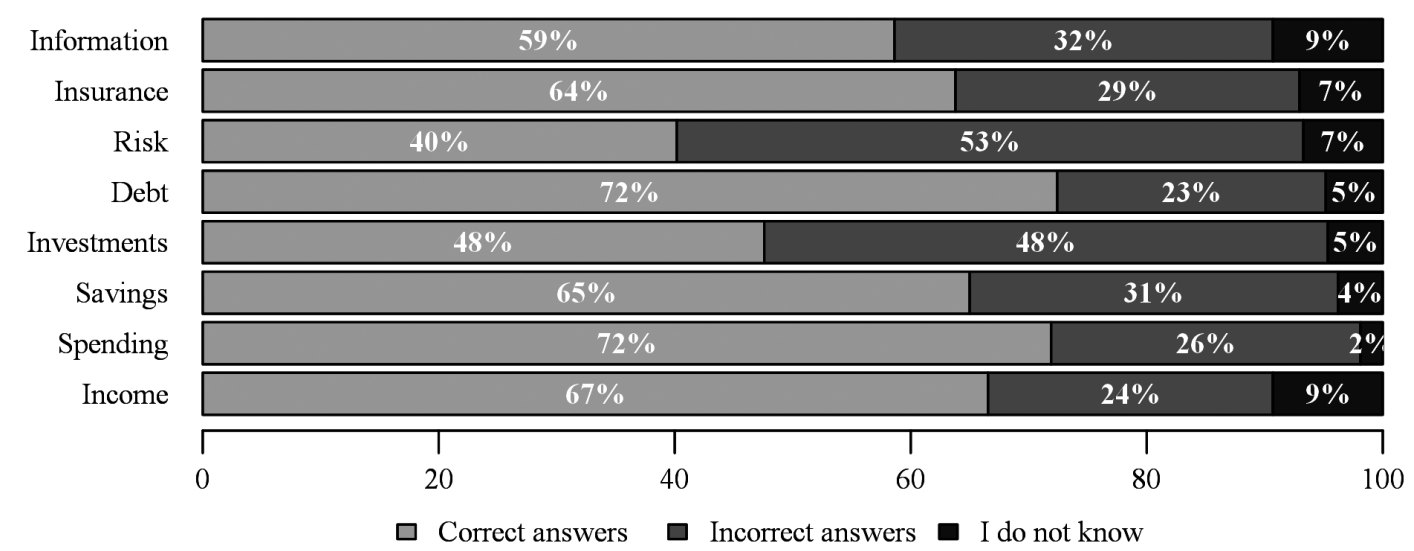

Figure 3. Percentages of correct and incorrect answers and „don’t know” answers of part-time students

Source: Own elaboration

Although we confirmed better results in part-time students, both groups show similar features in the individual components of the P-Fin index. This is clearly visible in the radar graphs in Figure 4. In both groups of students, we observe a significant drop in average scores in the areas of investment and in understanding and managing risk. 

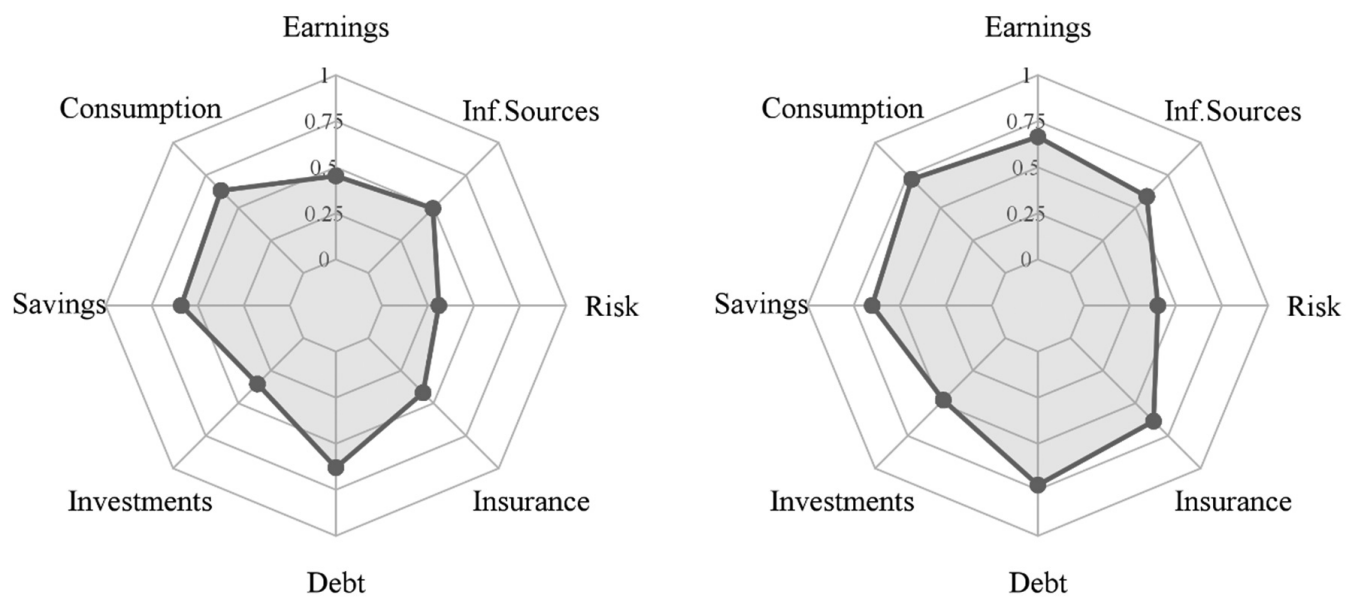

Figure 4. Radar graph of average scores of full-time students (left-hand side) and part-time students (right-hand side) by single areas of the P-Fin index

Source: Own elaboration

\section{DISCUSSION}

The results of our analysis show that part-time students achieve a better level of financial literacy than full-time students. This also confirms the validity of our research hypothesis H1. This state can be justified for several reasons. One of the primary reasons we see in the fact that parttime students come into contact with problems related to financial literacy competencies in their everyday practical life. Not only they often have to deal with financial decisions that result from their working position, but many of them also control their family budgets.

An important attribute of part-time students is their higher average age. While full-time students are all in the age group of 18-25 years (mostly from the lower end of the band), part-time students are also scattered in higher age groups for up to 60 years. In this context, our results are consistent with the work (Lusardi, Yakoboski, \& Oggero, 2017) which showed an increase in the mean P-Fin score along with increasing age in the 18-60 age groups. Similarly, widespread international research (Lusardi \& Mitchell, 2011) presents that young people are more financially illiterate than middle-aged. The study (Agarwall, Driscoll, Gabaix, \& Laibson, 2009) also showed that financial mistakes are prevalent among the young and the elderly.

Looking at the final value of the P-Fin index as a whole, we can evaluate the final score at 53\% as a positive result. Achieving more than half correctly answered questions corresponds to the results of the paper (Palac, Mabić, \& Lucović, 2017), which showed that university students achieve a relatively high level of financial literacy. Our results correspond also with the study (Chen \& Volpe, 1998). However, if we look at the individual functional categories of the P-Fin index, we can observe considerable disparities. Particularly it demonstrates a very low level of ability to work with finances in conditions of uncertainty, which is reflected in a significant lag in the area of investment evaluation and approach to risk. This decline in knowledge of risk and financial decision-making in conditions of uncertainty is in line with the findings published in (Arceo-Gómez \& Villagómez, 2017).

We see the cause of this phenomenon in the fact that financial decision-making in conditions of uncertainty and risk requires more advanced probabilistic thinking. It is precisely the absence of these elements of numeracy in the sphere of general training that is then reflected in the insuf- 
ficient evaluation of alternatives. Improvement of this state requires a better connection among the courses of the mathematical background with specialized financial courses. This places increased demands not only on students but also on the preparation for teaching, and cooperation of teachers of both categories of subjects.

On the other hand, it is worth mentioning that today's availability of information for students is at an ever-higher level. At both schools, study texts are prepared and provided to students. The Internet contains many relevant professional websites and professional books on given topics are commonly available in various languages. From the above findings and facts, four possible reasons for failure can be deduced:

1. Students are not able to orient, sort, evaluate and process such a large amount of data.

2. Students lack the motivation to master the issues of financial and other subjects.

3. People handle standard repetitive operations well, but emergencies are difficult for them.

4. People are affected by the desire to live in immediate prosperity, which reduces the willingness to understand topics that are, to some extent, in conflict with the notion of deferred prosperity. Investment, risk and change management, in general, are among the areas whose application in companies has always been more problematic.

Indent No. 1 encounters the problem of today's interconnected world, in which one has to work with a large amount of data, between which it is necessary to divide the data into what we need for our activities, or they are just a marketing message. Furthermore, we come across a lot of unnecessary or outdated data, and the currently solved problem is purposeful misinformation. Working with data should become part of teaching from the elementary level of education.

Indent 2 covers the question of whether the student has his / her inner motivation. A person with motivation can control the development of their personality to some extent by own self. For people without internal motivation, it is necessary to find a way to effectively motivate them and thus increase the effectiveness of preparation for practice. Full-time students lack the life experience to understand the importance of the knowledge passed on. One of the ways to arouse students' interest and increase motivation is the implementation of ,guided teaching" in teaching.

Within a specific subject, it is appropriate to have them processed and present in a group the work, which will be followed by the implementation (so-called in the laboratory), in which students will have to solve several practical problems chosen by the lecturers of the subject. This method of teaching is demanding on personnel and technical support; however, it allows the induction of internal motivation in students, or the identification of students who are not interested in the field, regardless of the quality of teaching.

However, there is another problem that occurred in the results regardless of motivation. Both of the above groups of students encountered shortcomings in the area of risk management and investment decision-making, which were reflected in the inferences in indents 3 and 4 . Among the topics taught is change management. The rules of change management should be incorporated into the ,guided teaching” mentioned in the previous text.

Indents 3 and 4, therefore, reflect the factor of life experience gained, based on which part-time students were able to achieve better results because they had to deal with many life situations without parental support. Critical thinking in a normal situation and a non-standard and stressful situation is different, which is reflected in the results of both groups of students. 


\section{FUTURE RESEARCH DIRECTIONS}

The objective of future research is to identify key cognitive and emotional elements that influence the level of financial literacy. Together with well-known predictors such as numeracy, age, gender, and education, create a model that elucidates their role. The resulting model will make it possible to identify predictors whose controlling can enforce better financial literacy and which interventions, on the other hand, do not have a longer-term effect on improving the level of financial literacy and economic education.

\section{CONCLUSION}

The article presents the results of the research based on the personal finance index that is recently developed an innovative measure of knowledge. The found results confirm the findings from previous research that the practical experience of part-time students improves the evaluation of the test. However, there are two areas in which the whole sample has demonstrated insufficient results: investment decisions and risk management. In the Discussion chapter, several conclusions are presented (e.g. the application of ,guided teaching”), which can be followed up in further new research. The previous chapter outlined the planned direction of the article's research. However, the results open up further possibilities for scientific research. In the application of ,guided teaching”, it is essential to evaluate its impact on students' knowledge and skills, including financial literacy. In the area of risk and investment management, it is possible to examine the causes of failure in more depth, confirm assumptions and propose solutions that shift the weakest identified link in financial literacy.

The results of the research also open up the possibility of continuing with research in the field of human resource management, where we encounter the fact that large multinational corporations prefer to employ young graduates. They are subsequently trained in the procedures and preferences of these corporations. Their employees then have to perform their work duties practically according to the manual with little space for the invention of workers. The companies prefer people without life experience. Research can focus on the reasons for this preference in the company, but also the quality of the thus formed workforce in the economy and its usability due to the experience gained in the controlled environment of large companies.

The results presented in the article are important within the theoretical knowledge in the field, for the comparison of outputs with other research and especially for the practice itself. A properly educated workforce reduces the complexity of a person's involvement in the work process and facilitates the employer's integration of the worker and reduces the associated costs. Financial literacy is essential for the performance of specific professions in the field of financial management. The effects of poor long-term decision-making and planning are difficult and costly to correct. At the same time, manifestations of the crisis in the corporate and private environment during the last months corresponded to the findings of the presented research and confirmed its importance. Firms where management failed to manage risk and disrupt the long-term plan faced significant cash flow management problems. Mastered knowledge in the field of financial literacy has its implications in everyday private life, which already touches on the issue of private finance. 


\section{REFERENCES}

Agarwall, S., Driscoll, J., Gabaix, X., \& Laibson, D. (2009). The age of reason: financial decisions over the life-cycle with implications for regulation. Brookings Papers on Economic Activity, 2, 51-117. doi:10.1353/eca.0.0067

Arceo-Gómez, E., \& Villagómez, A. F. (2017). Financial literacy among Mexican high school teenagers. International Review of Economics Education, 24, 1-17. doi:10.1016/j.iree.2016.10.001

Behrman, J. R., Mitchell, O. S., Soo, C., \& Bravo, D. (2012). How Financial Literacy Affects Household Wealth Accumulation. American Economic Review, 102(3), 300-304. doi:10.1257/ aer.102.3.300

Dahmen, P., \& Rodríguez, E. (2014). Financial Literacy and the Success of Small Businesses: An Observation from a Small Business Development Center. Numeracy, 7(1). doi:http:// dx.doi.org/10.5038/1936-4660.7.1.3

Giesler, M., \& Veresiu, E. (2014). Creating the Responsible Consumer: Moralistic Governance Regimes and Consumer Subjectivity. Journal of Consumer Research, 41(3), 840-857. doi:10.1086/677842

Chen, H., \& Volpe, R. P. (1998). An analysis of personal financial literacy among college students. Financial Services Review, 7(2), 107-128. doi:10.1016/S1057-0810(99)80006-7

Kim, J. (2001). Financial knowledge and subjective and objective financial wellbeing. Consumer Interests Annual, 47, 1-3.

Klapper, L., \& Panos, G. A. (2011). Financial literacy and retirement planning: The Russian case. Journal of Pension Economics \& Finance, 10(4), 599-618. doi:10.1017/S1474747211000503

Kozubík, A., Kozubíková, Z., \& Polák, J. (2019). Financial Literacy of Full-time and Part-time University Students. International E-Journal of Advances in Education, 5(13), 35-43.

Kozubíková, Z. (2015). Financial Literacy as an Important Objective of the Education in Economics. In P. Slavíčková (Ed.), Proceedings of the Conference: Knowledge for market use 2015: women in business in the past and present (s. 429 - 439). Olomouc: Societas Scientiarium Olomucensis II.

Lusardi, A., \& Mitchell, O. S. (10 2011). Financial literacy around the world: an overview. Journal of Pension Economics \& Finance, 10(4), 497-508. doi:10.1017/S1474747211000448

Lusardi, A., Yakoboski, P. J., \& Oggero, N. (2017). The TIAA Institute-GFLEC Personal Finance Index: A New Measure of Financial Literacy. New York: TIAA Institute.

Mandell, J. (2007). Financial literacy of high school students. In J. J. Xiao (Ed.), Handbook of Consumer Finance Research (s. 163-183). New York: Springer.

Palac, S., Mabić, M., \& Lucović, D. (2017). Financial Literacy Of Students At The University Of Mostar (in Croatian). Conference Proceedings of the ERAZ 2017 (s. 230-237). Beograd: Association of Economists and Managers of the Balkans - UdEkoM Balkan.

Polák, J., Kozubíková, Z., \& Kozubík, A. (2018). Financial Literacy of University Students and Effects of Practical Experience. SOCIOINT 2018, 5th International Conference on Education, Social Sciences and Humanities -Abstracts and Proceedings, 02-04 July 2018, Dubai, UAE (s. 17-26). Ocerint International Organization Center of Academic Research, Istanbul, Turkey.

van Rooij, M. C., Lusardi, A., \& Alessie, R. J. (2012). Financial Literacy, Retirement Planning and Household Wealth. The Economic Journal, 122(560), 449-478. doi:10.1111/j.14680297.2012.02501.x 



\title{
SUSTAINABILITY COMPETENCIES FROM THE UNIVERSITY DISCOURSE
}

\author{
Vesna Nikolić ${ }^{1}$ (i) \\ Tamara Vukić² (D)
}

DOI: https://doi.org/10.31410/ERAZ.S.P.2020.71

\begin{abstract}
The subject of the research is focused on identifying the conditions that determine university's specific response to sustainable development, as well as on identifying the characteristics of a transformative university, and the obstacles in the process of creating a sustainable university. Given the importance of educating the future decision makers, the paper is particularly focused on the problems and the possibilities for developing the competencies for sustainable development within the higher education.

The originality of the paper is found in its wholesome overview of the universities' response to the sustainable development challenge and in the identification of possible barriers that the universities face when striving to sustainability. The special value of the paper is in the analysis of the models for sustainable development competencies which should help to further understand these models and the possibilities for their application in university's teaching practice.
\end{abstract}

Keywords: Sustainable development, University, Transformation, Barriers, Competencies

\section{INTRODUCTION}

$\mathrm{O}$ ver the last few decades, the concept of sustainable development has become a global challenge for contemporary education (Bonnett, 2016; Wright, 2009). Integrative approach to economic, social and ecological goals, reconciliation with nature, critical and creative thinking, participation and action-oriented learning, justice, responsibility, human rights, peace, security, partnership and solidarity are the key words when it comes to education for sustainable development and the future educational policy of each society. The university is recognized as the key factor when it comes to responding to the challenges of sustainable development. Modern universities represent "small cities" which can directly or indirectly affect the environment and the sustainable development given their size, population and activities, (energy consumption, waste etc.). At the same time, their mission of creating and transmitting knowledge through research and education of the future decision makers is a condition required for the change of the existing mental models and transformation of the society towards sustainability.

The role of universities in achieving the goals of sustainability is promoted both in academic discourse and at the policy level, ever since the Rio Conference (1992) and Agenda 21, and further through the Millennium Development Goals (UN, 2000), The United Nations Decade of Education for Sustainable Development 2005-2014 (DESD), up until Agenda 2030 and other documents. Numerous declarations (e.g. Talloires (1990), Halifax (1991), Copernicus Charter (1994), Lüneburg (2001), Graz (2005), Bonn (2009), Abuja Declaration on Sustainable Development in Africa (2009), Turin Declaration on Education and Research for Sustainable and Responsible Development (2009), etc.) have encouraged reflecting on models and ways of im-

University of Niš, Faculty of Occupational Safety, Čarnojevića 10A, Niš, Serbia

University of Niš, Faculty of Philosophy, Ćirila and Metodija 2, Niš, Serbia 
plementing sustainable development in universities, both in teaching and research activities, as well as when it comes to the university management and community action. Despite their differences, these declarations generally require the following from the universities: sustainable physical operations; academic research in the field of sustainability; working on environmental literacy; cooperation with other universities and countries; development of an interdisciplinary curriculum; establishment of partnerships with the government, NGOs and industry; as well as public informing (Wright 2002). In addition, a large number of declarations and other documents emphasize that universities have a moral obligation to act towards a sustainable society, especially when it comes to "greening" the campus and educating the teachers for sustainable development (Lozano et al, 2013).

\section{METHODOLOGY}

The specific situation of the global pandemic crisis caused by the coronavirus influenced the authors' decision to conduct a desktop research. For the purpose of collecting data, Internet and desktop research was made, which was then followed by interviews with key informants from Serbian universities. The interviews were conducted by e-mail or via telephone. In addition, information collected from the interviews was compared with both the literature data, as well as the international documents.

The search for literature was conducted via ISI, Google Scholar and KoBSON databases. The research is especially focused on the sources and the documents published after the Rio conference and the adoption of Agenda 21. The following key words were used: "sustainable university", "education for sustainable development", "transformative university", "competencies for sustainable development", "greening the campus", "HE for ESD declarations", "green curriculum", "barriers to higher education for sustainable development". The collected literature covered various topics whose selection led to the papers listed at the references section. The analysis of these papers helped establish three directions of the research, which served as the basis for defining the following research tasks: (1) to identify the factors that impact the transformation of a university into a "sustainable university", (2) to identify the barriers of such transformation, and (3) to determine principal characteristics of competence models in the education for sustainable development by their comparative analysis.

\section{RESEARCH RESULTS}

\subsection{The factors of the transformation of a university into a "sustainable university"}

In the contemporary socio-economic context universities have a deep moral responsibility in creating a just and sustainable future (Cortese, 2003), as well as an obligation to implement the changes that lead towards sustainable development (Svanström et al., 2008). Numerous universities accepted public commitment to work on their transformation into "sustainable universities", by signing international and national declarations. However, sustainability in higher education is a fairly new area of research. Most of the research to date have focused on: environmental management (Lozano, 2011), carbon management plans and greening of university campus (Atherton \& Giurco, 2011); descriptive case studies and examples of good practice of universities (Cleaves et al., 2009); embedding sustainability in specific courses; theoretical developments on teaching and learning approaches towards sustainability; and university and policy analysis (Cebrián, 2018; Cotton et al., 2009; Wright, 2010). 
Based on the results of these research, it can be concluded that the transformation towards a sustainable university is noticeable in those universities that have focused their business on environmental management (especially the application of ISO 14001), carbon management and emission reduction, energy saving, waste management and other activities related to the fight against climate change (Lozano, 2011; Atherton \& Giurco, 2011; Button, 2009; Cleaves et al., 2009). In addition, this transformation is also reflected in the developed social responsibility within corporations (Nejati et al., 2011), hiring environmental managers and creating university's strategies, policies and sustainability plans (Sterling et al., 2013), cooperating with both local and wider communities, public sharing of information and reporting on the undertaken activities (such as universities' websites, media, etc.). Also, those universities that strive to sustainability are experiencing changes in decision-making processes, and are therefore becoming some kind of "learning organizations" that engage various stakeholders in their decision-making and actions (students, educators, staff, researchers, managers and executive groups, benchmarking agencies, external bodies, local community, NGOs and businesses amongst others) (Temple, 2010).

Considering the fact that monitoring, benchmarking and assessment are an integral part of the change towards a sustainable university, various tools have been developed, some of which are Auditing Instrument for Sustainability in Higher Education (AISHE) (Roorda, 2001); Graphical Assessment of Sustainability in Universities (GASU) tool (Lozano, 2006); The Sustainability Tracking, Assessment \& Rating System (STARS) (AASHE); Sustainability Assessment Questionnaire (SAQ) (ULSF) and the Sustainability Tool for Auditing University Curricula in Higher Education (STAUNCH) (Glover et al., 2011).

Kościelniak (2014) believes that the transformation of a university into a "sustainable university" should be considered in regard to the university's mission, education and research, management, regional mission, as well as in regard to the individual activities and contributions of the staff, the students and the researchers. The key characteristics of a sustainable university are: (1) transformative education that will prepare students to face complex challenges of sustainability; interactive learning and the development of critical thinking skills; (2) transdisciplinary research and studies; (3) education and research orientation towards solving social problems - the ability of students to respond to modern age problems and challenges; (4) network that connects different expertises of the entire university and provides rational, efficient and meaningful resource management; (5) leadership, mission and vision that promote the changes that are necessary for the transformation of universities into "sustainable universities". (van Weenen, 2000; Leal Filho, 2000; Adomssent, 2006; Adomssent et al., 2007; Max-Neef, 2005; Wals \& Corcoran, 2006).

Given that the universities' activities are mostly focused on education (van Weenen, 2000), the implementation of education for sustainable development in higher education study programs represents an important determinant of sustainable universities (Lambrechts et al., 2013). It has become clear that the education for sustainable development requires changes not only when it comes to the university's operations, that is the adoption of sustainable practices in the functioning of the campus, but also in regard to the curricula and the daily practice of academics. In addition, the universities are facing challenges, such as requiring that interdisciplinary learning and civic activism become the rule, instead of the exception; that the campus operations become linked to the formal curriculum; that the concepts of sustainability interconnect with every discipline; as well as that such educational goals become supported by research within the faculty, which should allow students and other staff to participate (Everett, 2008). 
The evaluation of teaching contents within higher education, which took place during the UN Decade of Education for Sustainable Development (DESD), has shown that most activities which are related to the implementation of education for sustainable development had been realized from the perspective of environmental education. The progress made in regard to professional education of environmental protection experts is indisputable, as well as in regard to introducing special subjects related to environmental protection in various faculties' study programs (Nikolić et al., 2015). However, there is still a lack of wider implementation of education for sustainable development. Environmental content should be expanded to issues such as poverty reduction, civil society, peace, ethics, responsibility, democracy, governance, justice, security, human rights, health, gender equality, cultural diversity, rural and urban development, economic development, consumer patterns etc. In some universities, study programs which are focused on environmental protection are gradually opening up to the contents of those scientific disciplines that belong to social sciences and humanities. However, it can be concluded that there is still a lack of a holistic approach, which would integrate all relevant content related to the environmental protection and sustainable development in an inseparable whole and connect them to the interests of various stakeholders in the higher education system (Nikolić et al., 2017). The new paradigm of "sustainable universities" should address the weaknesses and the shortcomings of traditional higher education. The universities need to become the agents of social change in the fight against climate change and in ensuring sustainable development. In such manner, higher education can make its contribution to the transformation of society towards sustainable development and vice versa sustainable development has a reciprocal effect on education with the potential to improve and transform the university and the education system as a whole (Zilahy \& Huisingh, 2009).

\subsection{The barriers regarding the transformation of a university into a "sustainable university"}

The complexity of the issue of sustainable universities stimulated the research of the barriers and the obstacles that appear in the process of transforming the universities. The most important obstacles that the universities face when implementing sustainable development are: financial constraints (Barnes \& Jerman, 2002); lack of funds and other resources (Kanyimba \& Coetzer, 2011); economic development slowdown and budget reduction for universities (Velazquez \& Munguia, 1999); resistance of administration (Velazquez et al., 2004); staff overload (Orr, 2000); weak connections between different parts of academic community and lack of universities' initiatives, especially in less developed countries (Kanyimba \& Coetzer, 2011); deficit of binding policies that support the implementation of sustainable development in the universities (Whitmer et al., 2010); misunderstanding of the concept of sustainable development, i. e. lack of awareness of its purpose, consequences and implications for the universities (Leal Filho et al., 2017). According to the Decade of Education for Sustainable Development Report (UNESCO, 2012), the main obstacles for the transformation of universities into "sustainable universities" are the lack of resources, leadership, incentives and knowledge.

Some authors point out that the formation of sustainable universities is accompanied by institutional barriers, such as: lack of administrative support, lack of research and development, lack of legislation and state guidelines, lack of environmental committees, lack of infrastructure and technology (Leal Filho et al., 2017; Kanyimba \& Coetzer 2011).

According to Velazquez et al. (2005) interdisciplinary research is one of the most difficult tasks for the university, while Capdevila et al. (2002) point to a weak link between the teaching 
process and the research - higher education process is rarely supported by research, therefore remaining abstract and theoretical.

In the context of education for sustainable development, the biggest problem is the conservatism of universities and their resistance to change (Lozano et al., 2013), i.e. the fact that the higher education institutions are still basically traditional (Torres et al., 2017), and whose educational organization implies a division into highly specialized areas of knowledge and traditional disciplines (Cortese, 2003). Sustainable development, on the other hand, imposes the need for a holistic and integrative approach in order to perceive complex difficulties in the relationship between men, society and nature from the perspective of different disciplines (Milutinović \& Nikolić, 2014). Because of the complexity of sustainable development issues, there is a need for cooperation and communication between the disciplines (Bosselmann, 2001), i.e. for interdisciplinary learning and research (Howlett et al., 2016), the integration of different subjects and disciplines, and the connection between the teaching and the real problems and people (Lambrechts et al., 2013). This requires some changes in teaching in order for students to become able to "translate" acquired knowledge into positive actions regarding sustainable future at a global level (Wright, 2009).

The lack of teachers' understanding of the concept of sustainable development, the lack of abilities and skills for implementing the contents and the topics of sustainable development (Kanyimba \& Coetzer, 2011); and the lack of a holistic approach in integrating sustainability into the university curricula (Leal Filho et al., 2017) are the barriers that particularly complicate the universities' transformation. Teaching and learning in the context of sustainability require a wholesome experience: "discovery learning rather than reproductive learning; investigative learning rather than linear transport of content, exploring reality rather than reading books; active learning rather than passive reception of information; productive action rather than reproduction of facts; gaining experience rather than acquiring knowledge" (Bosselmann, 2001, p. 176). Therefore, there is a need for application of different pedagogical approaches and strategies that will serve in function of developing the competencies for sustainable development of future professionals and decision makers in various human activities.

As stated by Svanström et al. (2008), it is necessary to provide capacity building for the educators who have to be equipped with the knowledge about sustainability and education for sustainable development, because it is a prerequisite for integrating sustainable development into their courses with adequate teaching methodologies. In this regard, the competency models which will be presented below, can serve as a significant guideline in the teachers' education for sustainable development.

\subsection{The competence models in the education for sustainable development}

The competence models can be understood as an "inventory" of desirable competencies of teachers that will contribute to their improvement in the field of sustainable development, both in terms of knowledge and in practical action and cooperation, as well as when it comes to their personal characteristics, such as their values and emotions. The basic characteristics of the following three competence models are briefly presented below: The CSCT Competence Model, The KOM-BiNE Competence Model and The ECE Competence Model. In addition, the competencies (general and specific) that the given models promote are presented through a comparative overview, with the aim to gain a deeper understanding of them, and thus facilitate their application in the "education of educators" in the field of sustainable development. 
The CSCT Competence Model. Within the CSCT (Curriculum, Sustainable Development, Competencies, Teacher Training) Competence Model the teacher is observed from three points of view: as an individual, as an actor in an educational institution and as a member of a society (Bertschy et al., 2013). Such perception of teachers indicates that it is not enough for a teacher to only have the competencies necessary for the classroom and the teaching management, but also the competencies related to the entire educational institution, as well as those necessary for achieving external interactions (Steiner, 2010). In order to encourage sustainable development within each level of action, the teacher needs to have specific competencies, which are presented through these five domains: (1) knowledge (creating an appropriate environment for teaching the issues regarding sustainable development, contributing to the creation of a program that integrates sustainable development into the entire school curricula, cooperating with organizations which promote sustainable development, etc.); (2) systems thinking (thinking in models and patterns, encouraging students to respect biological, social and cultural diversities, using existing networks for education for sustainable development, etc.); (3) emotions (expressing and managing one's own emotions, stimulating positive feelings, acting as a mediator in resolving the conflicts, etc.); (4) ethics and values (encouraging the students to reconsider their own beliefs and assumptions, developing the students' critical understanding of sustainable development, focusing on understanding the values, the rights and the responsibilities that are a part of the European citizenship concept, etc.); (5) action (imagining an alternative future, organizing and monitoring the learning process, strategical thinking and acting, etc.) (Sleurs, 2008). In addition, the model presents some general competencies, which also refer to the already mentioned levels of teachers' activity (Ibid.): thinking and envisioning (teacher as an individual); teaching and communication (teacher in an educational institution) and cooperation and networking (teacher in the society).

The KOM-BiNE Competence Model. The KOM-BiNe Competence Model (Kompetenzen für Bildung für Nachhaltige Entwicklung) focuses on the team of teachers/educators of education for sustainable development, and the reason for this is because "in a complex field like ESD it is not possible for one single person to command all the competencies required" (Steiner, 2010, p. 10). The core of the model contains highly personal competencies (Steiner, 2010) divided into four areas: knowing (acquiring general knowledge on sustainable development and ESD; linking contents from different disciplines, etc.); acting (being familiar with and further developing the methods and strategies for the application of knowledge; teachers are oriented towards the action and the contextualization of contents); feeling (the ability to empathize; believing that teamwork can contribute to sustainable development; teachers show enthusiasm for ESD and inspire others to do the same); valuing (values propagated by teachers themselves; educational goals that are promoted; values that express attitudes and beliefs). The middle layer of the model includes communicating and reflecting that connect the core with the outer layer. The communication is a prerequisite for the competencies of the outer layer, while it is less important for the individual areas (the first layer). Reflection, as a means of critical observation of oneself - one's knowledge, skills, values and feelings, is equally important for the core and the outer layer. The outer layer includes: visioning (developing visions for the future through questions such as How do we want to live sustainably?); planning and organizing (setting the goals, reflecting on the given possibilities, implementing ideas); networking (building and maintaining the networks within and outside the organizations) (Rauch \& Steiner, 2013).

The ECE Competence Model. The ECE Competence Model is a catalogue of competencies in education for sustainable development that focuses on educators in general rather than exclu- 
sively on teachers. These competencies should be understood as guidelines rather than minimal standards (Bertschy et al., 2013). The model contains of four competence fields: learning to know (understanding local and global social challenges and the potential role of educators and learners), learning to do (developing practical skills and action competence related to ESD), learning to live together (developing partnerships and a respect for interdependence, pluralism, mutual understanding and peace) and learning to be (developing personal qualities and greater autonomy, judgment and personal responsibility in relation to sustainable development). In each of these competence fields, the competencies are grouped around three essential characteristics of education for sustainable development: a holistic approach that includes integrative thinking, inclusivity and dealing with complexities; envisioning change that involves learning from the past, inspiring the present action and exploring the alternative futures; and achieving transformation of what it means to be an educator, transformation of pedagogy (transformative approaches to teaching and learning) and transformation of the education system as a whole (UNECE, 2011).

\subsection{The comparative analysis of the competence models}

Each of the analyzed models includes the competencies in the domains of knowledge, action and cooperation/networking.

Knowledge. CSCT and KOM-Bine competence models emphasize the need for the teacher to be familiar with the concept of sustainable development and the education for sustainable development, as well as to develop the awareness of cultural dependencies regarding knowledge. In the ECE Competence model, the competencies in the domain of knowledge are presented in a broader way, i.e. they do not relate specifically to the need for teachers to know the concept of sustainable development, but to gain a broader understanding of the challenges that are facing society, as well as of both their and the students' roles in facing these challenges. Thus, the teacher should understand the functioning and the interrelationship of the society, the economy and the environment; the connection between current actions and the sustainable future; the basic causes of unsustainable development; the necessity to transform educational systems; the importance of preparing the students to face challenges, etc. (UNECE, 2011).

Action. In the domain of action, all three models emphasize critical thinking, orientation towards problem-solving and forming an idea about a sustainable future. The CSCT and ECE models also have some other competencies in common, those related to seeing the environment as a learning opportunity, participatory education; identification of the future consequences of one's own decisions and actions; monitoring the learning process; being aware of the need for change. In addition, the common competencies of the CSCT and KOM-BiNE models are the acceptance of responsibility and teamwork.

Cooperation. The cooperation within the CSCT model is presented as a general competence. According to Steiner (2010), the collaboration with partners inside and outside the school is necessary in order to create learning opportunities based on the real life situations and social problems. It is based on the skills such as communication, conflict solving, teamwork, planning and organization (Ibid.). The KOM-BiNE competence model also assumes the collaboration within and outside the organization. As stated by Rauch \& Steiner (2013), such networking is crucial for the ESD competencies of teachers. This competence is also based on communication skills and the ability to resolve conflicts, as well as on tolerance, respect for diversity, etc. (Ibid.). 
The need for cooperation is recognized in the ECE model in the competencies from the learning to live together domain, particularly in those competencies that point out that the teacher should work with others in a way which: actively involves different groups from all generations, cultures, places and disciplines; encourages negotiation of future alternatives; challenges the unsustainable ways of acting within educational systems and institutions etc. (UNECE, 2011).

In addition, each of the models emphasizes the need for visioning, for creating ideas about an alternative, sustainable future that would serve as a basis for designing the changes necessary in the present. Furthermore, each of the models orientates towards the change, by emphasizing the importance of reflecting about what has already been achieved, planning the necessary changes and implementing them actively.

The CSCT and KOM-BiNE models emphasize the values and emotions, while the competencies in the domain of learning to be represent the specificity of the ECE model. These competencies describe a teacher as someone who: takes into account different disciplines, cultures and attitudes; is motivated to implement positive changes both locally and globally; questions the assumptions on which the unsustainable practice is based, etc. (UNECE, 2011). The specificity of the CSCT model is in the competencies in the domain of systems thinking: resisting the tendency to simplify problems and search for quick solutions; developing students' empathy through their identification with others; being aware that schools are a part of local, national and global systems etc. This model separates the teaching competence as a general competence, emphasizing that the education for sustainable development requires a different, constructive approach to teaching (Sleurs, 2008). Constructivism helps the teachers to understand that "acquiring competencies is a self-steered and active process, which can be fostered but not created" (Sleurs, 2008, p. 27).

All of the above, including the need to acquire knowledge in the field of SD and ESD, indicates that all models emphasize the personal dimension, the importance of developing personal competencies and self-improvement. On the other hand, there is a need for cooperating with others, which is especially emphasized within the KOM-BiNE model, given that it is aimed towards a team of teachers.

Alongside the already mentioned, other model specifics are reflected in the following competencies: choosing the goals of the education for sustainable development in accordance with prior knowledge and the abilities of students; contributing to the integration of sustainable development into the curriculum; acting as an "agent for changing"; (CSCT); managing the complexities; acting independently and confidently; (COM-BiNE); connecting the students with their local and global fields of influence; understanding the importance of scientific evidence in support of sustainable development (ECE), etc. (Sleurs, 2008; Rauch \& Steiner, 2013; UNECE, 2011).

\section{CONCLUSION}

The overall presence of the sustainable development issues generated new challenges for universities - they are required to change their way of functioning and the activities they perform, i.e. to transform and to become "sustainable universities". The analysis of relevant sources has shown that the basic characteristics of a transformed/"sustainable university" are reflected in "greening" the property and caring about the universities' functioning in terms of energy saving, waste management, reduction of harmful emissions etc. A "sustainable university" is also 
characterized by the changes within the research and the teaching processes. In other words, it is required for the research and the teaching processes to integrate sustainable development in a way that enables to apply the results of the research focused on sustainable development in the teaching practice at universities. However, the universities' response to the challenges of sustainable development is accompanied by numerous obstacles and barriers: financial and administrative barriers, lack of awareness of the need for integrating sustainable development into the university practice, lack of appropriate legal and regulatory guidelines, resistance to change, lack of competencies, etc.

The analysis of the obstacles and barriers indicates that the universities should: (1) incorporate sustainable development as an idea into their strategic plans; (2) integrate the sustainable development issues into the everyday teaching; (3) design their own waste recycling plans and establish efficient alternative energy initiatives; (4) inspire and promote the idea of sustainability and environmental awareness and actively work on the transformation of the society, both inside and outside their own campuses; (5) actively promote the education of teachers in the field of sustainable development.

Starting from the fact that the teachers are in direct interaction with the students, i.e. the future experts and decision makers in the field of sustainable development, the conclusion is logical: educating the teachers about sustainable development is a prerequisite for educating the students about sustainable development. Therefore, the competence models are an important guideline for the teachers' education in the field of sustainable development. Comparative analysis of the available competence models, The CSCT Competence Model, The KOM-BiNE Competence Model and The ECE Competence Model, showed that the key areas of the education of teachers for sustainable development are: the competencies in the domain of knowledge about sustainable development and education for sustainable development; the competencies related to supporting the teachers' acting in favor of sustainable development; the competencies for establishing partnerships with actors significant within and outside the institution in which the teacher is employed; but also the competencies that require a continuous reflection and envisioning a sustainable future. The models indicate that there is a need for developing teacher competencies that cover not only the teachers' performance in the classroom, but also a wide range of skills, abilities and knowledge related to integrating sustainable development into their beliefs, on one hand, and to cooperating with the others on the path to sustainability, on the other.

In order for the transformation of a university towards sustainable development to be possible, there is a need for introducing incentive mechanisms, such as legal obligations in the field of teachers' education for sustainable development, and also the establishment of a system for assessing the achievements of the universities in the field of sustainable development.

\section{ACKNOWLEDGMENT}

This research was funded by the Ministry of Education, Science and Technological Development of the Republic of Serbia. 


\section{REFERENCES}

Adomssent, M. (2006). Higher education for sustainability: challenges and obligations from a global perspective. In M. Adomssent, J. Godemann, A. Leicht \& A. Busch (Eds.), Higher Education for Sustainability. New challenges from a global perspective (pp. 10-22). Frankfurt: VAS.

Adomssent, M., Godemann, J., \& Michelsen, G. (2007). Transferability of approaches to sustainable development at universities as a challenge. International Journal of Sustainability in Higher Education, 8(4), 385-402. https://doi.org.10.1108/14676370710823564

Atherton, A., \& Giurco, D. (2011). Campus sustainability: climate change, transport and paper reduction. International Journal of Sustainability in Higher Education, 12(3), 269-279.

Barnes, P. \& Jerman, P. (2002). Developing an environmental management system for a multiple-university consortium. Journal of Cleaner Production, 10(1), 33-39.

Bertschy, F., Künzli, C., \& Lehmann, M. (2013): Teachers' competencies for the implementation of educational offers in the field of education for sustainable development. Sustainability, 5(12), 5067-5080. https://doi.org/10.3390/su5125067

Bonnett, M. R. (2016). Sustainability, nature, and education: a phenomenological exploration. Inovacije u nastavi, 29(4), 1-15. https://doi.org/10.5937/inovacije1604001B

Bosselmann, K. (2001). University and sustainability: compatible agendas? Educational Philosophy and Theory, 33(2), 167-186. https://doi.org/10.1111/j.1469-5812.2001.tb00261.x

Button, C. E. (2009). Towards carbon neutrality and environmental sustainability at CCSU. International Journal of Sustainability in Higher Education, 10(3), 279-286.

Capdevila, I., Bruno, J., \& Jofre, L. (2002). Curriculum greening and environmental research co-ordination at the Technical University of Catalonia, Barcelona, Journal of Cleaner Production, 10(1), 29-33. https://doi.org/10.1016/S0959-6526(01)00019-1

Cebrián, G. (2018). The I3E model for embedding education for sustainability within higher education institutions. Environmental Education Research, 24(2), 153-171.

Cleaves, S. M., Pasinella, B., Andrews, J., \& Wake, C. (2009). Climate action planning at the University of New Hampshire. International Journal of Sustainability in Higher Education, 10(3), 250-265. https://doi.org/10.1108/14676370910972567

Cortese, A. D. (2003). The critical role of higher education in creating a sustainable future. Planning for Higher Education, 31(3), 15-22.

Cotton, D., Bailey, I., Warren, M., \& Bissell, S. (2009). Revolutions and second-best solutions: education for sustainable development in higher education. Studies in Higher Education, 34(7), 719-733. https://doi.org/10.1080/03075070802641552

Everett, J. (2008). Sustainability in higher education: Implications for the disciplines. Theory and Research in Education, 6(2), 237-251. https://doi.org/10.1177/1477878508091115

Glover, A., Peters, C., \& Haslett, S. K. (2011). Education for sustainable development and global citizenship: An evaluation of the validity of the STAUNCH auditing tool. International Journal of Sustainability in Higher Education, 12(2), 125-144.

Howlett, C., Ferreira, J., \& Blomfiels, J. (2016). Teaching sustainable development in higher education: building critical, reflective thinkers through an interdisciplinary approach. International Journal of Sustainability in Higher Education, 17(3), 305-321.

Kościelniak, C. (2014). A consideration of the changing focus on the sustainable development in higher education in Poland. Journal of Cleaner Production, 62, 114-119.

Kanyimba A.T and Coetzer I.A (2011). The Integration of Sustainability Education in Namibian Colleges of Education. Africa Education Review. http://dx.doi.org/10.1080/18146627.20 11.586157. 
Lambrechts, W., Mulà, I., Ceulemans, K., Molderez, I., \& Gaeremynck, V. (2013). The integration of competences for sustainable development in higher education: an analysis of bachelor programs in management. Journal of Cleaner Production, 48, 65-73.

Leal Filho, W. (2000). Sustainability and university life. Frankfurt: Peter Lang.

Leal Filho,W., Wu Y-C. J., Londero Brandli, L., Veiga Avila,L., Miranda Azeiteiro, M., Caeiro, S., \& Rejane da Rosa Gama Madruga, L. (2017). Identifying and overcoming obstacles to the implementation of sustainable development at universities. Journal of Integrative Environmental Sciences, 14(1), 93-108.

Lozano, R. (2006). A tool for a Graphical Assessment of Sustainability in Universities (GASU). Journal of Cleaner Production, 14, 963-972.

Lozano, R. (2011). The state of sustainability reporting in universities. International Journal of Sustainability in Higher Education, 12(1), 67-78.

Lozano, R., Lukman, R., Lozano, F. J., Huisingh, D., \& Lambrechts, W. (2013). Declarations for sustainability in higher education: becoming better leaders, through addressing the university system. Journal of Cleaner Production, 48, 10-19.

Max-Neef, M. A. (2005). Foundations of transdisciplinarity. Ecological Economics, 53, 5-16. Milutinović, S. \& Nikolić, V. (2014). Rethinking higher education for sustainable development in Serbia: An assessment of Copernicus Charter principles in current higher education practices. Journal of Cleaner Production, 62, 107-113.

Nejati, M., Shafaei, A., Salamzadeh, Y., \& Daraei, M. (2011). Corporate social responsibility and universities: A study of top 10 world universities' websites. African Journal of Business Management, 5(2), 440-447.

Nikolić, V., Milutinović, B., \& Ranitović, J. (2015). Greening of higher education in the Republic of Serbia, Envigogica, 10 (1), 1-17. https://doi.org/10.14712/18023061.453

Nikolić, V., Milutinović, B., Nedenovski, P., \& Mrnjaus, K. (2017). ESD professional development of university educators in Serbia, Croatia and Macedonia: A comparative analysis. International Journal of Sustainability in Higher Education, 18(6), 923-938.

Orr, D. (2000). Transformation of academic planning for environmental education in the $21^{\text {st }}$ century. In Leal Filho, W. (Ed.), Sustainability and University Life (p. 221), Frankfurt: Peter Lang.

Rauch, F., \& Steiner, R. (2013). Competences for education for sustainable development in teacher education. CEPS Journal, 3(1), 9-24.

Roorda, N. (2001). Auditing Instrument for Sustainability in Higher Education. http://www. eauc.org.uk/audit instrument for sustainability in higher educ

Sleurs, W. (2008). Competencies for ESD (Education for Sustainable Development) Teachers: A Framework to Integrate ESD in the Curriculum of Teacher Training Institutes. https:// platform.ue4sd.eu/downloads/CSCT_Handbook_11_01_08.pdf

Steiner, R. (2010). Teacher Competencies for Education for Sustainable Development: Report. https://www.umweltbildung.at/fileadmin/umweltbildung/dokumente/Teacher_Competences_for_ESD/Teacher_Competencies_for_ESD_Report_by_Regina_Steiner.pdf

Sterling, S., Maxey, L., \& Luna, H. (Eds.). (2013). The Sustainable University: Progress and Prospects, Abingdon: Routledge.

Svanström, M., Lozano-García, F. J., \& Rowe, D. (2008). Learning outcomes for sustainable development in higher education. International Journal of Sustainability in Higher Education, 9(3), 339-351.

Temple, P. (2010). Sustainability: A job for managers. Perspectives: Policy and Practice in Higher Education, 14(4), 105-107. 
Torres, R., Vieira, R. M., Rodrigues, A. V., Sá, P., \& Moreira, G. (2017). Education for sustainable development: an exploratory study in a Portuguese University. International Journal of Sustainability in Higher Education, 18(6), 956-970

UN (2000). United Nations Millennium Declaration. Resolution adopted by the General Assembly on 18 September 2000 (A/55/L.2). Available at: http://www.un.org/millennium/ declaration/ares552e.pdf

UNECE (2011). Learning for the Future: Competences in Education for Sustainable Development, Strategy for Education for Sustainable Development. https://www.unece.org/filead$\mathrm{min} / \mathrm{DAM} / \mathrm{env} / \mathrm{esd} / \mathrm{ESD}$ _Publications/Competences_Publication.pdf

UNESCO (2012). Shaping the Education of Tomorrow. 2012 Report on the UN Decade of Education for Sustainable Development, Abrigded. Paris: UNESCO. http://sustainabledevelopment.un.org/content/documents/919unescol.pdf

van Weenen, H. (2000). Towards a vision of sustainable university. International Journal of Sustainability in Higher Education, 1(1), 20-34. https://doi.org/10.1108/1467630010307075

Velazquez, L. \& Munguia, N. (1999). Education for sustainable development: the engineer of the $21^{\text {st }}$ century. European Journal of Engineering Education, 24(4), 359-70.

Velazquez, L., Munguia, N., \& Sanchez, M. (2005). Deterring sustainability in higher education institutions: An appraisal of the factors which influence sustainability in higher education institutions. International Journal of Sustainability in Higher Education, 6(4), 383-391.

Velazquez, L., Munguia, N., \& Taddei, J. (2004). A sustainable university: what can be the matter? Journal of Cleaner Production, 14(9-11):810-819.

Wals, A. E. J., \& Corcoran, P. B. (2006). Sustainability as an outcome of transformative learning. In J. Holmberg \& Samuelsson, B. (Eds.), Drivers and barriers for implementing sustainable development in higher education (pp. 103-108). Paris: UNESCO.

Wright, T. S. A. (2002). Definitions and frameworks for environmental sustainability in higher education. Higher Education Policy, 15, 105-120.

Wright, T. S. A. (2009). Sustainability, internationalization, and higher education. New Directions for Teaching and Learning, 118, 105-115. https://doi.org/10.1002/tl.357

Wright, T. S. A. (2010). University presidents' conceptualizations of sustainability in higher education. International Journal of Sustainability in Higher Education, 11(1), 61-73.

Whitmer A, Ogden L, Lawton J, Sturner P, Groffman, P.M, Schneider L, Hart D, Halpern B, Schlesinger W, Raciti S, (2010): The engaged university: providing a platform for research that transforms society. Front. Ecol. Environ. 8, 314-321.

Zilahy, G. \& Huisingh, D. (2009). The roles of academia in regional sustainability initiatives. Journal of Cleaner Production, 17(12), 1057-1066. 


\title{
AN EXPLORATORY ANALYSIS OF BRAND EQUITY \\ BASED ON TANGIBLE AND INTANGIBLE ATTRIBUTES \\ ON TWEETS OF THE LARGEST WESTERN EUROPE MANUFACTURING COMPANIES
}

\author{
Fernando Jurado Ramos ${ }^{1}$ \\ Javier Perez-Aranda ${ }^{2}$
}

DOI: https://doi.org/10.31410/ERAZ.S.P.2020.83

\begin{abstract}
Social networks have become a means of interaction between companies or organizations and consumers. However, few studies have dealt with the use of tangible and intangible attributes on social networks of manufacturing companies. This work deepens the concept of brand equity of European manufacturing companies through the analysis of brand engagement and electronic word-ofmouth (eWOM) generated by social media posts. Firstly, tangible and intangible attributes have been identified on tweets. Secondly, it has been analysed if there is a link between tweets based on tangible and intangible attributes and number of likes (brand engagement) or retweets (eWOM). The multivariate analysis results show relationships between publications including the analysed attributes and brand equity. In contrast, eWOM is only related with tangible attributes. Conclusions are discussed.
\end{abstract}

Keywords: Brand equity, Social networks, Manufacturing sector, Tangible and intangible, Brand engagement and eWOM.

\section{INTRODUCTION}

$I^{\mathrm{n}}$ the last decade, information and communication technology (ICT) have had a huge impact on our society (Servera Francés, Gil Saura, \& Fuentes Blasco, 2009). Specifically, social networks have played a leading role in the advancement of ICT since the early 2000s (Campos Freire, 2008). The availability, thanks to the variety and diversification of social networks (Parveen, Jaafar, \& Sulaiman, 2015) and information dissemination capacity (González Hernando, Valdivieso-León, \& Velasco González, 2020) allow their use in different forms of communication (Bernal Triviño, 2010).

In addition to connecting people with family and friends, the use of social media has evolved over time (Kwak, Lee, Park \& Moon, 2010). For instance, Twitter is a social networking platform in which branding depends on increasing social and economic gain (Page, 2012). This virtual environment where companies and consumers are related can be especially useful at the business level (Culnan, McHugh \& Zubilaga, 2010), since it provides an ideal space for communication with which to deepen the knowledge of consumer needs and opinions.

Business benefits of this virtual communication channel have been widely studied in the last ten years (e.g. Hanna, Rohm \& Critenden, 2011; Michaelidou, Siamagka \& Christodoulides, 2011; Capriotti \& Ruesja, 2018). Specifically, previous studies of business Twitter accounts examine their use in strategic communication (Hanna, Rohm \& Critenden, 2011; Capriotti \& Ruesja, 2018). Also, literature refers to the use of Twitter for business purposes as an engagement tool

\footnotetext{
University of Malaga, Campus de Teatinos, 29071 Málaga, Spain
}

2 University of Malaga, Campus de Teatinos, 29071 Málaga, Spain 
(Rybalko \& Seltzer, 2010); promotion tool (Greer \& Ferguson, 2011); branding tool (Cui, Zhang, Qin, Sellis \& Wu, 2017); customer service enquiries tool (Xiong \& Mackenzie, 2015); or even a distraction tool (Schneiker, Dau, Joachim, Martin \& Lange, 2019).

The available literature with regard to the use of Twitter by the manufacturing or industry sector is scarce, however some studies stand out (e.g. He, Zha \& Li, 2013; Linvill \& Warren, 2020; Rodriguez \& Chalmeta, 2020; Rybalko \& Seltzer, 2010; and Xiong \& Mackenzie, 2015). These studies on tweets by manufacturing or industry sector provide guidelines for developing a competitive analysis strategy $(\mathrm{He}, \mathrm{Zha} \& \mathrm{Li}, 2013)$ and offer insights into the adoption and interaction with customers on Twitter (Xiong \& Mackenzie, 2015).

This study contributes to industrial marketing literature by identifying attributes in the tweets published by manufacturing firms and relating those attributes with consumer behaviour. The objective of this study is to determine the relationship between the content of the tweets (referring to tangible or intangible attributes) and brand equity. To do so, the relationship between the number of likes (brand Engagement) and retweets (eWOM) of tweets published by the largest Western European manufacturing firms and the content of these tweets is empirically tested.

This paper is structured as follows: first, we provide a literature review of brand equity, theoretical framework and hypotheses development. Then, methodology and results are presented. Finally, we offer some concluding remarks that can be of use for manufacturing and industrial businesses in defining customer interaction in Twitter.

\section{LITERATURE REVIEW}

\subsection{Brand Equity in Social Networks}

Brand has been defined as: "a name, term, sign, symbol or design, or some combination of these elements, intended to identify the products or services of one seller or group of sellers and to differentiate them from those of competitors" (Kotler \& Armstrong, 2008). On the other hand, the American Marketing Association (AMA) defines it as: "a name, term, design, symbol, or any other feature that identifies one seller's good or service as distinct from those of other sellers" (American Marketing Association, 2017). In both cases, the brand is considered as a distinguishing element that affects consumer perception.

There is no unique criterion in the literature to measure brand equity, its sources, determinants or drivers (Davcik, Da Silva \& Hair, 2015). Also, brand equity is a term associated with customers' feelings and perceptions about the brand (Pride \& Ferrell, 2003). It is made up of attributes associated with the brand, name or symbols that can add or remove value to the product or service offered (Aaker, 1991). Particularly, both tangible and intangible attributes have been considered as important contributors to brand choice and brand equity (Myers, 2003).

On the other hand, social networks are presented as a great option to increase brand equity of companies through their publications. Some studies have verified the ability of companies to generate brand equity through social networks, such as in the mobile (As'ad \& Alhadid, 2014), luxury (Godey, Manthiou, Pederzoli, Rokka, Aiello, Donvito, \& Singh, 2016), hotel (Callarisa, García, Cardiff, \& Roshchina, 2012), or fashion (Sharma \& Sahni, 2015) industries. 
Specifically, brand loyalty is seen as a key factor of brand equity (Severi, Ling \& Naseroadeli, 2014), while eWOM is considered to be a measure of brand equity (Callarisa, Sánches, Cardiff \& Roshchina, 2012). Brand loyalty is the ability of companies to generate a relationship with their audience, which creates a commitment to the brand which leads to purchase intention (Kuvykaite \& Piligrimiene, 2014). This interaction or commitment to the brand can be key in purchase decisions (Peri \& Lepe, 2010). In turn, eWOM is the process that is carried out by consumers electronically, when they share information and opinions about the brand, products, and services offered.

Nevertheless, previous literature on social networks use different metrics to assess brand engagement and eWOM, depending on the network analysed. For instance, number of references for blogs, incoming links or number of likes for forums, number of reviews or balance of reviews for review sites, number of posts or reposts for social networks or number of likes for video sharing sites (Hoffman \& Fodor, 2010). Thus, in this study, drawing on Hoffman and Fodor's (2010) study "Can you measure the ROI of your social media marketing?" we used the number of tweet likes to measure brand engagement and the number of retweets per tweet to measure word-of-mouth in social media Twitter.

\subsection{Conceptual Framework and Hypotheses Development}

Different theoretical frameworks are currently used to investigate branding and eWOM behaviours in social networks, such as socialization theories (Chu \& Sung, 2015; de Vries, Peluso, Romani, Leeflang \& Marcati, 2017; Zhang, Jansem \& Chowdhury, 2011; Zhang, Omran \& Cobanoglu, 2017), attribution theory (Qiu \& Li, 2010), theory of planned behaviour and justice theory (Fu, Ju \& Hsu, 2015).

In socialization theories, Chu and Sung (2015) draw on social learning theory (Moschis, 1987), largely used in the study of consumption roles (Moschis \& Churchill, 1978). According to Moschis, social learning theory highlights external sources of socialization, like peers (de Gregoria \& Sung, 2010). Within this framework, they concluded that those brand followers who heavily use Twitter and follow many brands were most likely to tweet and retweet brands. In this line, the study of de Vries, Peluso, Romani, Leeflang and Marcati (2017) found that socializing with others promotes participation in engaging activities and encourages people to contribute content. In the work of Zhang, Omran and Cobanoglu, social exchange theory focuses on reciprocity to explain how a person could engage in eWOM (Zhang, Omran \& Cobanoglu, 2017).

The last social theory analysed is social interaction (Godes, Mayzlin, Chen, Das, Dellarocas, Pfeiffer \& Verlegh, 2005) used by Zhang, Jansen and Chowdhury (2011). Their study draws on previous literature assumptions, such as considering consumer reactions to brand tweets as eWOM forms (Jansen, Zhang, Sobel \& Chowdhury, 2009) and promotion materials as driving factors of WOM communication (Keller, 2007). Their study addresses Twitter as a tool for online WOM communication and the influence of company engagement on eWOM communication. By studying the diffusion of messages of different brands they conclude that retweeting tweets is a clear response to business engagement.

On the other hand, according to Qui and Li (2010), when a positive review has negative ratings, consumers are more likely to attribute that review to non-product-related factors. Furthermore, for $\mathrm{Fu}$, Ju and $\mathrm{Hsu}$ (2015), underlying attitudinal factors appear to drive consumers who intend 
to post positive eWOM and satisfaction appear to be influenced by interactional and procedural justice perceptions in positive shopping experiences.

Since the objective of this study is to investigate consumer social interactions to brand communication activities on Twitter, we follow the theory of social interactions (Godes, Mayzlin, Chen, Das, Dellarocas, Pfeiffer \& Verlegh, 2005). In particular, this research extends the study of Zhang, Jansen, and Crowdhury (2011) by highlighting the use of tangible and intangible attributes in brand tweets and investigating consumer reactions, retweets (eWOM), or likes (brand engagement).

Previous literature has linked brand engagement on Twitter to the number of tweet likes (Hoffman \& Fodor, 2010). Recent studies on this linkage was applied in different industries, such as alcohol companies (Carrotte, et al. 2016); movie box offices (Oh, et al. 2017); and healthcare businesses (Leek, Houghton \& Canning, 2019). Particularly, the study of Leek, Houghton and Canning (2019), based on a sample of 838 tweets, examines if the content of tweets posted by product and service companies drives engagement in terms of likes on Twitter. Their results suggest that engagement depends on the type of company and the tweet function analysed. According to these studies it can be hypothesized that:

H1: There is a relationship between industry tweets containing tangible attributes and the number of likes (brand engagement) received.

H2: There is a relationship between industry tweets containing intangible attributes and the number of likes (brand engagement) received.

Regarding eWOM in Twitter, the study by Hoffman and Fodor (2010) links eWOM to the number of retweets. In addition, studies linking different tweet contents and eWOM were encouraging (Adnan, et al. 2019; Cork \& Eddy, 2017; Soboleva, et al. 2017). Specifically, the results of Adnan et al. (2019) state that promoting intervention, or including vaccine price in the content of a tweet about World Pneumonia Day has more retweet count than when the tweet content is a personal experience. According to the results of Cork and Eddy (2017), levels of high vividness or high interactivity in the content of the tweets from athletes generates a higher number of retweets. Furthermore, Sovoleva et al. (2017) find that including a retweet request or a photo in a tweet from industry companies are predictors of the number of retweets, regardless of the industry. In this context, the following hypotheses were tested:

H3: There is a relationship between industry tweets containing tangible attributes and the number of retweets (eWOM) received.

H4: There is a relationship between industry tweets containing intangible attributes and the number of retweets (eWOM) received.

\subsection{Methodology}

The goal of this research is to study the relationship between tweets content and consumer reaction (Figure 1). To achieve this objective, we developed an explorative and descriptive analysis of data collected from different manufacturing companies in Western Europe. 


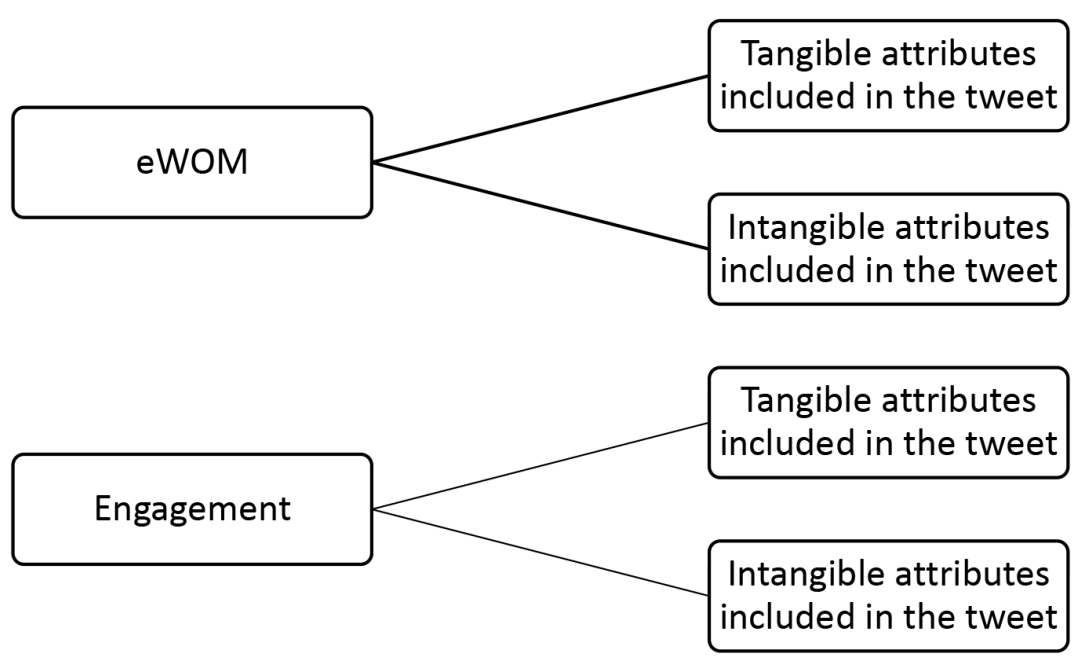

Figure 1. Research model

Source: The authors

\subsection{Sample and Data Collection}

To test the hypotheses, we carried out an investigation consisting of four phases: research design, data collection, data analysis, and treatment and interpretation of the results (Green \& Tull, 1978). In the first phase, a cross-sectional design was used to examine the relationship between the frequency of occurrence of attributes in the publications (tangible or intangible) and the variables of study, i.e. number of retweets (eWOM) and number of likes (brand engagement). This data set is primary data of a quantitative nature, which means that it is specific to this research and analysed statistically. Data collected from observation were entered into a database which totalled more than 5,000 publications to be content analysed.

The initial sample consisted of the top 250 companies with the largest market capitalization in Western Europe (Peiro Ucha, 2015). However, the final sample was reduced to 100 because companies had to meet three criteria. The first criterion is that only industrial companies were included, the second is that said companies must have a Twitter account and, finally, the company must be active in Twitter. That is, we included companies with a minimum of 1,000 tweets and publications made in the weeks preceding this study. Sample collection took place in two one-week periods, in which the first ten publications of each company were compiled in the period analysed (Swani, Brown, \& Milne, 2014). This is to improve the representativeness of all the companies analysed in the sample and take into account the time factor. Table 1 presents the fieldwork data.

Table 1. Datasheet

\begin{tabular}{ll}
\hline Geographic scope & Western Europe \\
\hline Population & Industrial companies in Europe present on Twitter \\
\hline Methodology & Observation/ Content analysis \\
\hline \multirow{2}{*}{ Sample period } & $01 / 03 / 2017-07 / 03 / 2017$ \\
\hline Sample size & $01 / 09 / 2016-07 / 09 / 2016$ \\
\hline Sampling & 100 companies \\
\hline
\end{tabular}

Source: The authors 


\subsection{Variables and Dimensions}

As can be seen in Table 2, the study variables are related to company brand value. In addition, the measures of the variables are based on the use of tangible and intangible elements in tweets, the number of retweets and number of likes on tweets published by the company on its Twitter account.

Table 2. Study variables

\begin{tabular}{ccc}
\hline Variables & Metrics & Authors \\
\hline Engagement & Number of retweets \\
eWOM & Number of tweet likes & Hoffman \& Fodor, 2010 \\
\hline Tangible attributes & $\begin{array}{c}\text { Tangible attributes in the tweet } \\
\text { Intangible attributes in the tweet }\end{array}$ & Myers, 2003 \\
\hline
\end{tabular}

Source: The authors.

When analysing the publications, we collected the number of retweets and the number of tweet likes at the time of data collection. For attributes the following coding and tabulation was performed:

Table 3. Codification of variables

\begin{tabular}{|c|c|c|}
\hline Codification 1 & \multicolumn{2}{|l|}{ Codification 2} \\
\hline \multirow{3}{*}{$\begin{array}{l}1=\text { Tangible attributes } \\
2=\text { Intangible attributes } \\
3=\text { Both attributes } \\
4=\text { None }\end{array}$} & Tangible attributes & $1=1,3=$ YES \\
\hline & \multirow{2}{*}{ Intangible attributes } & $1=2,3=\mathrm{YES}$ \\
\hline & & $2=1,4=\mathrm{NO}$ \\
\hline
\end{tabular}

Source: The authors

\section{RESULTS}

\subsection{Descriptive Results}

Table 4 shows the results of the descriptive analysis of the variables 'number of retweets' and 'number of likes'. It can be observed that, in the 889 tweets studied in the first period and the 804 tweets of the second period, the standard deviation for both variables is between 75 and 207, which suggests that some companies, or some types of publications, have much more impact than others. Asymmetry of distribution in both variables is due to high values that affect the mean, while not affecting the median as much.

Table 4. Descriptive analysis, retweets and likes

\begin{tabular}{llcc}
\hline Period & & & \\
\hline \multirow{3}{*}{ First week } & Tweets frequency & 889 & 889 \\
& Retweets Mean/ Likes mean & 19.09 & 39.75 \\
& Retweets Standard Deviation / Likes stan- & 97.305 & 169.665 \\
& dard deviation & 11.019 & 8.556 \\
\hline \multirow{3}{*}{ Second week } & Retweets Asymmetry / Likes asymmetry & 804 & 804 \\
& Tweets frequency & 20.30 & 49.79 \\
& Retweets Mean/ Likes mean & 75.622 & 207.286 \\
& Retweets Standard Deviation / Likes stan- & 7.279 & 6.859 \\
\hline
\end{tabular}

Source: The authors

The results in Table 5 show the descriptive analysis carried out with the aim of determining the profile of the tweets written by the companies that make up the sample. 
Table 5. Descriptive analysis of coded attributes

\begin{tabular}{l|lcc|lcc}
\hline \multirow{2}{*}{ Period } & \multicolumn{1}{|c}{ Attribute } & Frequency & $\begin{array}{c}\text { Percentage } \\
(\mathbf{\%})\end{array}$ & Attribute & Frequency & $\begin{array}{c}\text { Percentage } \\
(\mathbf{\%})\end{array}$ \\
\hline \multirow{5}{*}{ First week } & Tangible & 231 & 26 & Tangible & 336 & 37.8 \\
& Intangible & 196 & 22 & No tangible & 553 & 62.2 \\
\cline { 2 - 8 } & Both & 105 & 11.8 & Intangible & 301 & 33.9 \\
& None & 357 & 40.2 & No intangible & 588 & 66.1 \\
\hline \multirow{5}{*}{ Second week } & Tangible & 210 & 26.1 & Tangible & 282 & 35.1 \\
& Intangible & 178 & 22.1 & No tangible & 522 & 64.9 \\
\cline { 2 - 8 } & Both & 72 & 9 & Intangible & 250 & 31.1 \\
& None & 344 & 42.8 & No intangible & 554 & 68.9 \\
\hline
\end{tabular}

Source: The authors

It is observed that the sample, in both observation periods, is made up of tweets in which tangible attributes appear in a $26 \%$ of cases, intangible attributes in a $22 \%$ of cases, both in a $10 \%$ of cases and none in a $40 \%$ of cases, approximately. It is also perceived that the appearance of these elements in tweets is similar in the two periods.

In addition, to focus the study on the content that generates the most interaction with the consumer, the variables 'number of retweets' and 'number of likes' were classified according to their frequencies. The procedure was as follows. The analysis showed that, independently of attributes included, approximately $80 \%$ of the sample has between 0 to 10 retweets, and the remaining $20 \%$ has more than 10 retweets. In the case of the variable 'number of likes', approximately $70 \%$ of tweets have received between 0 and 10 likes, thus leaving $30 \%$ of the remaining sample in the ranking of high number of likes. Table 6 shows the frequencies for this new rank.

Table 6. Frequencies, after reordering

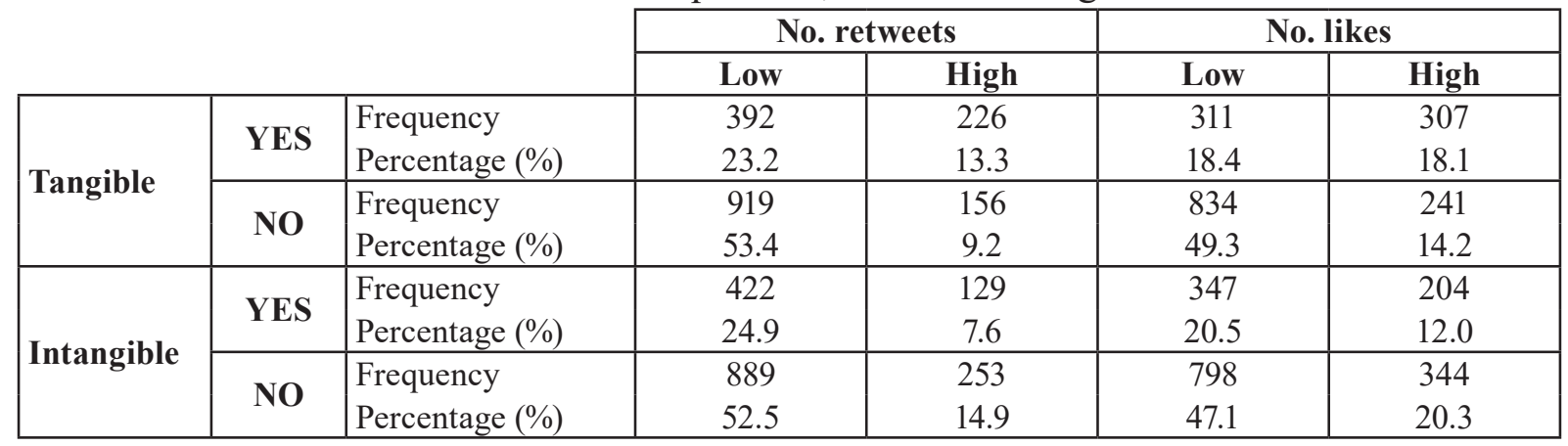

Source: The authors.

\subsection{The Chi-Square Test of Independence}

The relationship between the number of retweets and the number of likes with tangible and intangible attributes was investigated with non-parametric (distribution free) test of independence. Therefore, as they are dichotomous nominal variables, we used the Pearson's Chi-square test to determine if there is a significant relationship between the variables.

Table 7 shows the asymptotic (bilateral) significance between tangible attributes and the high number of retweets and likes received. The results are significant in both cases since the bilateral asymptotic significance is less than 0.05 , which suggests that there is a relationship between the variables. 
Table 7. Association testing of tangible attributes

\begin{tabular}{|l|c|c|c|c|c|c|c|c|}
\cline { 2 - 9 } & \multicolumn{4}{c|}{ Tangible attributes - No. retweets } & \multicolumn{4}{c|}{ Tangible attributes - No. likes } \\
\cline { 2 - 10 } & Value & df & $\begin{array}{c}\text { Asymptotic } \\
\text { significance } \\
\text { (bilateral) }\end{array}$ & $\begin{array}{c}\text { Exact } \\
\text { significance } \\
\text { (bilateral) }\end{array}$ & Value & df & $\begin{array}{c}\text { Asymptotic } \\
\text { significance } \\
\text { (bilateral) }\end{array}$ & $\begin{array}{c}\text { Exact } \\
\text { significance } \\
\text { (bilateral) }\end{array}$ \\
\hline Pearson's Chi-square & 109.274 & 1 & 0.000 & & 133.183 & 1 & 0.000 & \\
\hline Continuity correction & 108.016 & 1 & 0.000 & & 131.941 & 1 & 0.000 & \\
\hline Likelihood ratio & 105.951 & 1 & 0.000 & & 131.044 & 1 & 0.000 & 0.000 \\
\hline Fisher's exact test & & & & 0.000 & & & & \\
\hline $\begin{array}{l}\text { Linear-by-linear } \\
\text { association }\end{array}$ & 109.21 & 1 & 0.000 & & 133.104 & 1 & 0.000 & \\
\hline
\end{tabular}

Source: The authors

Table 8. Association testing of intangible attributes

\begin{tabular}{|c|c|c|c|c|c|c|c|c|}
\cline { 2 - 10 } & \multicolumn{2}{c|}{ Intangible attributes - No. retweets } & \multicolumn{3}{c|}{ Intangible attributes - No. likes } \\
\cline { 2 - 10 } & Value & df & $\begin{array}{c}\text { Asymptotic } \\
\text { significance } \\
\text { (bilateral) }\end{array}$ & $\begin{array}{c}\text { Exact } \\
\text { significance } \\
\text { (bilateral) }\end{array}$ & Value & df & $\begin{array}{c}\text { Asymptotic } \\
\text { significance } \\
\text { (bilateral) }\end{array}$ & $\begin{array}{c}\text { Exact } \\
\text { significance } \\
\text { (bilateral) }\end{array}$ \\
\hline Pearson's Chi-square & 0.337 & 1 & 0.562 & & 8.086 & 1 & 0.004 & \\
\hline Continuity correction & 0.268 & 1 & 0.604 & & 7.773 & 1 & 0.005 & \\
\hline Likelihood ratio & 0.335 & 1 & 0.563 & & 7.996 & 1 & 0.005 & \\
\hline Fisher's exact test & & & & 0.577 & & & & 0.005 \\
\hline $\begin{array}{c}\text { Linear-by-linear } \\
\text { association }\end{array}$ & 0.336 & 1 & 0.562 & & 8.081 & 1 & 0.004 & \\
\hline
\end{tabular}

Source: The authors

Table 8 shows the analysis of the intangible elements and the high number of retweets and likes received. The results obtained in the asymptotic significance (bilateral) suggest that there is a relationship between intangible attributes and a high number of likes. On the other hand, it is concluded that there is no relationship between intangible attributes and a high number of retweets.

\section{4, CONCLUSION AND FUTURE RESEARCH DIRECTIONS}

Interesting conclusions can be drawn from the results of the different analyses that have been carried out. The descriptive analysis showed that the companies in the sample do not vary much their tangible and intangible contents over time, since the presence of those elements in the publications in both periods is similar. The companies seem to prefer to include some attribute - be it tangible, intangible or both - rather than none in their publications. Finally, we found that companies are more prone to include tangible than intangibles attributes.

To test the hypotheses, and to investigate the relationships between the elements included in the tweets (tangible and intangible) and brand value generated (eWOM and brand engagement), a multivariate analysis was performed using the Chi-square test. Table 9 summarizes the hypotheses testing results.

In view of the results obtained with this sample, there is a relationship between the tweets that contain or mention company's tangible and intangible attributes and a high number of likes. On the contrary, there is a relationship between tweets that contain or mention company's tangible and intangible attributes and a high number of retweets in the case of tangible attributes. Therefore, tangible and intangible attributes in the content of tweets are variables that are related to brand engagement. In turn, only tangible attributes in the content of tweets are related to eWOM. 
Table 9. Summary of hypotheses testing

\begin{tabular}{lll}
\hline Hypothesis & Result \\
\hline H1: & $\begin{array}{l}\text { There is a relationship between industry tweets containing tangible attributes } \\
\text { and the number of likes (brand engagement) received. }\end{array}$ & Supported \\
\hline H2: & $\begin{array}{l}\text { There is a relationship between industry tweets containing intangible attributes } \\
\text { and the number of likes (brand engagement) received. }\end{array}$ & Supported \\
\hline H3: & $\begin{array}{l}\text { There is a relationship between industry tweets containing tangible attributes } \\
\text { and the number of retweets (eWOM) received. }\end{array}$ & Supported \\
\hline H4: & $\begin{array}{l}\text { There is a relationship between industry tweets containing intangible attributes } \\
\text { and the number of retweets (eWOM) received. }\end{array}$ & Not Supported \\
\hline
\end{tabular}

Source: The authors

There are several limitations in this study. The first one, is the size of the sample that includes companies from a single geographic area. Secondly, given the importance that social networks are gaining, conducting this study on another social network or on several at the same time could provide more information on how industrial companies can develop their brand equity. Finally, this study only performs an exploratory and descriptive approach to the analysed phenomenon. Future studies could include other industries, use different social networks to collect information, and further the study by including explanatory variables and cause-effect relationships in the analysis.

\section{ACKNOWLEDGMENTS}

This research was supported by the Plan Andaluz de Investigación, Desarrollo e Innovación (Convocatoria 2017), Grupo SEJ-567 (Spain).

\section{REFERENCES}

Aaker, D. a. (1991). Managing Brand equity. Journal of Marketing.

American Marketing Association. (2017). What is Marketing? - The Definition of Marketing. Retrieved May 31, 2020, from https://www.ama.org/the-definition-of-marketing-what-is-marketing/

Adnan, M. M., Yin, J., Jackson, A. M., Tse, Z. T. H., Liang, H., Fu, K. W., ... \& Fung, I. C. H. (2019). World Pneumonia Day 2011-2016: Twitter contents and retweets. International health, 11(4), 297-305.

As' ad, H. A. R., \& Alhadid, A. Y. (2014). The impact of social media marketing on brand equity: An empirical study on mobile service providers in Jordan. Review of Integrative Business and Economics Research, 3(1), 315.

Bernal Triviño, A. I. (2010). Presencia de las redes sociales en los cibermedios españoles. Textual \& Visual Media, 3, 25-42.

Campos Freire, F. (2008). Revista Latina de Comunicación Social 63-2008 Las redes sociales trastocan los modelos de los medios de comunicación tradicionales

Callarisa, L., García, J. S., Cardiff, J., \& Roshchina, A. (2012). Harnessing social media platforms to measure customer-based hotel brand equity. Tourism Management Perspectives, 4, 73-79.

Capriotti, P., \& Ruesja, L. (2018). How CEOs use Twitter: A comparative analysis of Global and Latin American companies. International journal of information management, 39, 242-248.

Carrotte, E. R., Dietze, P. M., Wright, C. J., \& Lim, M. S. (2016). Who 'likes' alcohol? Young Australians' engagement with alcohol marketing via social media and related alcohol consumption patterns. Australian and New Zealand journal of public health, 40(5), 474-479. 
Cork, B. C., \& Eddy, T. (2017). The retweet as a function of electronic word-of-mouth marketing: A study of athlete endorsement activity on twitter. International Journal of Sport Communication, 10(1), 1-16.

Cui, L., Zhang, X., Qin, A. K., Sellis, T., \& Wu, L. (2017). CDS: Collaborative distant supervision for Twitter account classification. Expert Systems with Applications, 83, 94-103.

Culnan, M. J., McHugh, P. J., \& Zubillaga, J. I. (2010). How large US companies can use Twitter and other social media to gain business value. MIS Quarterly Executive, 9(4).

Chu, S. C., \& Sung, Y. (2015). Using a consumer socialization framework to understand electronic word-of-mouth (eWOM) group membership among brand followers on Twitter. Electronic Commerce Research and Applications, 14(4), 251-260.

Davcik, N. S., Da Silva, R. V., \& Hair, J. F. (2015). Towards a unified theory of brand equity: conceptualizations, taxonomy and avenues for future research. Journal of Product \& Brand Management.

de Gregorio, F., Sung, Y., 2010. Understanding attitudes toward and behaviors in response to product placement: a consumer socialization framework. Journal of Advertising 39 (1), 83-96.

de Vries, L., Peluso, A. M., Romani, S., Leeflang, P. S., \& Marcati, A. (2017). Explaining consumer brand-related activities on social media: An investigation of the different roles of self-expression and socializing motivations. Computers in Human Behavior, 75, 272-282.

Fu, J. R., Ju, P. H., \& Hsu, C. W. (2015). Understanding why consumers engage in electronic word-ofmouth communication: Perspectives from theory of planned behavior and justice theory. Electronic Commerce Research and Applications, 14(6), 616-630.

Godes, D., Mayzlin, D., Chen, Y., Das, S., Dellarocas, C., Pfeiffer, B., ... \& Verlegh, P. (2005). The firm's management of social interactions. Marketing letters, 16(3-4), 415-428.

Godey, B., Manthiou, A., Pederzoli, D., Rokka, J., Aiello, G., Donvito, R., \& Singh, R. (2016). Social media marketing efforts of luxury brands: Influence on brand equity and consumer behavior. Journal of business research, 69(12), 5833-5841.

González Hernando, C., Valdivieso-León, L., \& Velasco González, V. (2020). Estudiantes universitarios descubren redes sociales y edublog como medio de aprendizaje. RIED. Revista Iberoamericana de Educación a Distancia, 23(1). https://doi.org/10.5944/ried.23.1.24213

Green, P. E., \& Tull, D. S. (1978). Research for Marketing Decisions. Journal of Marketing Research $J M R$ (Vol. 15).

Greer, C. F., \& Ferguson, D. A. (2011). Using Twitter for promotion and branding: A content analysis of local television Twitter sites. Journal of Broadcasting \& Electronic Media, 55(2), 198-214.

Hanna, R., Rohm, A., \& Crittenden, V. L. (2011). We're all connected: The power of the social media ecosystem. Business horizons, 54(3), 265-273.

He, W., Zha, S., \& Li, L. (2013). Social media competitive analysis and text mining: A case study in the pizza industry. International Journal of Information Management, 33(3), 464-472.

Jansen, B. J., Zhang, M., Sobel, K., \& Chowdury, A. (2009). Twitter power: Tweets as electronic word of mouth. Journal of the American society for information science and technology, 60(11), 21692188.

Keller, E. (2007). Unleashing the power of word of mouth: Creating brand advocacy to drive growth. Journal of advertising research, 47(4), 448-452.

Kwak, H., Lee, C., Park, H., \& Moon, S. (2010, April). What is Twitter, a social network or a news media?. In Proceedings of the 19th international conference on World wide web (pp. 591-600).

Kotler, P., \& Amstrong, G. (2008). Fundamentos de Marketing. Prentice Hall. https://doi.org/9789702604006

Kuvykaite, R., \& Piligrimiene, Z. (2014). Consumer Engagement into Brand equity Creation. Procedia - Social and Behavioral Sciences, 156, 479-483. https://doi.org/10.1016/j.sbspro.2014.11.225

Leek, S., Houghton, D., \& Canning, L. (2019). Twitter and behavioral engagement in the healthcare sector: An examination of product and service companies. Industrial Marketing Management, 81, 115-129. 
Linvill, D. L., \& Warren, P. L. (2020). Troll factories: Manufacturing specialized disinformation on Twitter. Political Communication, 1-21.

Michaelidou, N., Siamagka, N. T., \& Christodoulides, G. (2011). Usage, barriers and measurement of social media marketing: An exploratory investigation of small and medium B2B brands. Industrial marketing management, 40(7), 1153-1159.

Moschis, G.P., 1987. Consumer Socialization. Lexington Books, Lexington, MA.

Myers, C. A. (2003). Managing brand equity: a look at the impact of attributes. Journal of product \& brand management.

Oh, C., Roumani, Y., Nwankpa, J. K., \& Hu, H. F. (2017). Beyond likes and tweets: Consumer engagement behavior and movie box office in social media. Information \& Management, 54(1), 25-37.

Page, R. (2012). The linguistics of self-branding and micro-celebrity in Twitter: The role of hashtags. Discourse \& communication, 6(2), 181-201.

Parveen, F., Jaafar, N. I., \& Sulaiman, A. (2015). Role of social media on information accessibility. In Pacific Asia Conference on Information Systems, PACIS 2015 - Proceedings (Vol. 8). Pacific Asia Conference on Information Systems. https://doi.org/10.17705/1pais.08402

Peiro Ucha, A. (2015). Empresas más grandes de Europa Occidental. Retrieved December 21, 2016, from http://economipedia.com/ranking/empresas-mas-grandes-de-europa-occidental-2015.html

Peri, P. C., \& Lepe, F. S. (2010). Responsabilidad Social Empresarial.

Pride, W. M., \& Ferrell, O. C. (2003). Marketing: Concepts and strategies. Boston, MA: Houghton Mifflin Company.

Qiu, L., \& Li, D. (2010). Effects of Aggregate Rating on eWOM Acceptance: An Attribution Theory Perspective. In PACIS (p. 147).

Rodríguez, P., \& Chalmeta, R. (2020). Analysis of the use of Twitter as a tool for the management and communication of the CSR of leading European firms. International Journal of Web Based Communities, 16(2), 180-201.

Rybalko, S., \& Seltzer, T. (2010). Dialogic communication in 140 characters or less: How Fortune 500 companies engage stakeholders using Twitter. Public relations review, 36(4), 336-341.

Schneiker, A., Dau, M., Joachim, J., Martin, M., \& Lange, H. (2019). Hiding in plain sight: Private military and security companies' use of Twitter as a distraction tool. Media, War \& Conflict, 12(4), 483-503.

Servera Francés, D., Gil Saura, I., \& Fuentes Blasco, M. (2009). La influencia de la calidad de servicio logístico en la lealtad. un análisis del papel moderador de las tic 1. Investigaciones Europeas de Direccion y Economia de La Empresa, 15(3), 33-54. https://doi.org/10.1016/S11352523(12)60099-9

Severi, E., Ling, K. C., \& Nasermoadeli, A. (2014). The impacts of electronic word of mouth on brand equity in the context of social media. International Journal of Business and Management, 9(8), 84-96.

Sharma, R. B., \& Sahni, M. M. (2015). Evaluating the efficacy of Facebook communities \& Twitter tweets on brand equity: an empirical study on fashion brands. Advances in Economics and Business Management (AEBM), 2(5), 503-508.

Xiong, F., \& MacKenzie, K. (2015). The business use of Twitter by Australian listed companies. The Journal of Developing Areas 49(6), 421-428. https://doi:10.1353/jda.2015.0107

Zhang, M., Jansen, B. J., \& Chowdhury, A. (2011). Business engagement on Twitter: a path analysis. Electronic Markets, 21(3), 161.

Zhang, T. C., Omran, B. A., \& Cobanoglu, C. (2017). Generation Y's positive and negative eWOM: use of social media and mobile technology. International Journal of Contemporary Hospitality Management. 



\title{
THE DIFFERENT APPROACHES FOR THE MARKET SEGMENT B2G (B2A) COMPARED TO B2B AND B2C, BASED ON A CASE STUDY FOR INFRASTRUCTURE IN THE PHILIPPINES
}

\author{
Bernhard Alexander Krah ${ }^{1}$
}

DOI: https://doi.org/10.31410/ERAZ.S.P.2020.95

\begin{abstract}
In today's highly competitive marketing methods, the market segments B2B (Business-to-Business) and B2C (Business-to-Consumer) are very well established and applied. The worldwide largest market segment, the B2A/B2G (Business-to-Administration/Business-to-Government) however, has until now received little or no attention in the literature.

In the theoretical part of this paper, a focus has been placed on the measurements, how a company is able to find the right approach to operate its business successfully in this very specific business segment, where the players have completely different motivations. The aim of this paper is to gain insight into the basic concepts what rules must be followed to avoid delays, errors and losses, especially considering suppliers, who want to work internationally.

This paper is complemented by a case study of an infrastructure product (sewage pipe system), that was manufactured and successfully launched and installed in the Philippines.

This research shows the strategy for an infrastructure product market penetration for a new player in the market, with a ,non-existent "product.
\end{abstract}

Keywords: Marketing, B2G, B2A, Market segments, Business-to-Administration, Business-to-Government, Infrastructure, Philippines.

\section{INTRODUCTION}

Towadays, the marketing literature is mainly focused on $\mathrm{B} 2 \mathrm{~B}$ or $\mathrm{B} 2 \mathrm{C}$. But the "forgotten" 1 field of B2G / B2A is the most stable and largest market, even due to the fact, that the B2G/ B2A market is the biggest worldwide. Basically, B2G/B2A is the market that serves "public spending". The public spending enables governments to purchase/obtain services and goods in order to fulfil their objectives. As an example, products can be considered, which are required to operate and be used in local infrastructure, the military and other government services to the population (for example social spending, education, transfers). The source of money for spending is tax, money, credits, aid fonds and special private financed projects, called PPP (Public-Private-Partnership). Public-private partnerships involve a collaboration between a government agency and a private-sector company that can be used to finance, build, and operate projects, such as public transportation networks, parks, and convention centres (Kenton, 2012).

Excursus: After the last "Great Depression", John Maynard Keynes ${ }^{3}$ - one of the most famous and important economist for macroeconomic theories - presented his idea in the book "The general Theory of Employment, Interest and Money" (Keynes, 2018). According to his statement,

\footnotetext{
Faculty of Management, Comenius University, Bratislava

The Great Depression was a worldwide economic depression from 1929-1930 (started in the USA)

John Maynard Keynes (1883-1946), economist. Origin of various macroeconomic theories.
} 
the strongest method to increase the wealth and GNP (gross national product) of a country is to spend money in the public sector (even if the money is generated on credits).

The possibility that governments around the world try to stimulate their economy by public spending is currently very high (even financed on government depts), after the Corona-effect caused by COVID-19. So, it can be a great opportunity to approach the B2G/B2A market to create more business.

In the second part (number 5) of this article a case study is included. This case study shows how a start-up (production of large pipes systems mainly for infrastructure projects) has successfully implemented the B2G/B2A marketing. To obtain the relevant information, many interviews with the General Manager ${ }^{4}$ and the Sales Manager ${ }^{5}$ were conducted in January 2020.

\section{MARKET SEGMENTS}

A market is the "place" where supply and demand meet each other. The value, cost and price of items traded are as per forces of supply and demand in a market (What Is Markets? Definition of Markets, Markets Meaning - the Economic Times, 2020.000Z). Basically, a market can be segmented according to geographical, temporal, product, product-related and demand-related factors.

There are three different main types of markets: the monopoly, oligopoly and polypoly market - and combinations of those three.

Table 1. Market forms, own description of the author, according to information from Heinrich Freiherr zu Stackelberg6

\begin{tabular}{|c|l|l|l|}
\hline Suppliers Demanders & \multicolumn{1}{c|}{ One } & \multicolumn{1}{c|}{ Few } & \multicolumn{1}{c|}{ Many } \\
\hline One & Bilateral Monopoly & Limited Monopoly & Monopoly \\
\hline Few & Limited Monopson & Bilateral Oligopoly & Oligopoly \\
\hline Many & Monopson & Oligopson & Polypoly \\
\hline
\end{tabular}

A monopoly exists in areas where one company, firm, or entity is the only - or dominant - force that sells a product or service in an industry. This gives the company enough power to keep other competitors away from the marketplace.

In an oligopoly, a group of smaller firms controls the market. However, none of them can keep the others from having significant influence in the industry. They may sell products that are slightly different (Hall, 2014).

A polypoly is a market situation where there are many small buyers and small sellers, none of which can influence prices (What Is Polypoly? Definition and Meaning, 2020.000Z). The polypoly represents the „normal case” of markets; it is also called "complete competition”.

In the B2A/B2G sector, an oligopoly supplier meets a monopoly demand: a few companies (e.g. road construction, pipe production, defence technology) bid to the state (Timm Gudehus, 2015). So, the correct wording of this is monopsony.

\footnotetext{
$4 \quad$ Sajid Anonuevo, General Manger and shareholder of Krah-Pipes Manila Inc.

5 Jeneleen Lansangan, Sales manager of Krah-Pipes-Manila Inc.

$6 \quad$ Heinrich Freiherr zu Stackelberg was a German Economist (1905-1946) 
An important point to be respected to be a player in B2G/B2A market is that this market segment compared to the other markets is absolutely transparent in the procedures. Nearly every firm/company can attend, but the bureaucratical work is high.

\section{CHARACTERISTICS OF THE DIFFERENT MARKETS}

B2B - The focus of the analysis is on transactions between industrial and service companies and organisations, including state administration (Caspar \& Metzler, 2002). The focus is on economic efficiency and economic calculations are an integral part of this market segment.

$\mathrm{B} 2 \mathrm{C}$ - In the $\mathrm{B} 2 \mathrm{C}$ sector, the business relationship exists between companies and end consumers. The B2C sector covers, ,the information, communications and transactions between companies and their customers or prospects” (Wolf Engelbach et al., 2010). Feelings and the level of spending are in the foreground and there is a typical marketing approach (many suppliers, many customers). The decision-maker on the market launch is usually also the user.

B2G/B2A - This sector covers all the company's relations with public institutions, from legal matters to lobbying. An increasingly important factor is also the public-private partnership. Political interests, geopolitics, infrastructure, and other factors are decisive for the B2G/B2A sector. Decisions on product introductions are usually made within the available budget and only listed companies and products can be used/purchased.

There is a great influence in decisions by political interests (e.g. "green"), geopolitics (military), infrastructure (country's future). Decisions are mostly taken as budget decision (a certain budget has to be spent, otherwise it will be reduced in the future).

Table 2. Comparison of Business-to-Government and Business-to-Business Relationships (Brett W. Josephson et al., 2019), adding some further criteria, as well as considering interna-

\begin{tabular}{|l|l|l|}
\hline Criteria & B2G/B2A & B2B \\
\hline Nature of business & $\begin{array}{l}\text { Exchange of goods and services } \\
\text { between businesses and government } \\
\text { agencies }\end{array}$ & $\begin{array}{l}\text { Exchange of goods and services } \\
\text { between businesses }\end{array}$ \\
\hline Examples of customers & $\begin{array}{l}\text { Department of Defence, Department } \\
\text { of Public Works, Department of } \\
\text { Justice, Department of Education }\end{array}$ & Walmart, IBM, Apple BMW, Siemens \\
\hline Value proposition & $\begin{array}{l}\text { Driven by stakeholder interests } \\
\text { and welfare, required to provide } \\
\text { societal welfare to satisfy specific } \\
\text { stakeholder requirements set by the } \\
\text { government }\end{array}$ & $\begin{array}{l}\text { Driven by value and solutions, } \\
\text { procurement decisions are geared } \\
\text { toward solving critical problems and } \\
\text { optimizing performance of solution }\end{array}$ \\
\hline Procurement risk preference & $\begin{array}{l}\text { Low risk tolerance; purchase based } \\
\text { on prior specifications with little } \\
\text { incentive for innovation }\end{array}$ & $\begin{array}{l}\text { Medium to high risk tolerance; purchase } \\
\text { based on the needs of the organisation; } \\
\text { a firm may seek innovative solutions to } \\
\text { differentiate itself from competitors }\end{array}$ \\
\hline Spending pressures & $\begin{array}{l}\text { Close monitoring of government } \\
\text { spending from voters and parliament }\end{array}$ & $\begin{array}{l}\text { Varies depending on the nature of } \\
\text { organisation }\end{array}$ \\
\hline Regulatory minutia & $\begin{array}{l}\text { Subject to the Federal Acquisition } \\
\text { Regulation and agency-specific } \\
\text { regulations }\end{array}$ & $\begin{array}{l}\text { Idiosyncratic to the organisation; not } \\
\text { subject to the Federal Acquisition } \\
\text { Regulation }\end{array}$ \\
\hline
\end{tabular}




\begin{tabular}{|l|l|l|}
\hline Procedural transparency & $\begin{array}{l}\text { Most aspects of the bidding and } \\
\text { procurement process are open to } \\
\text { public discourse }\end{array}$ & $\begin{array}{l}\text { Difficult to gain information about } \\
\text { competitors' offerings and prices }\end{array}$ \\
\hline Relationship-building tactics & $\begin{array}{l}\text { Subject to Code of Federal } \\
\text { Regulations: heavy regulations } \\
\text { related to provide incentives to } \\
\text { procurement officers }\end{array}$ & $\begin{array}{l}\text { Not subject to Code of Federal } \\
\text { Regulations; less stringent rules related } \\
\text { to providing incentives to buyers }\end{array}$ \\
\hline Size and variety of contracts & $\begin{array}{l}\text { Multiple contract sizes (small dollar } \\
\text { amounts to multibillion-dollar } \\
\text { awards); multiple contract structures } \\
\text { (fixed price, cost reimbursement, } \\
\text { etc.) }\end{array}$ & Varies \\
\hline $\begin{array}{l}\text { Solvency and prompt } \\
\text { payment }\end{array}$ & $\begin{array}{l}\text { Timely payment schedule; virtually } \\
\text { no solvency issue }\end{array}$ & $\begin{array}{l}\text { Less prompt payment schedules; } \\
\text { varying degrees of solvency }\end{array}$ \\
\hline
\end{tabular}

\section{SPECIAL APPROACHES IN THE B2A / B2G}

Compared to B2C or B2B, contracts and decisions in governments (B2A/B2G) should be transparent. This means, the procurement-process is clear and structured, but not quick or easy. But it seems, that the $\mathrm{B} 2 \mathrm{G} / \mathrm{B} 2 \mathrm{~A}$ market is very impenetrable, with bureaucratic obstacles, tight budgets and comprehensive contracts.

In addition to the supply monopoly, there is also the market form of the demand monopoly, also called monopsony. In a monopsony, a large buyer controls the market. Because of their unique position, monopsonies have a wealth of power (Young, 2003). In the field of B2G/B2A this is the standard for one country or a group of countries like the European Union.

The intention of public spending is (should be) minimizing risks, as taxpayers' money is being used. Another key word is transparency in this context: no decision-making process is as clear and public as that in $\mathrm{B} 2 \mathrm{G}$ - because all structures are publicly available. The authorities are not very interested in new products, but in increasing efficiency and if it only means using the budget more efficiently. All product presentation should focus to "pain-points" of the agencies and not to the product.

The first and most important step is to register a company as a supplier in the different agencies of the government. Depending on the amount of contract, different supplier-classifications can be applied (for example in large infrastructure projects).

Because the government is very politically driven, several criteria can help to receive some "special credits" for a company during a procurement process. For example, the protection of minorities, etc. possibly using special company conditions, like a certain ratio of handicapped people being employed, veteran owned, woman owned, small businesses, etc. can be used to have a better ranking in public orders.

The customer - a government / country - has several „front-ends” (agencies) depending on the products offered. Sometimes the communication culture between the agencies is high and also the information flow - this should be taken into account while spreading information. An investigation of government regulation is absolutely needed to understand the procedure of public procurement.

It is very common and useful to invest in extensive lobby-work. 


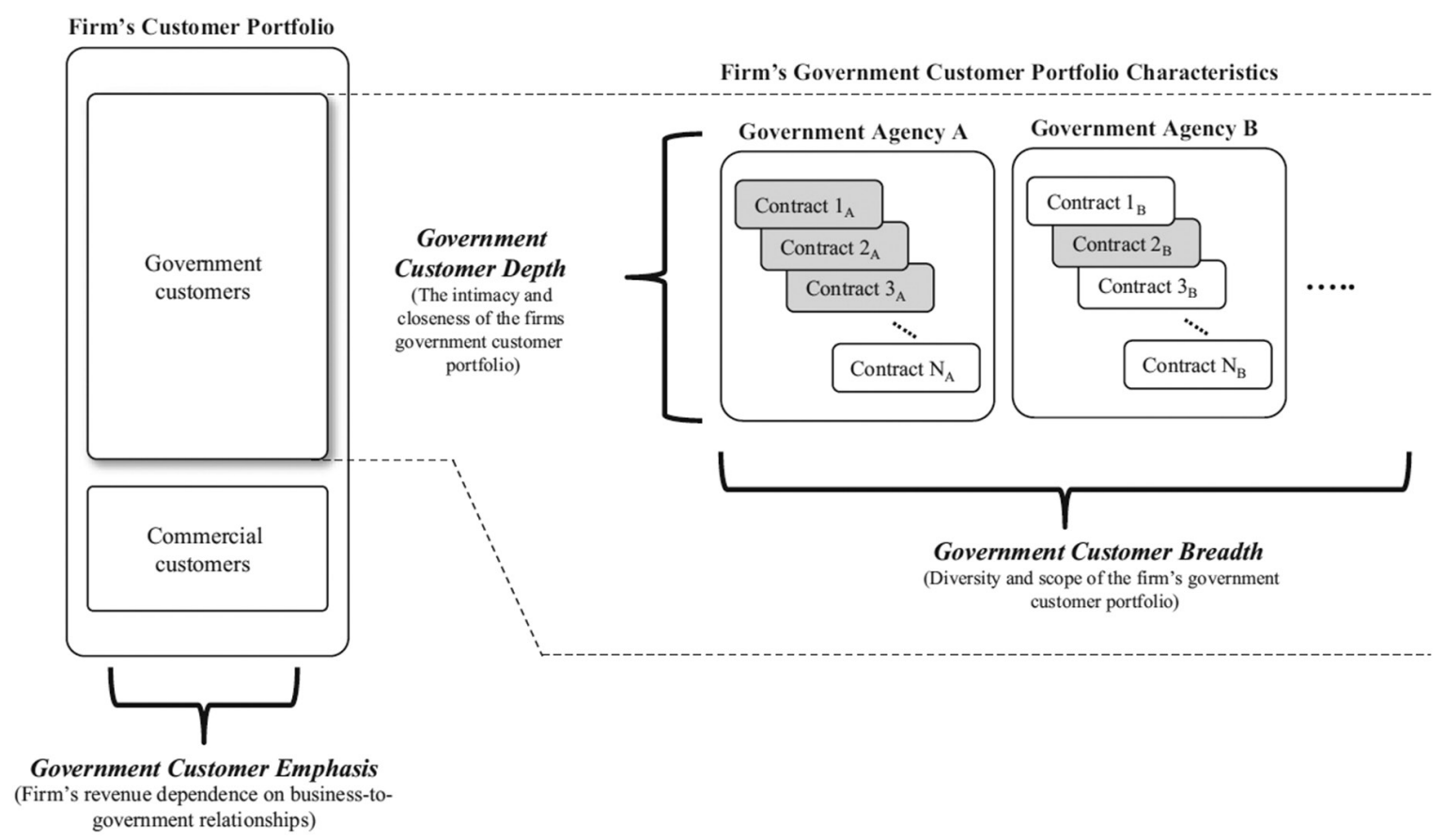

Diagram 1. Uncle Sam Rising: Performance Implications of Business-to-Government Relationships, Figure 1 (Brett W. Josephson et al., 2019)

If a company/firm is focused on several agencies, the „Government Customer Breath” increases. In case many contracts/projects/tenders are processed within one agency, the „Government Customer Depth" also increases.

Public spending enables governments to produce and purchase goods and services, in order to fulfil their objective such as the provision of public goods or the redistribution of resources. There are huge differences between countries in terms of public spending. Central governments in high-income countries - particularly those in Europe - tend to control a much larger share of national production than governments in low-income countries. For example, in France, central government is spending accounts for almost $50 \%$ of all national output. In Nigeria, the corresponding figure is close to $6 \%$. If we focus on the social spending component of government expenses, it is the same: high-income countries also have higher levels of social spending, particularly in the form of transfers. This correlation reflects the fact that high-income countries tend to have more capacity to extract revenues, which in turn is due to their capacity to implement efficient tax collection systems. The situation is different for the compensation of government employees. Throughout Europe, the share of government spending that is devoted to the compensation of government employees ranges between 5\% and 15\%. In contrast, throughout most of Africa the available figures range between 30\% and 50\% (Esteban Ortiz-Ospina \& Max Roser, 2016). Some national projects are also funded from the world-bank, IWF, etc. when they are human oriented for education, environment, and development - in this kind of projects other "additional" regulations are applicable.

In general, there are two ways of tenders/contract distributions: Single source (there are several suppliers, public tender) and sole source: there is only one supplier for a ,unique" product - but basically it is "the winner takes it all" - single source.

The product must be listed or at least following the national standard. For example, in the USA, it may only be tendered according to codes, approvals and standards listed in the North Ameri- 
can Industrial Classification System (NAICS) Product and Service Code (PSC). If the products are not listed, it can't be in a public tender or in an RFI (Request for Information), RFP (Request for proposal) or RFQ (request for Quotation) - or only as an alternative. Tenders, FfP, RfQ, RfI cannot be changed after being published and it includes mandatory, and non-mandatory requirements and evaluation criteria - only with a re-tendering process.

Tenders that do not comply with mandatory requirements are rejected, and most of the evaluation will be concentrated on non-mandatory requirements and prices following the evaluation criteria. As a result, one or several suppliers are chosen for decision taking (Helena Lindskog et al., 2010).

It is very helpful, to know the available budget before you quote your products, because the decision time is shorter, when you are with the financial borders, otherwise a complete procedure to increase the budget is necessary.

The very transparent procurement has a small disadvantage, it takes a long time, due to a lot of bureaucracy.

\section{CASE STUDY: START-UP FOR INFRASTRUCTURE PRODUCTS IN THE PHILIPPINES}

The complete company story of Krah Pipes Manila was monitored from start-up until now (the production capacity is doubled in the year 2020). The monitoring took place in all kind of business fields (financing, human resourcing, etc.) but in this case study only the marketing part is published. During many customer visits, registration and approval periods, I had the possibility to join and to talk extensively with the involved people. Everyone was very open and transparent during the interviews.

\section{a. The company/firm}

In 2017, a group of local investors decided to establish a new company, called Krah Pipes Manila. Inc. in Cavite, Philippines. It was a start-up company with a non-existent product in the national market of the Philippines. The plant should produce large size pipes including fittings and manholes for drainage and sewage application for the national market. Export of the product was not planned.

\section{b. The product}

The product is a large pipe system, including joints, fittings and manholes, produced out of polyethylene with some unique properties. The product is completely new for the existing market. The existing market was served for many years via a few local companies with other pipe materials and system properties. The product itself was superior compared to the available alternatives. So, the marketing concept was an aggressive market-penetration strategy for a displacement market.

\section{c. Market}

In general, all national markets (government customer and private/commercial customer) require large diameter pipe systems for drainage and sewage, but the emphasis is on government customers and government contracts. 
The Philippines consist of about 7,641 islands with a total area of $300,000 \mathrm{~km}^{2}$. As of 2015 , it had a population of at least 100 million people and is the $12^{\text {th }}$-most populated country in the world (Highlights of the Philippine Population 2015 Census of Population | Philippine Statistics Authority, 2020.000Z). The Philippine economy has an estimated 2018 gross domestic product (nominal) of $\$ 371.8$ billion. Primary exports include semiconductors and electronic products, transport equipment, garments, copper products, petroleum products, coconut oil, and fruits (East Asia/Southeast Asia :: Philippines - The World Factbook - Central Intelligence Agency, 2020.000Z). A fast growing and important future market for the Philippines is the touristic market (Wikipedia, 2020) - to serve this market an extensive environmental program combined with infrastructure projects started.

The infrastructural challenges in the Philippines include limited access to sanitation services, high pollution of water resources, often poor drinking water quality and poor service quality (Asian Water Development Outlook 2007, 2007).

Rodrigo Duterte started his presidency with a promise that his time will be the golden age of infrastructure. The Build! Build! Build! (BBB) Program is the centrepiece program of the Duterte administration. The BBB Program seeks to accelerate public infrastructure expenditure from an average of 2.9 percent of gross domestic product (GDP) during the Aquino regime to about 7.3 percent at the end of the Duterte administration ("FF2019-07_BUILD_BUILD_ BUILD," 2019).

The geographical market for the product is the local Philippine market (a monopsony, definition on page 2). Due to the large product size compared to its weight, an export in other countries is not feasible - but possible. The focus of the company is on supplying the local market. The end user of the product is mostly the public sector (infrastructure).

The ministry of construction is the DPWH (Department of Public Works and Highways). This department is one of the three departments of the government undertaking major infrastructure projects. The DPWH is mandated to undertake:

a) the planning of infrastructure, such as national roads and bridges, flood control, water resources projects and other public works, and

b) the design, construction, and maintenance of national roads and bridges, and major flood control systems (Department of Public Works and Highways, 2020.000Z).

The DPWH divided all public construction works in three areas. The areas with their own undersecretaries are Luzon, Visayas and Mindanao. Each area is composed of several regions (and each region again in districts).

For water supply and sewerage projects, DPWH is using a special government agency called MWSS (Metropolitan Waterworks and Sewerage System) (Metropolitan Waterworks and Sewerage System | Corporate Office, 2020.000Z). This MWSS sub-contracted two private companies to execute the work: a) Mayniland (Maynilad Water Services Inc, 2020.000Z) and b) Manila Water (Manila Water Company, 2020.000Z). They have their own accreditation and approval work, but a DPWH approval is suitable in their projects, too.

So, the DPWH is the only final customer for all national projects and the counterpart (divided in several branches, offices, structures) to handle, to promote and sell infrastructure products 
successfully in the Philippines. The market value or the amount of public spending in infrastructure is Php581.7 billion (25 percent growth) for 2020 (President Duterte Signs P4.1 Trillion 2020 National Budget, 2020.000Z).

Risk: Since DPWH is the main (maybe the only) customer, the supplier should be aware that there is a political structure besides the public and people can be changed easily when the government changes. The budgets can be adjusted easily (mostly in a negative way) and in case that the customer will delay or not pay, it is difficult to receive the money.

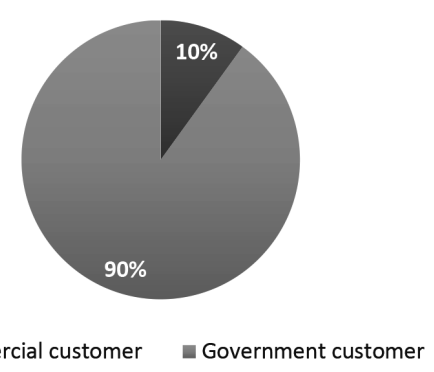

Diagram 2. Sales Structure 2019, published in the internal management report 31.12.2019 from Krah Pipes Manila Inc.

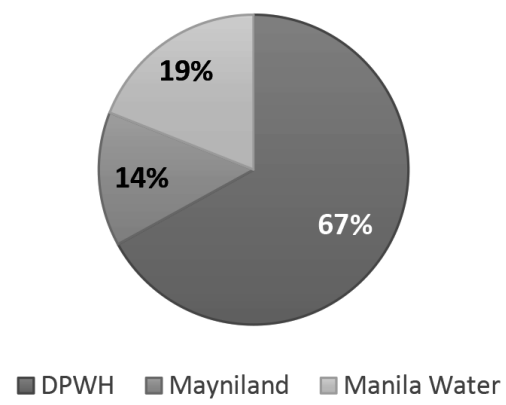

Diagram 3. Sales Structure "Agencies" in 2019, published in the internal management report 31.12.2019 from Krah Pipes Manila Inc.

The company decided to work with a Government Customer Breath, of Drainage/Flooding with DPWH and sewerage with the government agency Mayniland and Manila Water and the Government Customer Depth is only for large pipes system pipe size bigger than $600 \mathrm{~mm}$ for none- and low-pressure application.

The "commercial customers" like private land developer have a share of only $10 \%$ of the total sales (year 2019 and the $1^{\text {st }}$ quarter 2020).

\section{d. Competition}

The competitors are the local, long-existent companies that have produced drainage and sewage pipe out of other material - with much lower life span and less resistant. But the lobby work of the competitors was built solidly in all important organisations, during many years. Basically, it is not the aim of the government customer to eliminate suppliers, because a good employment rate is needed. Further the government customers prefer NOT to have just a sole supplier, but on the other hand they would like to have a single supplier for a contract. Due to import duty and high transportation costs (relation between volume and weight), external suppliers have a negative cost effect and can be kept out of the national large pipe market. 


\section{e. Registration and accreditation of the company}

Difficulties in setting up the company occurred from the fact that start-ups have problems registering its new company, as balance sheets and history are missing. Therefore, reference was made to the balance sheets and histories of the shareholders. Necessary in this regard were the respective DUNS numbers of the shareholders as well as of the new company. The time period of a company registration is between one and three months.

\section{f. Registration and accreditation of the product}

To specify a product in the Philippines, it is necessary that your product is approved and part of the "blue book" (Standards and Specification Book). The blue book is a register of all products to be used in public tenders. This technical surveillance and approval should be done at the Bureau of Research and Standards (BRS) - this is a subdivision of DPWH. It was not so easy, because the accepted standards were mainly American ASTM standards, but all in metric sizes. The usual time span for this procedure is 6 months to 2 years - the company needed only 6 months. The reason, that the company needed only 6 months was, that the produced pipe system is already internationally accepted and was complying to many international standards since decades, otherwise it would have taken even more than 2 years. Beside using international standards and the approval of BRS, shop-drawings were needed for all products and the quality control procedure was accredited by the agencies.

\section{g. A submittal}

Public projects should be awarded through public tenders to document transparency towards the government (the people). Among many other chapters, a part of the scope of supply will be a specified product request. The bid (the formal reply to a tender) consists of a table of required products and prices. The easiest way is that the tender document fits already the company's product. The other legal way could be to offer an alternative solution - but usually this is a long and difficult way.

To make tenders in the wanted way, the company spent much time and efforts to train and teach national consultants and the official departments of the client (DPWH) - like the Bureau of Design and the Bureau of Construction. In this step it is important to provide a technical guideline to implement the products in tenders and teach the right usage beside providing and explaining the advantages of the product. In particular, it is important to convince the engineers of the introduction of a new product and reduce the risk of planning errors. A helpful tool in this case can be a design software and of course a technical template of the new product, based on which the tender is prepared.

The submittal should be updated continuously, it is a dynamic document with the results of experiences and know-how from different tender phases.

The tender phases are:

i. Under design (projects/contracts/tenders are still in the planning phase, technical knowhow and smart inputs are needed).

ii. Under construction (projects/contracts/tenders are already in the bidding phase, if the tender is not made for our product, we have to bid an alternative - remembering it 
should be completely according to the regulation, otherwise the bid is mandatorily out of decision)

iii. After construction (projects/contracts/tenders are realized, historical data - like DUPA - should be collected, sorted and prepared as an "case study"-attachment in the submittal).

\section{h. Good relation to the construction companies}

Many projects are EPCC-projects, another used name is "turnkey-projects", where the EPCC-Contractor is receiving a complete order and the design and procurement is outsourced from the owner (DPWH) to one of the large construction companies.

For example, the largest construction companies in the Philippines for infrastructure (sewage and drainage) projects (Top 10 Contractors Under DU30 Run Record of Fraud, Delays, Blacklisting, 2020.000Z):

- St. Gerrard Construction Gen. Contractor and Development Corp.

- Ulticon Builders, Inc.

- Development Corp. and Equi-Parco Construction Company (under the BBB project of Duterte's administration)

The supplier of the product is swapping now from B2A/B2G to an extended B2B business, the profitability of the product is now the main property. Of course, also the EPCC contractor has to follow the B2A-tender and the regulations.

\section{i. The reference project}

The first project is always the most difficult one, because nobody likes to be the guinea pig. Krah Pipes Manila Inc. was very lucky to receive the big and famous project for the rehabilitation of the paradise island of Boracay, due to a lot of preparatory work and good relations with DPWH and the construction companies (Bläcker, 2020.000Z).

To convince the government of the project, it was demonstrated how the product has already been successfully used in other projects. Moreover, many photos were shown, customers from other countries were visited and many details explained.

Reference projects are the key to provide the government customer a certain level of confidence - social proof. So, many photos were taken and we invited different government agencies to visit the site and also to visit the plant (to see the quality assurance system).

One of the results of a realized project is a document called DUPA (Detailed Unit Price Analysis); this analysis will be considered for the project budget.

\section{j. Marketing Instruments}

According to an interview with Mr. Sajid Anonuevo (General Manager) and Jeneleen Lansangan (sales manager) in January 2020, the success of the marketing activities is built on the following instruments. The instruments listed below are the summary of the interview. The sales 
team is very lean with a good technical backup, to provide a close relation with the agencies, consultants, and construction companies.

i. Personal contact, developing of key account with the agencies, to build strong and personal relation;

ii. Visiting all regions and districts, to present the product physically and showing references we did in the Philippines and the usage of the product world-wide;

iii. Supporting lobby work, by using ex-government (retired) experts;

iv. Attending national trade show, to increase the public appearance of the company and the products;

v. Producing and spreading of white papers, these are documents to help understanding the product and hints for a proper end economical use of the products;

vi.Public relation / public opinion together with the own national basketball team (Basketball is the "main and most popular" sport in the Philippines) (Sport in Philippines, 2020.000Z);

vii. Supporting international magazines / e-Newsletters for large plastic pipes (The Pipe Magazine, 2020.000Z) and providing them local;

viii. Social media and Blogs: The young engineers in the Philippines are very computer-affine - like mainly the other Asian countries, so a steady activity in social media is very well accepted to increase the branding. Platforms used are Facebook, Instagram and LinkedIn (depending on the platform, the content is adjusted accordingly);

ix.Case studies: After every project, a short case study is produced with photos and naming the way why our product could solve the problem of the customer in the best economical and technical way;

x. Videos: Videos say more than words - so we use videos to back-up words, especially in social media and life-presentation;

xi.Academic report: We support academic works in our region and we help to produce technical books;

xii. Seminar/webinar: one of our strongest points is to educate young engineers with new „,internationally used“ products and their application. Very often we give design software for free, so the possibility that they will consider our product in the next tenders is very high.

\section{CONCLUSION}

The B2A/B2G market is very large, attractive and is open to everyone - but it has its own rules and structures that must be respected. It is not enough just to deliver a good product at good prices, but structures and protocols must be followed. The B2A/B2G market requires long market penetration time and high start-up costs, but then (with good reference projects) large volume business and loyalty will follow. The example of the Philippines has shown that it is possible to implement a new product on this market, but that it needs a certain starting period (especially for infrastructure projects). The marketing instruments are different than the marketing instruments for B2B or B2C market.

Lately a trend of online-tendering online procurement is seen, but for large infrastructure project still the conventional way of tendering is the state of art. 


\section{REFERENCES}

Asian Water Development Outlook 2007: Achieving water security for Asia. (2007).

Bläcker, L. (2020, May 28.000Z). KRAH - Krah Pipes - Emerging solution for Philippines. https://www.krah.net/de/news/latest-news/481-krah-pipes-emerging-solution-for-philippines

Brett W. Josephson, Ju-Yeon Lee, Babu John Mariadoss, \& Jean L. Johnson (2019). Uncle Sam Rising: Performance Implications of Business-to-Government Relationships. Journal of Marketing, 83(1), 51-72. https://doi.org/10.1177/0022242918814254

Caspar, M., \& Metzler, P. (2002). Entscheidungsorientierte Markenführung: Aufbau und Führung starker Marken. Arbeitspapier / Marketing-Centrum Münster [Münster].

Department of Public Works and Highways. (2020, May 28.000Z). http://www.dpwh.gov.ph/ dpwh/

East Asia/Southeast Asia: Philippines - The World Factbook - Central Intelligence Agency. (2020, May 21.000Z). https://www.cia.gov/library/publications/the-world-factbook/geos/ rp.html

Esteban Ortiz-Ospina, \& Max Roser (2016). Government Spending. Our World in Data. https:// ourworldindata.org/government-spending

FF2019-07_BUILD_BUILD_BUILD: Facts in Figures. (2019).

Hall, M. (2014, December 15). Monopoly vs. Oligopoly: What's the Difference? Investopedia. https://www.investopedia.com/ask/answers/121514/what-are-major-differences-between-monopoly-and-oligopoly.asp

Helena Lindskog, Staffan Brege, \& Per-Olof Brehmer (2010). Corruption in public procurement and private sector purchasing. Organisational Transformation and Social Change, 7(2), 167-188. https://doi.org/10.1386/jots.7.2.167_1

Highlights of the Philippine Population 2015 Census of Population | Philippine Statistics Authority. (2020, May 28.000Z). https://psa.gov.ph/content/highlights-philippine-population-2015-census-population

Kenton, W. (2012, June 20). Public-Private Partnerships. Investopedia. https://www.investopedia.com/terms/p/public-private-partnerships.asp

Keynes, J. M. (2018). The General Theory of Employment, Interest, and Money. Springer International Publishing. https://books.google.de/books?id=SullDwAAQBAJ

Manila Water Company, I. (2020, May 28.000Z). Manila Water Company, Inc. https://www. manilawater.com/

Maynilad Water Services Inc. (2020, May 28.000Z). http://www.mayniladwater.com.ph/

Metropolitan Waterworks and Sewerage System | Corporate Office. (2020, May 28.000Z). http://mwss.gov.ph/

The Pipe Magazine. (2020, May 28.000Z). https://www.krah.net/en/news/the-pipe-magazine

President Duterte signs P4.1 trillion 2020 national budget. (2020, May 28.000Z). https://www. dbm.gov.ph/index.php/secretary-s-corner/press-releases/list-of-press-releases/1589-president-duterte-signs-p4-1-trillion-2020-national-budget

Sport in Philippines. (2020, April 25.000Z). https:/www.topendsports.com/world/countries/ philippines.htm

Timm Gudehus. (2015). Dynamische Märkte: Grundlagen und Anwendungen der analytischen Ökonomie.

Top 10 contractors under DU30 run record of fraud, delays, blacklisting. (2020, May 28.000Z). https://pcij.org/article/1400/top-10-contractors-under-du30-run-record-of-fraud-delaysblacklisting 
What is Markets? Definition of Markets, Markets Meaning - The Economic Times. (2020, May 27.000Z). https://economictimes.indiatimes.com/definition/markets

What is polypoly? definition and meaning. (2020, May 27.000Z). http://www.businessdictionary.com/definition/polypoly.html

Wikipedia (Ed.), (2020). Markt. https://de.wikipedia.org/w/index.php?title=Markt\&oldid=200379299

Wolf Engelbach, Sandra Frings, \& Anette Weisbecker. (2010). Platforms for Local Mobile Services: Case studies of Commercial Applications in Germany. https://www.researchgate. net/publication/228947450_Platforms_for_Local_Mobile_Services_Case_studies_of_ Commercial_Applications_in_Germany

Young, J. (2003, November 24). Monopsony. Investopedia. https://www.investopedia.com/ terms/m/monopsony.asp 



\title{
APPLICATION OF ECOSERV MODEL IN SERVICE QUALITY MEASUREMENT: CASE STUDY OF NATIONAL PARKS IN CROATIA
}

\author{
Iva Valcic \\ Suzana Markovic ${ }^{1}$ \\ Jelena Kljaic Sebrek ${ }^{2}$ (D)
}

DOI: https://doi.org/10.31410/ERAZ.S.P.2020.109

\begin{abstract}
Service quality plays an important role in improving competitiveness across tourism sectors. In this context, there is a need to gain a better understanding of service quality in the growing segment of ecotourism. This study aims to measure service quality perceptions of visitors of Croatian national parks and identify its key dimensions by using a modified ECOSERV model. Data were collected using a self-administered questionnaire. Descriptive statistics and exploratory factor analysis were used to analyse the data. Six dimensions that seem to best explain perceived service quality in national parks were identified. The results of the study could be relevant for both academics and management active in the area of ecotourism and national parks.
\end{abstract}

Keywords: ECOSERV, Service quality, Perceptions, Ecotourism, Factor analysis.

\section{INTRODUCTION}

$\mathrm{T}$

he concept of service quality and its implications have been a topic of research interest for several decades. Literature suggests that high levels of service quality result in many advantages for organisations, such as customer satisfaction and loyalty, increased profitability, improved business performance and lower costs (Seth et al., 2005).

Service quality is often operationalised as a multi-dimensional concept, although the dimensions of service quality may be dependent on the type of services being examined (Babakus and Boller, 1992). Therefore, it is important to determine the specific factors that define service quality in the area of interest. Furthermore, much of the scientific work places the users' perspective at the core of the service quality assessment, often measured through service quality perceptions.

Like many other service-oriented industries, tourism has recognised service quality as a critical factor in its success (Fick and Ritchie, 1991). Numerous studies on service quality measurement in different tourism-related sectors have been carried out on the basis of the widely used SERVQUAL instrument, such as the hotel industry (Juwaheer, 2004; Marković and Raspor, 2010; Shafiq et al., 2019), historic houses and museums (Frochot and Hughes, 2000; Marković et al., 2013), restaurants (Bojanic and Rosen, 1994; Marković et al., 2010), rural tourism (Loureiro and González, 2009; Kljaić Šebrek, 2020), health tourism (Marković et al., 2014), hostels (Brochado et al., 2015), and the wine tourism experience (Haverila et al., 2020). The results can contribute to the view that service quality dimensions depend on the type of service offered, and can vary across different tourism sectors.

Faculty of Tourism and Hospitality Management, Primorska 42, p.p. 97, 51410 Opatija, Croatia WYG Consulting Ltd. 
Against this background, this paper focuses on service quality in the sector of ecotourism. The paper aims to measure service quality perceptions of visitors of Croatian national parks and to identify its key dimensions by using a modified ECOSERV model. The following sections present the literature review, methodology, study findings, discussion and conclusion.

\section{LITERATURE REVIEW}

Ever since the research on service quality gained momentum in the 1980s (Lovelock, 1983; Grönroos, 1984; Parasuraman et al., 1985), an increasing number of articles has been published on the concept of service quality, its definition, characteristics and methods of measurement. However, even after several decades of research, there is still no single, comprehensive and universally accepted definition of service quality. To a large degree, this is due to the nature of services itself. There are several unique characteristics associated with services: intangibility, heterogeneity, inseparability and perishability. These characteristics imply that service quality is an elusive and abstract construct that is more difficult to define and measure than product quality (Parasuraman et al., 1985).

The Nordic and American schools are often considered as the two key schools of thought on service quality. The latter has provided the SERVQUAL model (Parasuraman et al., 1985, 1988, 1991) which is one of the most prominent models in the field up to date. On the basis of the disconfirmation paradigm, Parasuraman et al. (1988) have proposed that service quality can be measured by identifying the gaps between customer's expectations and perceptions of service performance. The discrepancy between the expected and perceived service indicates the level of service quality, with a higher score representing a higher level of service. Originating from 10 initially conceptualised dimensions, the final SERVQUAL scale consisted of 22 paired items to measure expectations and perceptions across five distinct dimensions: reliability, assurance, empathy, responsiveness and tangibles. The sound and stable psychometric properties of the scale have been established based on data from four different industries. As noted by its authors, SERVQUAL serves as a skeleton which, when necessary, can be adapted to specific research needs.

Since its publication, the SERVQUAL scale has been widely used and adapted to a variety of service environments. In addition to tourism, it was used in industries such as healthcare, banking, airlines, public transportation, education and others. Despite the wide use, the SERVQUAL model has also been subject to scholarly criticism at both theoretical and operational level (for a full review and critique, consult Buttle, 1996) and alternative measurements have been proposed. For instance, Cronin and Taylor (1992) offered an alternative method of operationalising service quality. Their SERVPERF model is based on a perceptions-only measure of service quality, an approach followed by some other authors as well. The debate about service quality measurement is still ongoing in the literature, with the choice of the measurement being mostly governed by the aim of the individual research.

With regard to ecotourism, there is a general agreement in the literature that it is a growing sector of tourism, although the statistical data differ from source to source (Fennell, 2020). It could be argued that this, in part, is owed to the concept being elusive of a universally accepted definition. According to the International Ecotourism Society (2015), ecotourism is defined as "responsible travel to natural areas that conserves the environment, sustains the well-being of the local people, and involves interpretation and education". The World Tourism Organization has defined five main characteristics of ecotourism, such as the motivation of tourists being the 
observation and appreciation of nature and the traditional cultures prevailing in natural areas, the inclusion of educational and interpretation features, as well as the minimisation of negative impacts upon the natural and socio-cultural environment, to name a few. Despite many definitions and differently described principles of ecotourism, Blamey (2011) suggests that the essence of the concept is nature based, environmentally educated, and sustainably managed.

Services provided in the ecotourism sector should be in accordance with the abovementioned ecotourism characteristics and guiding principles. In order to measure service quality expectations in ecotourism, Khan (2003) developed ECOSERV, a modified SERVQUAL model. The ECOSERV scale includes 30 items with some of them being adapted or added to emphasize the environmental and cultural issues. The study confirmed ECOSERV's validity and reliability and resulted in six dimensions:

- eco-tangibles: physical facilities and equipment that are safe and appropriate to the environment;

- tangibles: material and appearance of the personnel that reflects local influence;

- reliability: ability to perform the promised service dependably and accurately;

- responsiveness: willingness to help customers and provide prompt service;

- assurance: knowledge and courtesy of the employees and their ability to convey trust and confidence, and provide necessary information; and

- empathy: caring, individualized attention the firm provides its customers.

However, based on a review of the available literature, there is scope to include additional items into the ECOSERV model, as also suggested by the model's author herself. Yusof et al. (2014) make a more general suggestion to strengthen the element of sustainability in service quality measurement in tourism and which should also not be overlooked in ecotourism. Ban and Ramsaran (2016) propose to introduce new items to the ECOSERV model, for example covering aspects of learning and education.

Therefore, this study proposes additional service quality items to try to further capture the specific characteristics of ecotourism. In addition, the study focuses on a perceptions-only measurement and thus provides a relevant extension to the ECOSERV model, which was based on an expectations-only measurement of service quality.

\section{METHODOLOGY}

A self-administered structured questionnaire was developed based on the original ECOSERV scale. This was further adapted in two respects. First, on the basis of a literature review, an additional pool of service quality attributes relevant for ecotourism were identified (Akama and Kieti, 2003; Yusof and Rahman, 2011; Naidoo et al., 2011; Crilley et al., 2012). Second, all the items were adapted to the specific setting of national parks. This resulted in 42 service quality items. Respondents were asked to rate their perceptions of service quality items on a five-point Likert scale anchored at "strongly disagree" as 1 and "strongly agree" as 5. The questionnaire also included additional questions on the socio-demographic profile of the respondents, such as country of residence, gender, level of education, age, employment, mode of visiting the national park, and the number of previous visits to the national park.

The initially developed questionnaire was pre-tested in two steps, through an expert review and a pilot study, and minor adjustments were made before conducting the main study. Both the 
pilot and main studies were carried out in national parks in Croatia. The questionnaire was prepared and distributed in four languages: Croatian, English, Italian and German. A total of 541 valid questionnaires were collected from visitors of national parks in Croatia (Brijuni National Park, Kornati National Park, Krka National Park, Mljet National Park, Paklenica National Park, Plitvice Lakes National Park, Risnjak National Park, and Sjeverni Velebit National Park).

The processing and analysis of collected data were carried out using SPSS Statistics 21. The statistical analysis included descriptive analysis, exploratory factor analysis and reliability analysis. As a first step, the descriptive statistics were used to investigate the socio-demographic profile of the respondents. After evaluating the observed service quality perceptions by means of a descriptive analysis, an exploratory factor analysis (EFA) was performed to identify the key dimensions of service quality perceptions. The suitability of the data for the EFA was determined with the Kaiser-Meyer-Olkin measure and the Bartlett's sphericity test. The exploratory factor analysis was performed using the principal components extraction technique and Varimax rotation. Lastly, the reliability of the extracted factors and of the overall scale was estimated by means of the Cronbach's Alpha coefficients.

\section{RESULTS}

Descriptive statistics were used to analyse the respondents' demographic characteristics. The sample included an almost equal share of male (50.3 per cent) and female (49.7 per cent) respondents. The majority of the respondents were foreign visitors (more than 70 per cent). More than half of the respondents had a university education (56 per cent) and were employed (68 per cent). In terms of age, the two most frequent groups of respondents were between 26-35 years old (27.9 per cent) and between 36-45 years old (19.7 per cent). A large proportion of the respondents visited the national park for the first time (65 per cent) and in a private arrangement, i.e. not as part of an organised group (61 per cent).

The mean values of the service quality perceptions in this study range from 3.53 to 4.18 , with an average mean value of 3.88 . For all items of service quality perceptions, the mode was a score of 4 . Therefore, it can be suggested that service quality perceptions were relatively high across all items. The highest mean value was calculated for the item 'visitors feel safe during visit in the national park', while the lowest mean value was calculated for the item 'the national park employees wear clothes that reflect local influence (e.g. employees' uniforms include details which are typical of the respective area)'.

The underlying dimensions or factors of service quality perceptions were identified through the EFA. The 42 items were subject to the EFA using the principal components method and Varimax rotation. As noted earlier, prior to performing the EFA, the suitability of data was confirmed. The KMO measure had a value of 0.952 indicating sample adequacy (Field, 2009). Bartlett's test of sphericity was statistically significant, confirming the data is suitable for factor analysis (Hair et al., 2010).

The research relied on multiple criteria for the extraction of factors as recommended by the literature (Fabrigar et al., 1999). Only factors with eigenvalues greater than 1 were retained and an inspection of the scree test was performed. Additional requirements were considered for determining the number of factors. Given the sample size, the value of factor loadings needed to be equal or above 0.4 (Hair et al., 2010). Furthermore, only factors with three or more items were considered. 
Following a number of iterations, a 6-factor solution with 39 items was chosen as the final solution. This solution had eigenvalues higher than 1 for each factor, exhibited a high level of reliability, explained a relatively high percentage of the total variance, and each factor had at least three items and was interpretable.

The results of the factor analysis for service quality perceptions are presented in Table 1 . The findings suggest that, in this research, six factors represent the dimensions of service quality in national parks based on the modified ECOSERV model. The six extracted factors accounted for 62.231 per cent of total variance. The factor loadings ranged from 0.479 to 0.749 .

Table 1. Results of the factor analysis for service quality perceptions

\begin{tabular}{|c|c|c|c|c|c|c|}
\hline \multirow[b]{2}{*}{ Item } & \multirow[b]{2}{*}{1} & \multirow[b]{2}{*}{2} & \multicolumn{3}{|l|}{ Factor } & \multirow[b]{2}{*}{6} \\
\hline & & & 3 & 4 & 5 & \\
\hline Personal attention & 0.749 & & & & & \\
\hline Understanding of specific needs & 0.730 & & & & & \\
\hline Individual attention & 0.727 & & & & & \\
\hline Never too busy to respond & 0.643 & & & & & \\
\hline Telling when service will be performed & 0.639 & & & & & \\
\hline Having visitors' best interest & 0.598 & & & & & \\
\hline Convenient operating hours & 0.589 & & & & & \\
\hline Willingness to help & 0.561 & & & & & \\
\hline Prompt service & 0.541 & & & & & \\
\hline Interest to solve problems & 0.536 & & & & & \\
\hline Visually appealing natural attractions & & 0.717 & & & & \\
\hline Natural resources used for equipment & & 0.683 & & & & \\
\hline Facilities appropriate to environment & & 0.681 & & & & \\
\hline Min. negative impact of equipment on environment & & 0.670 & & & & \\
\hline Environmentally safe facilities & & 0.655 & & & & \\
\hline Use of natural resources for facilities & & 0.617 & & & & \\
\hline Facilities in unpolluted setting & & 0.563 & & & & \\
\hline Minimal changes to landform / vegetation & & 0.508 & & & & \\
\hline Knowledgeable site & & 0.479 & & & & \\
\hline Promotion of local customs & & & 0.739 & & & \\
\hline Facilities reflect local influence & & & 0.736 & & & \\
\hline Materials reflect local influence & & & 0.688 & & & \\
\hline Clothes reflect local influence & & & 0.645 & & & \\
\hline Visually appealing service-associated materials & & & 0.621 & & & \\
\hline Visually appealing facilities & & & 0.558 & & & \\
\hline Promises completed by a certain time & & & & 0.718 & & \\
\hline Service provision in promised time & & & & 0.715 & & \\
\hline Service right the first-time & & & & 0.675 & & \\
\hline Courtesy & & & & 0.564 & & \\
\hline Error-free service & & & & 0.491 & & \\
\hline Knowledge to answer questions & & & & & 0.643 & \\
\hline Necessary information & & & & & 0.642 & \\
\hline Safety & & & & & 0.584 & \\
\hline Instilling confidence & & & & & 0.552 & \\
\hline Neat appearance & & & & & 0.448 & \\
\hline Recycle and reuse & & & & & & 0.737 \\
\hline Uncrowded & & & & & & 0.693 \\
\hline Development integrated with the local culture & & & & & & 0.681 \\
\hline Nature-based activities & & & & & & 0.515 \\
\hline Percentage of variance explained & 41.374 & 7.557 & 4.756 & 3.817 & 2.991 & 2.736 \\
\hline Reliabilities (Cronbach's $\alpha$ ) & 0.928 & 0.901 & 0.861 & 0.884 & 0.838 & 0.784 \\
\hline
\end{tabular}

Note: Extraction methods: principal component analysis; rotation method: varimax with Kaiser normalisation.

Source: Authors 
The first factor was labelled Empathy and Responsiveness and contained ten items. As five items coincide with the original ECOSERV dimension empathy and four items belong to the original ECOSERV dimension responsiveness, it could be argued that this factor is best described as caring, individualized attention that national parks provide to their visitors along with the willingness to help visitors and provide prompt service. In this study, these nine items are accompanied by an additional item related to national parks showing interest in solving the problems of visitors. As this factor has most items and explains most of the variance, it could be suggested that it is an important contributor to the perceptions of service quality and could offer a competitive advantage to the national parks.

The second factor was labelled Ecological Orientation and included nine items. To a large extent, it is related to the facilities and equipment meeting the needs of ecotourists while being environmentally sensitive. The factor also includes items related to the natural surrounding and the learning opportunity provided by the national park. Together, these aspects imply a need for an overall ecologically oriented management concept that promotes environmentally conscious behaviours, facilities, and practices implemented by national parks.

The third factor was labelled Local Impact and Appearance and had six items. The factor is related to the promotion of local customs in the national parks and the reflection of local influences through facilities and service-associated materials (e.g. brochures). The factor also reflects aesthetic aspects of services.

The fourth factor was labelled Reliability and included five items. It is primarily associated with the original ECOSERV dimension reliability. Additionally, this factor includes an item focused on staff kindness, which can be seen as contributing to the provision of a reliable service.

The fifth factor was labelled Assurance and included five items. It contains several items from the original ECOSERV dimension assurance and an additional item related to staff's neat appearance. All these items contribute to the level of visitors' trust in the service provided.

Finally, the sixth factor was labelled Sustainability and Activities and included four items. It represents a combination of elements focused on sustainable practices and activities in the national parks.

The Cronbach's Alpha value for the overall perceptions scale was 0.961, with values ranging from 0.784 to 0.928 across the six extracted factors. The values exceeded the recommended level of 0.6 (Hair et al., 2010), and thus both the scale and the factors were considered to have a satisfactory reliability.

\section{CONCLUSION}

The objective of this study was to measure service quality perceptions of visitors of Croatian national parks and to identify its key dimensions by using a modified ECOSERV model. The results of the study suggest six reliable dimensions of perceived service quality. The visitors of national parks placed emphasis on empathy and responsiveness, ecological orientation, local impact and appearance, reliability, assurance, and sustainability and activities. As suggested by previous literature, based on the identified factors, this research confirms that the richness and preservation of natural resources are a necessary, but not sufficient condition for the development of high-quality ecotourism services. 
This study provided both theoretical and practical contributions to the field of service quality in ecotourism. In terms of theoretical contributions, the research confirms that service quality perceptions in ecotourism are multi-dimensional and that the modified ECOSERV model is applicable in the context of Croatian national parks. In terms of practical contributions, the research may be used by the management of national parks to map the performance of key elements contributing to service quality. On this basis, the national park management could make targeted improvements of service quality and monitor its performance over time.

The main limitations of this study are reflected in the following opportunities for future research. First, research examining management and staff perceptions of service quality could provide additional insights and allow for comparison of perceptions between different stakeholders. A second possible approach could be to explore both expectations and perceptions of service quality in ecotourism and calculate their gap, in line with the disconfirmation paradigm. Lastly, future research could also be conducted in different types of ecotourism destinations and in different geographies to examine whether the results of this modified ECOSERV model could be generalised.

\section{REFERENCES}

Akama, J.S., \& Kieti, D.M. (2003). Measuring tourist satisfaction with Kenya's wildlife safari: a case study of Tsavo West National Park. Tourism Management, 24(1), 73-81. https://doi. org/10.1016/S0261-5177(02)00044-4

Babakus, E. \& Boller, G.W. (1992). An empirical assessment of the SERVQUAL scale. Journal of Business Research, 24(3), 253-268. https://doi.org/10.1016/0148-2963(92)90022-4

Ban, J., \& Ramsaran, R.R. (2016). An Exploratory Examination of Service Quality Attributes in the Ecotourism Industry. Journal of Travel \&Tourism Marketing, 34(1), 132-148. https:// doi.org/10.1080/10548408.2016.1141155

Bojanic, D.C., \& Rosen, L.D. (1994). Measuring Service Quality in Restaurants: An Application of the Servqual Instrument. Journal of Hospitality \& Tourism Research, 18(3), 3-14. https://doi.org/10.1177/109634809401800102

Blamey, R.K. (2001). Principles of ecotourism. In Weaver, D.B. The Encyclopaedia of Ecotourism (pp. 5-22). CAB International, Wallingford, UK.

Brochado, A., Rita, P., \& Gameiro, C. (2015). Exploring backpackers' perceptions of the hostel service quality. International Journal of Contemporary Hospitality Management, 27(8), 1839-1855. https://doi.org/10.1108/IJCHM-03-2014-0145

Buttle, F. (1996). SERVQUAL: review, critique, research agenda. European Journal of Marketing, 30(1), 8-32. https://doi.org/10.1108/03090569610105762

Crilley, G., Weber, D., \& Taplin, R. (2012). Predicting Visitor Satisfaction in Parks: Comparing the Value of Personal Benefit Attainment and Service Levels in Kakadu National Park, Australia. Visitor Studies, 15(2), 217-237. https://doi.org/10.1080/10645578.2012.715038

Cronin Jr. J., \& Taylor, S. A. (1992). Measuring Service Quality: A Reexamination and Extension. Journal of Marketing, 56(3), 55-68.

Fabrigar, L., Wegener, D., MacCallum, R., \& Strahan, E. (1999). Evaluating the Use of Exploratory Factor Analysis in Psychological Research. Psychological Methods, 4(3), 272-299. https://doi.org/10.1037/1082-989X.4.3.272.

Fick, G. R., \& Brent Ritchie, J. R. (1991). Measuring Service Quality in the Travel and Tourism Industry. Journal of Travel Research, 30(2), 2-9. https://doi.org/10.1177/004728759103000201

Field, A.P. (2009). Discovering statistics using SPSS (and sex and drugs and rock' $n^{\prime}$ roll) (3 ${ }^{\text {rd }}$ edition). London: Sage Publication. 
Fennell, D. (2020). Ecotourism (5 $5^{\text {th }}$ Edition). London: Routledge. https://doi. org/10.4324/9780429346293

Frochot, I., \& Hughes, H. (2000). HISTOQUAL: the development of a historic houses assessment scale. Tourism Management, 21(2), 157-167. https://doi.org/10.1016/S0261-5177(99)00045-X

Grönroos, C. (1984). A Service Quality Model and its Marketing Implications. European Journal of Marketing, 18(4), 36-44. https://doi.org/10.1108/EUM0000000004784

Hair, J.F., Black, W.C., Babin, B.J., \& Anderson, R.E. (2010). Multivariate Data Analysis (7 ${ }^{\text {th }}$ edition). NJ: Prentice Hall.

Haverila, M., Haverila, K., \& Arora, M. (2020). Comparing the service experience of satisfied and non-satisfied customers in the context of wine tasting rooms using the SERVQUAL model. International Journal of Wine Business Research, 32(2), 301-324. https://doi. org/10.1108/IJWBR-12-2018-0070

Juwaheer, T.D. (2004). Exploring International Tourist's Perceptions of Hotel Operations by Using a Modified SERVQUAL Approach - A Case Study of Mauritius. Managing Service Quality, 14(5), 350-364. http://doi.org/10.1108/09604520410557967

Khan, M. (2003). ECOSERV: Ecotourists' Quality Expectations. Annals of Tourism Research, 30(1), 109-124. https://doi.org/10.1016/S0160-7383(02)00032-4

Kljaić Šebrek, J. (2020). Mjerenje kvalitete usluga u ruralnom turizmu: primjena modificiranoga ruralqual modela (Doctoral dissertation, University of Rijeka, Faculty of Tourism and Hospitality Management, Opatija). Retrieved from: https://dr.nsk.hr/en/islandora/object/ fthm\%3A1758/datastream/PDF/view

Loureiro, S.M.C., \& González, F.J.M. (2009). Perceived quality in rural lodgings in Spain and Portugal: the ruralqual scale. Portuguese Journal of Management Studies, 14(1), 33-52.

Lovelock, C. H. (1983). Classifying Services to Gain Strategic Marketing Insights. Journal of Marketing, 47, 9-20.

Marković, S. \& Raspor, S. (2010). Measuring Perceived Service Quality Using SERVQUAL: A Case Study of the Croatian Hotel Industry. Management 5(3), 195-209.

Marković, S., Raspor S., \& Šegarić, K. (2010). Does restaurant performance meet customers' expectations? An assessment of restaurant service quality using a modified DINESERV approach. Tourism and Hospitality Management 16(2), 181-195.

Marković, S., Raspor Janković, S., \& Komšić, J. (2013). Museum Service Quality Measurement Using the Histoqual Model. 2nd International Scientific Conference Tourism in South East Europe. 2011-2016.

Marković, S., Lončarić, D., \& Lončarić, D. (2014). Service quality and customer satisfaction in the health care industry-towards health tourism market. Tourism and hospitality management, 20(4), 155-170.

Naidoo, P., Ramseook-Munhurrun, P., \& Seegoolam, P. (2011). An Assessment of Visitor Satisfaction with Nature-Based Tourism Attractions. International Journal of Management and Marketing Research, 4(1), 87-98.

Parasuraman, A., Berry, L. L., \& Zeithaml, V. A. (1991). Refinement and Reassessment of the SERVQUAL Scale. Journal of Retailing, 67(4), 420-450.

Parasuraman, A., Zeithaml, V. A., \& Berry, L. L. (1985). A Conceptual Model of Service Quality and Its Implications for Future Research. The Journal of Marketing, 49(4), 41-50.

Parasuraman, A., Zeithaml, V.A., \& Berry, L.L. (1988). SERVQUAL: A Multiple-Item Scale for Measuring Consumer Perceptions of Service Quality. Journal of Retailing, 64(1), 12-40.

Seth, N., Deshmukh, S.G., \& Vrat, P. (2005). Service quality models: a review. International Journal of Quality \& Reliability Management, 22(9), 913-949. https://doi. org/10.1108/02656710510625211 
Shafiq, A., Mostafiz, M.I., \& Taniguchi, M. (2019). Using SERVQUAL to determine Generation Y's satisfaction towards hoteling industry in Malaysia. Journal of Tourism Futures, 5(1), 62-74. https://doi.org/10.1108/JTF-01-2018-0004

The International Ecotourism Society. (2015). What Is Ecotourism?. Retrieved June 24, 2020, from https://ecotourism.org/what-is-ecotourism/

The World Tourism Organization. Retrieved June 24, 2020, from https://www.unwto.org/sustainable-development/ecotourism-and-protected-areas

Yusof, N., \& Rahman, F.A. (2011). Tourists' Perceptions of Service Quality in a Lake-Based Tourism Area. International Conference on Business and Economics Research, 16, 84-89.

Yusof, N., Rahman, F.A., Jamil, M.F.C., \& Iranmanesh, M. (2014). Measuring the Quality of Ecotourism Services: Case Study-Based Model Validation. SAGE Open, 4, 1-9. https:// doi.org/10.1177/2158244014538270 


